Check for updates

Cite this: Mater. Adv., 2022, 3,2990

Received 9th January 2022, Accepted 6th February 2022

DOI: 10.1039/d2ma00022a

rsc.li/materials-advances

\section{Polyindole and polypyrrole as a sustainable platform for environmental remediation and sensor applications}

\author{
Anjitha Thadathil, ${ }^{a}$ Hareesh Pradeep, ${ }^{a}$ Deepak Joshy, ${ }^{a}$ Yahya A. Ismail (D) a and \\ Pradeepan Periyat iD *b
}

\begin{abstract}
Conducting polymer (CPs), which are Nobel Prize-winning materials, have opened an exciting area of research due to their substantial electrical conductivity, unique structures, and ability to generate new composite materials, and have wide applications ranging from optoelectronics to material science. Research on conducting polymers has triggered much attention in nanoparticle-incorporated composites, which provide enhanced synergistic properties even at low filler concentration, resulting in high-level performance in important fields such as chemistry and material science. This review focuses on the synthesis of nanocomposites of two main types of $\mathrm{N}$-containing conducting polymers, namely, polypyrrole (PPY) and polyindole (PIN), as well as an in-depth analysis of their binary and ternary nanocomposites in the treatment of contaminants, sensing, and green chemistry. This review also covers different strategies for the versatile property improvement of these conducting polymers with unique applications. This review is expected to be useful for the field of chemistry to explore the possibility of new composite mixtures of conducting polymers in environmental and sensing applications.
\end{abstract}

\section{Introduction}

Conducting polymers (CPs) have attracted a lot of attention owing to their distinctive one-dimensional (1D) delocalized conjugated structures with excellent optical and electronic properties. ${ }^{1}$ The historical development of CPs started with the discovery of iodine-doped polyacetylene by Shirakawa and coworkers in 1977, which was followed by $N$ - or $S$ polyheterocycles and polyaniline (PANI) ${ }^{2-5}$ (Fig. 1). Since their discovery, these Nobel Prize-winning materials have opened the floodgates of research into distinctive applications such as rechargeable batteries, ${ }^{6}$ sensors, ${ }^{7}$ actuators, ${ }^{8}$ antistatic coatings, ${ }^{9}$ photocatalysts, ${ }^{10}$ EMI shielding, ${ }^{11,12}$ anticorrosion, ${ }^{13,14}$ organic light-emitting diodes, ${ }^{15}$ electrochromics, ${ }^{8}$ organic photovoltaics, ${ }^{16}$ printed electronic circuits, ${ }^{17}$ flexible transparent displays, ${ }^{18}$ supercapacitors,${ }^{19}$ and biomedicine. ${ }^{1}$ CPs are very attractive for sensing and environmental applications due to their good intrinsic conductivity (from $0.01 \mathrm{~S} \mathrm{~cm}^{-1}$ to $500 \mathrm{~S} \mathrm{~cm}^{-1}$ in the doped state), fast charge-discharge kinetics, unique redox properties, lower adverse effect on the environment, and ability to be synthesized through cost-effective approaches. ${ }^{5,20,21}$ In addition, CPs are

\footnotetext{
${ }^{a}$ Department of Chemistry, University of Calicut, Kerala, 673635-India

${ }^{b}$ Department of Environmental Studies, Kannur University, Kerala, India.

E-mail:pperiyat@kannuruniv.ac.in
}

potential candidates in electrocatalysis and photocatalysis due to their excellent biocompatibility and ability to be fabricated in the form of flexible films and nanostructures. ${ }^{22}$ However, their application is restricted due to their small surface area, low sensitivity at room temperature, poor stability, and low conductivity in comparison to metallic conductors. ${ }^{5}$ The electrical conductivity characteristic of CPs originates from alternating double-single bond arrangements along the backbone of the polymer chain and the overlapped $\pi$-bonds aid free shifting and transfer of electrons in the bound atom space of the polymer. ${ }^{23}$ However, these delocalized $\pi$-electrons moving freely within the unsaturated backbone bonds deteriorate the processability and stability of the conducting polymers. Thus, in contrast to conventional polymers, CPs exhibit some amount of rigidity. ${ }^{23}$ The incorporation of nanoparticles generally provides some kind of processability, namely, colloidal stability or mechanical strength to CPs, and the specific properties of the former can be utilized in some aspects with the existing qualities of the latter. ${ }^{24}$ In this regard, nanofillers in the conducting polymer matrix afford innovative outcomes in conducting polymer nanocomposites and are an attractive strategy due to the synergistic effect of the desired physiochemical, thermal, optical, and electrical properties concerning the constituent phases. Thus, instead of pointing to the mere enhancement in the properties of the conducting polymer, the recent trend is to use nanoparticles that have 


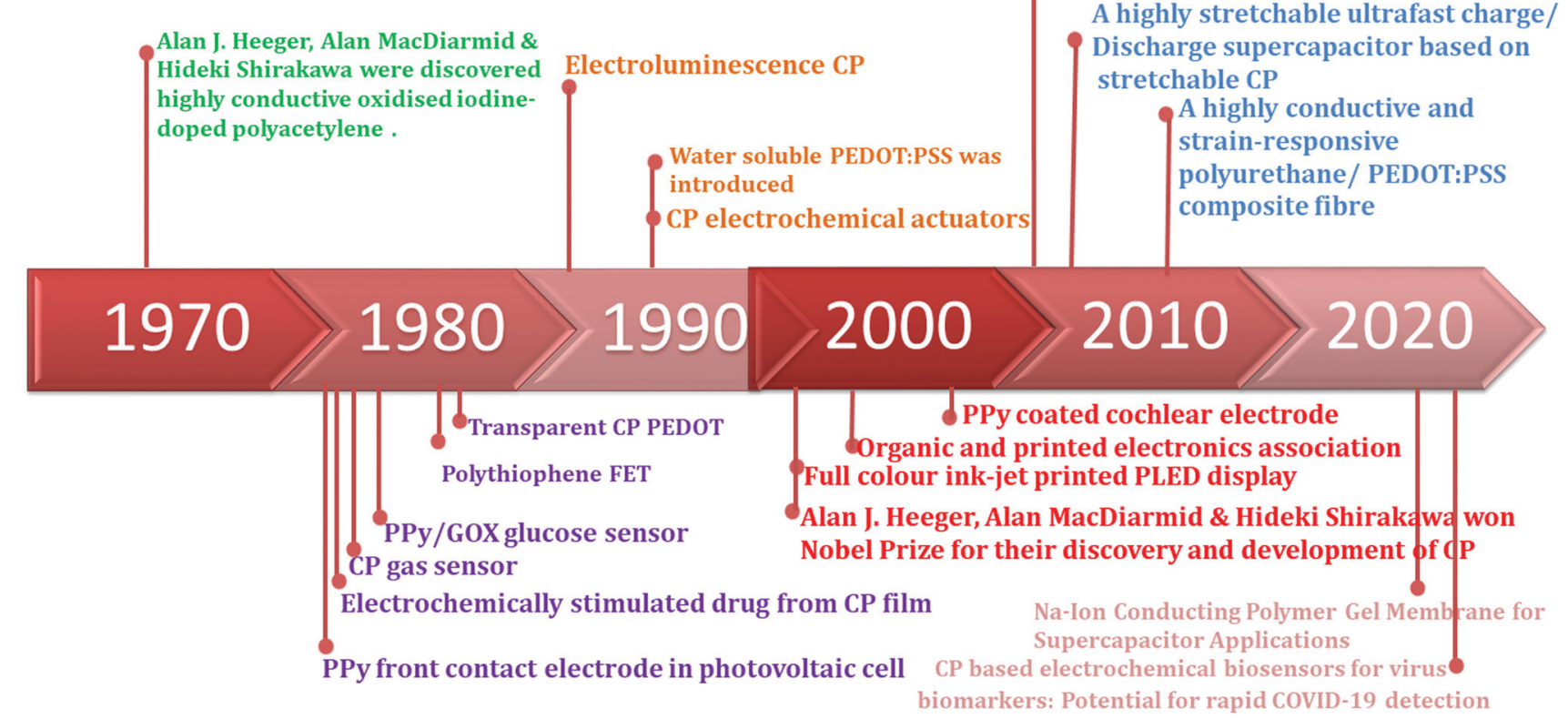

Fig. 1 A timeline of the history of CPs and their applications.

excellent magnetic and electrical properties as a dynamic tool for customizing the final performance of CPs. The most widely incorporated potential nanofillers in CPs consist of conducting nanostructures such as metals, graphene, carbon nanotubes, metal oxides, and insulating ceramic nanoparticles. ${ }^{25}$ Due to interfacial interactions and synergistic or complementary effects, these conducting polymer nanocomposites give rise to interesting properties that can be exploited for newer and novel applications. In short, the improved electroactivity and redox properties of nanocomposites make them appropriate for catalyzing redox reactions in sensor applications. The nanocomposites of these CPs proven enhanced photocatalytic activity under both UV and visible light irradiation, which cannot be done using semiconductors alone. $^{26}$ The outstanding electrical and optical properties of conducting polymer nanocomposites are beneficial for photocatalytic applications.

The most popularly studied CPs in sensing and environmental applications include polyacetylene (PAC), polyaniline (PANI), polypyrrole (PPY), polythiophene (PTH), and polyindole (PIN), which are quickly starting to attract research interest. In view of the copious information that exists on PPy and PIN in the field of CPs, after a concise description of the different strategies adopted for the synthesis of nanocomposites of PIN and PPY, this review will primarily focus on the applications of nanocomposites in environmental remediation, dealing with the areas of electrocatalytic reduction/oxidation, pollutant adsorption, photocatalysis, dechlorination, dioxygen removal, and sensing applications in analytical chemistry. We explicitly noted that only a few recent review articles have tried to summarize the environmental remediation $^{23,27,28}$ and sensing applications ${ }^{29-32}$ of PPy-based nanocomposites and there is only one article on PIN-related composites. $^{31}$ This article is different from those mentioned above, and focuses on the robust performance of PPy and PIN and their nanocomposites in sensing and environmental applications in a much more detailed manner.

\section{Polyindole (PIN)}

Polyindole (PIN), a rising conducting polymer, is being explored and developed as a possible candidate for electrochromic devices, ${ }^{33,34}$ sensors, ${ }^{35,36}$ photocatalysis, ${ }^{37,38}$ electrocatalysis, ${ }^{39}$ anticorrosion, ${ }^{40,41}$ diodes, ${ }^{42,43}$ supercapacitors, ${ }^{4,45}$ batteries, and biological applications. ${ }^{45-47}$ The studies on PIN had started as early as 1976; Youmans, H. L et al. synthesized polyindole from indole through chemical polymerization. ${ }^{48} \mathrm{PIN}$ is a polymer of indole monomer, which has a fused aromatic molecular structure consisting of a five-membered nitrogen-containing pyrrole ring and a six-membered benzene ring. Thus, PIN is regarded as an interesting material that can show the combined property of polyphenylene and polypyrrole. In comparison to other conducting polymers such as PANI, PIN shows relatively slow hydrolytic degradation and improved thermal stability. In addition, PIN exhibited competitive redox potential as compared to PPY. ${ }^{49}$ Some other useful features include excellent photoluminescent properties, ${ }^{50}$ very stable redox activity, ${ }^{51}$ low cost, ${ }^{52}$ ease of synthesis, ${ }^{53}$ fast switchable electrochromic properties, ${ }^{34,54}$ and air-stable electrical conductivity in the doped state. ${ }^{55}$ Another interesting feature is that PIN does not form any salt during the complete charged or discharge phase such as leucoemeraldine and pernigraniline as it is a common case with $\mathrm{PANI}^{56}$ and shows increased internal conductivity, especially useful when functioning 
<smiles>c1ccc2[nH]ccc2c1</smiles>

$1 \mathrm{H}$-indole<smiles>Clc1ccc2[nH]ccc2c1</smiles>

5-chloro-1 $\mathrm{H}$-indole<smiles>Nc1ccc2[nH]ccc2c1</smiles>

$1 H$-indol-5-amine<smiles>Cc1cc2ccccc2[nH]1</smiles>

2-methyl-1 $H$-indole<smiles>N#Cc1ccc2[nH]ccc2c1</smiles>

$1 \mathrm{H}$-indole-5carbonitrile<smiles>O=[N+]([O-])c1cccc2[nH]ccc12</smiles>

4-nitro-1 $H$-indole<smiles>Cn1ccc2ccccc21</smiles>

1-methyl-1 $H$-indole<smiles>O=C(O)c1ccc2[nH]ccc2c1</smiles>

$1 \mathrm{H}$-indole-5-carboxylic acid<smiles>Nc1cccc2[nH]ccc12</smiles>

$1 \mathrm{H}$-indol-4-amine<smiles>O=C(O)c1ccc2cc[nH]c2c1</smiles>

$1 \mathrm{H}$-indole-6-carboxylic acid<smiles>c1ccc(-c2cc3ccccc3[nH]2)cc1</smiles>

2-phenyl-1 $H$-indole<smiles>O=Cc1ccc2cc[nH]c2c1</smiles>

$1 \mathrm{H}$-indole-6-carbaldehyde<smiles>O=Cc1c[nH]c2ccccc12</smiles>

$1 H$-indole-3-carbaldehyde

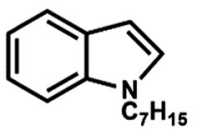

1-heptyl-1 $H$-indole<smiles>Cc1ccc2[nH]ccc2c1</smiles>

5-methyl-1 $H$-indole<smiles>Nc1ccc2cc[nH]c2c1</smiles>

$1 H$-indol-6-amine<smiles>Brc1ccc2[nH]ccc2c1</smiles>

5-bromo- $1 \mathrm{H}$-indole<smiles>O=[N+]([O-])c1ccc2cc[nH]c2c1</smiles>

6-nitro- $1 H$-indole<smiles>Fc1ccc2[nH]ccc2c1</smiles>

5-fluoro-1 $H$-indole<smiles>COc1ccc2[nH]ccc2c1</smiles>

5-methoxy-1H-indole

Scheme 1 Chemical structures of indole and its derivatives.

as an energy storage device. However, the polymerization efficiency and the conductivity of polyindole is lower than the other conducting polymers; hence, not much attention has been given compared to other types of conducting materials. ${ }^{57}$ With the development of various composites and copolymers based on polyindole and its derivatives, the attention on polyindole has become vast. Scheme 1 shows the derivatives of indole that can be also Be polymerized into the polyindole family; to date, there have been about 20 indole derivatives. This series of polyindole derivatives, obtained via the polymerization of indole derivatives, exhibit tunable properties, such as enhanced photoluminescence, conductivity, and redox activity. ${ }^{58}$ The synthesis of PIN can be achieved by electrochemical polymerization, ${ }^{59}$ oxidative polymerization, ${ }^{60}$ emulsion polymerization, ${ }^{61}$ interfacial polymerization, ${ }^{62,63}$ and other methods. ${ }^{64}$ These methods open up possibilities to fine tune the polymer morphologies including nanowires, nanorods, nano and microfiber, nano and microspheres, and nanobelts, and can meet other specific applications. The different methods of 
synthesis of PIN will not be further discussed here since excellent reviews are available. ${ }^{58,65}$

\section{Polypyrrole (PPY)}

Polypyrrole (PPY) is a biocompatible electrically conducting polymer that has potential applications as microelectronic devices, ${ }^{66}$ electrochemical sensors, ${ }^{32}$ antistatic coatings, ${ }^{67}$ supercapacitors, ${ }^{68}$ electrode-based detectors, ${ }^{69}$ EMI shielding, ${ }^{70}$ biomedicine, ${ }^{71}$ secondary batteries, ${ }^{72}$ dye-sensitized solar cells, ${ }^{73}$ and molecular memory devices. ${ }^{74}$ The pyrrole monomer is an easily oxidizable, water-soluble, and commercially available material that polymerizes to give PPY, showing high electrical conductivity, outstanding redox properties, high electron affinity, low oxidation potential, and superior environmental stability. ${ }^{75-78}$ In 1963, Weiss and colleagues synthesized PPY as a highly conductive polymer material for the first time from the pyrolysis of tetraiodopyrrole. ${ }^{79}$ Thereafter, PPY has become the most thoroughly investigated conductive polymer due to a broader range of conductivity rather than PANI. ${ }^{23}$ However, neat PPY is brittle, crystalline, mechanically rigid, and insoluble, which is hard to process further, which makes it unsuitable for most applications. However, PPY is more flexible than PANI, metals, and metal oxides. ${ }^{23}$ In addition, they have economical and muchimproved processing processes than metals and metal oxides. The processability of PPY can be significantly improved by copolymerization with different nanomaterials. ${ }^{80,81}$ PPY has easy, low-cost fabrication techniques including chemical or electrochemical methods. ${ }^{65,82}$ It has been reported that a wider range of oxidizing agents could be employed for the chemical polymerization of PPY compared to other kinds of CPs. ${ }^{23}$ Recently, the electrodeposition of PPY on different metallic substrates has achieved much more scientific interest due to the control over the coating thickness and morphology of PPY. ${ }^{83}$ Usually, several doping-developing strategies are also used for the polymerization of PPY, which is accomplished in a protonated acid solution accompanied by a dopant. Depending on the type and amount of the dopant, the conductivity of PPY can reach up to $10^{-3} \mathrm{~S} \mathrm{~cm}^{-1} \cdot{ }^{84,85}$ There are various derivatives of pyrrole that can be also polymerized into the polypyrrole family, as shown in Scheme 2. This review does not concentrate on in-depth concerns on the synthesis of PPY. For further information, the reader is advised to check the publications by Habib Ashassi-Sorkhabi, ${ }^{82}$ Pang, ${ }^{86}$ and Tatyana. ${ }^{87}$

\section{Nanocomposites of PIN and PPY}

The fascinating perspective of implementing new physical, chemical, and novel characteristics to the host conducting polymer via the incorporation of a small number of fillers is what makes CP nanocomposites much more attractive. PPY and PIN are copolymerized with nanomaterials such as graphene, carbon nanotubes, metal, metal oxide nanoparticles, other useful dopants such as montmorillonites, clays, and zeolites, and with biopolymers including chitosan, chitin, gelatin, cellulose, and proteins yielding nanocomposites that cooperate with the benefits of individual component and achieve better performance in environmental and sensing applications. ${ }^{58,88}$ The interfacial interactions and complementary or synergistic effects are present in these nanocomposites and their properties can be tuned by a suitable combination of the conducting matrix and filler as well as the aspect ratio. ${ }^{89}$ Interfacial interactions include electrostatic interactions, Lewis acid-base interactions, weak physical adsorptions via van der Waals forces, steric interaction, hydrogen bondings, and strong interfacial interactions through covalent bonding. ${ }^{90}$ A good conductive network is also required for the entrapment or encapsulation of fillers with conducting polymers in the fabrication of conducting nanocomposites. ${ }^{91}$ These CP nanocomposites can be classified into two classes based on the nature of the entrapment or encapsulation of fillers in the matrix: (i) the filler is uniformly embedded in the conducting polymer matrix, (ii) the CPs are confined into an inorganic template. In this section, we tried to provide sufficient and brief information about the synthesis of nanocomposites of PPY and PIN, introduced here as the "inorganic-in-organic matrix". In brief, the recent trends in the progress of nanocomposites synthesized by embedding various fillers in the PPy and PIN matrix, which are suggested in the literatures, are schematically represented in Fig. 2.

\subsection{Synthesis of nanocomposites}

The nanocomposites of PIN and PPY are mainly synthesized by three methods: chemical, electrochemical, and photochemical. From the literature survey, it has been observed that both chemical and electrochemical methods can be further categorized into three sections based on the procedure of synthesis and mechanism: (i) ex situ synthesis, (ii) in situ synthesis, and (iii) one-pot/single step synthesis, ${ }^{92,93}$ while photochemical methods are mainly divided into two: direct photopolymerization and photopolymerization in the presence of photosensitizers. These methods are described one by one as follows.

4.1.1. Chemical methods. Chemical methods offer various possible means to synthesize composites of PPY and PIN and also allow the scale-up of nanocomposites. A summary of recent chemical methods for PIN and PPY nanocomposites described in the literature is given in Table 1.

4.1.1.1. Ex situ synthesis. Here, the conducting polymer and fillers are separately synthesized, then direct blending or mixing of these two or more individual components is done to fabricate the composites. ${ }^{92}$ An elegant method is direct mixing/mechanical mixing, which is an economical and convenient approach to construct nanocomposites of CPs. ${ }^{92,94,95}$ For example, the PPY/ ZnO nanocomposite with improved synergistic effects in optical and thermal properties was reported by G. N. Chaudhari et al., synthesized through mechanical mixing. ${ }^{95}$ A. T. Mane et al. synthesized $\mathrm{PPY}-\mathrm{WO}_{3}$ hybrid nanocomposites by the mechanical mixing procedure and then the solid-state synthesis method was employed to fabricate DBSA-doped PPY- $\mathrm{WO}_{3}$ nanocomposites. ${ }^{94}$ Structural, morphological, and compositional analyses verified the successful dispersion of DBSA into the $\mathrm{PPY}-\mathrm{WO}_{3}$ hybrid nanocomposite and improves its gas sensing characteristics. 
<smiles>c1cc[nH]c1</smiles>

$1 H$-pyrrole<smiles>Cc1ccc(C)[nH]1</smiles>

2,5-dimethyl-1H-pyrrole<smiles>Cc1c[nH]c(C)c1</smiles>

2,4-dimethyl-1 $H$-pyrrole<smiles>O=Cc1ccc[nH]1</smiles>

$1 H$-pyrrole-2-carbaldehyde<smiles>Cn1cccc1</smiles>

1-methyl-1 $H$-pyrrole<smiles>Cc1ccc[nH]1</smiles>

2-methyl-1 $H$-pyrrole<smiles>Cc1c[nH]cc1C</smiles>

3,4-dimethyl-1 $H$-pyrrole<smiles>CCc1ccc[nH]1</smiles>

2-ethyl-1 $H$-pyrrole<smiles>OCn1cccc1</smiles>

(1H-pyrrol-1-yl)methanol<smiles>Cn1cccc1C=O</smiles>

1-methyl-1 $H$-pyrrole-2-carbaldehyde<smiles>Cc1ccc(C=O)[nH]1</smiles><smiles>CCn1cccc1C</smiles><smiles>Cc1cc[nH]c1</smiles>

3-methyl-1H-pyrrole<smiles>Cc1cc[nH]c1C</smiles>

2,3-dimethyl-1 $H$-pyrrole<smiles>O=C(O)c1ccc[nH]1</smiles>

$1 H$-pyrrole-2-carboxylic acid<smiles>c1ccc2[nH]ccc2c1</smiles>

$1 \mathrm{H}$-indole<smiles>CC(=O)c1ccc[nH]1</smiles>

methyl $1 H$-pyrrole-2-carboxylate

1-ethyl-2-methyl-1 $H$-pyrrole 5-methyl-1 $H$-pyrrole-2-carbaldehyde

Scheme 2 Chemical structures of pyrrole and its derivatives.

Another simple ex situ synthesis method is solution mixing. In the solution-mixing technique, a suitable solvent is used to dissolve the conducting polymer, and the well-wetted nanofiller is mixed with the solution of the conducting polymer under vigorous mechanical stirring. ${ }^{25}$ The solution mixing method demands much better dispersion of nanofillers in the diluted solution. In brief, the procedure involves three main steps: (1) dispersing the nanofillers in a suitable solvent; (2) mixing the resultant suspension with the conducting polymer dissolved in the same solvent by sonication or simple mechanical stirring; and (3) the composite formation by precipitation or solvent evaporation. ${ }^{91}$ Notably, both organic solvents and water have been used to synthesize composites using this method. Only some illustrations are reported in the literature related to the solution mixing technique because PPY and PIN are not soluble in most common solvents and the fillers need to be colloidally stable to avoid aggregation in the final nanocomposite. ${ }^{96}$ Solution mixing has been successfully used to produce composites of iron oxide and polypyrrole derivatives. ${ }^{97}$ In another study, M. A. Alvi et al. fabricated MWCNTs/PPY nanocomposites via the solution mixing method. $N$-Methyl-2-pyrrolidone (NMP) solvent is employed to dissolve PPY synthesized via chemical polymerization by heating 


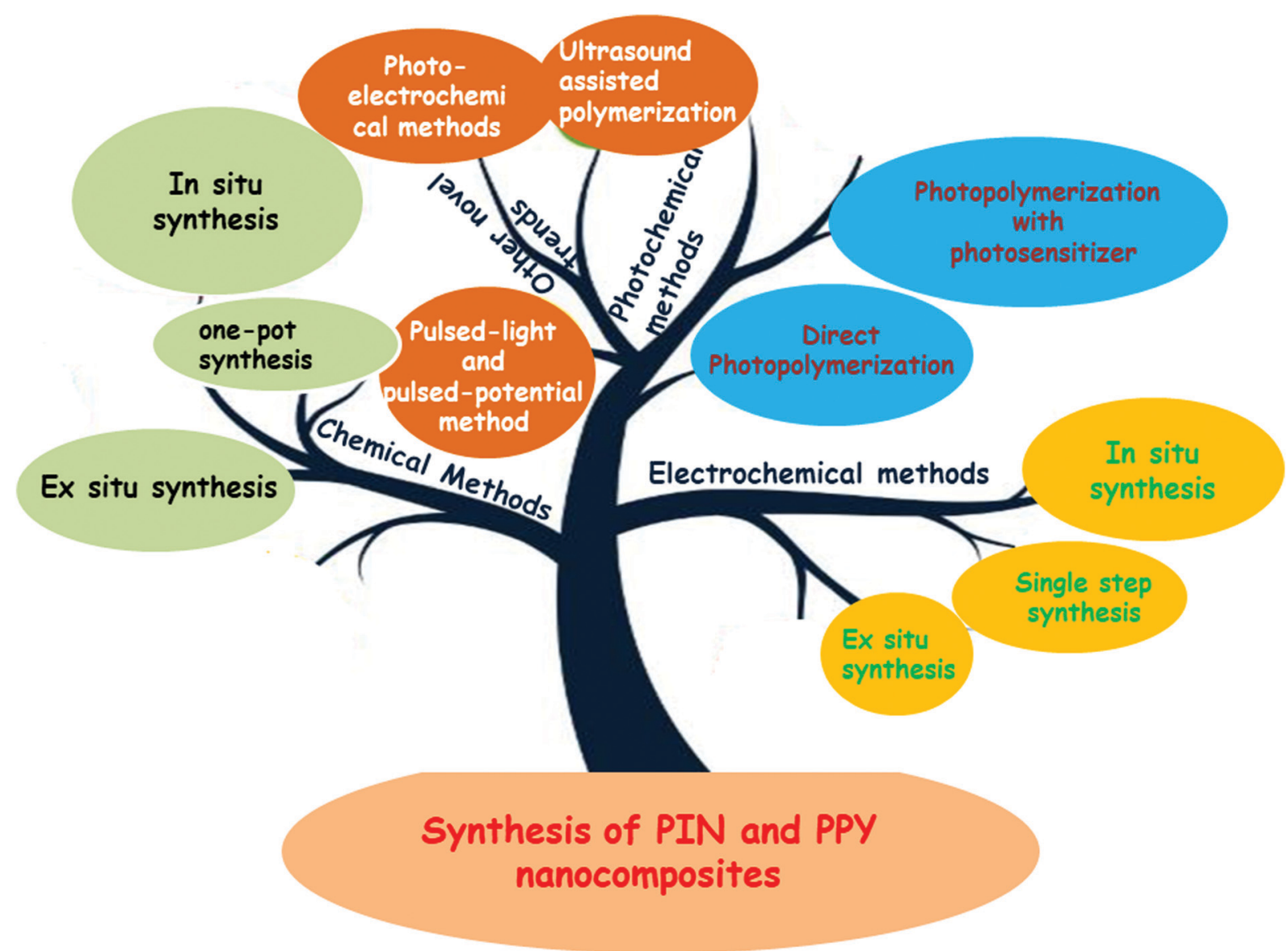

Fig. 2 Graphical representation of the synthetic methods for PPY and PIN nanocomposites.

and continuous stirring for 8-10 $\mathrm{h}$, followed by mixing with MWCNT powders. ${ }^{98}$ Then, the solution of the nanocomposites was dried in a furnace for about $1 \mathrm{~h}$ in the temperature range of $60-80{ }^{\circ} \mathrm{C}$.

The wet-spinning technique offers a simple ex situ method for the preparation of conducting polymer nanocomposites. ${ }^{99}$ For instance, Jiyoung Oh et al. reported nanocomposite electrodes consisting of single-walled carbon nanotubes (SWNT) and polypyrrole (PPY) synthesized by the wet-spinning technique. The process involves the vacuum filtration of SWNT/PPY methanol dispersion and the wet spinning of SWNT/PPy aqueous dispersion with the aid of sodium dodecyl sulfate (SDS) as a surfactant. Another well-known route for the ex situ synthesis of conducting polymer nanocomposite is the simple vacuum filtration method. ${ }^{100}$ Chao Yang et al. employed a facile vacuum filtration method for the synthesis of reduced graphene oxide (rGO)/polypyrrole nanotube (PPY NT). The PPY NTs were synthesized via a chemical oxidation process mixed with rGO suspension and the resulting mixture was vacuum-filtered through a nitrocellulose membrane. The volume of the rGO suspension and the quantity of PPY NTs are adjusted to fabricate the final rGO/PPY NT papers with different PPY NT contents.

4.1.1.2. In situ synthesis. In situ synthesis is an effective way to create nanocomposites where at least one of the components is synthesized in the presence of another one. ${ }^{93}$ Here, molecularlevel control over the interface in-between components results in a synergistic effect. In brief, the preparation methods through in situ syntheses can be classified in two main routes: ${ }^{25}$ (a) in situ polymerization and (b) In situ nanoparticle formation in the presence of the polymer.

In the first strategy, namely, the in situ polymerization technique, the polymer network is developed by adding a suitable oxidizing agent to a monomer solution containing fillers and doping agents. Without a doubt, this is the most common strategy to synthesize nanocomposites based on PPY and PIN, providing nanocomposites from films to core-shell particles. One of the main advantages of this method is that the nanostructures embedded relatively uniformly result in better interactions between the polymer matrix and the nanofiller, thus enhancing the properties. ${ }^{25}$ Studies show that a wide number of nanocomposites based on PPY and PIN have been prepared by the incorporation of different nanoparticles such as $\mathrm{MnO}_{2},{ }^{101} \mathrm{MWNT},{ }^{102,103} \mathrm{Fe}_{2} \mathrm{O}_{3},{ }^{104}$ graphene, ${ }^{105}$ and Al-MCM$41^{106}$ via in situ polymerization. Generally, typical oxidizing agents used include $\mathrm{FeCl}_{3}{ }^{105,106}$ and ammonium peroxodisulphate (APS) ${ }^{102}$ Moreover, the choice of the solvent plays a crucial role in the fabrication of a proper nanocomposite. ${ }^{96}$ The typical solvent should show capability to dissolve the monomer and the magnetic nanoparticles and to make a colloidally stable solution to avoid 
Table 1 Representative examples of chemical methods for the synthesis of PIN and PPY nanocomposites

\begin{tabular}{llll}
\hline Material & \multicolumn{2}{l}{ Preparation method } & Remarks \\
\hline PPY/ZnO & $\begin{array}{lll}\text { Ex situ } \\
\text { Synthesis }\end{array}$ & Mechanical mixing & $\begin{array}{l}\text { ZnO nanoparticles are embedded in the PPy matrix, forming the core-shell } \\
\text { structure. }\end{array}$ \\
DBSA-doped PPY/ & & Solid-state synthesis & Uniform dispersion of DBSA into the ${\mathrm{PPY}-\mathrm{WO}_{3} \text { hybrid nanocomposite. }}^{\text {Und }}$
\end{tabular}

$$
\mathrm{WO}_{3}
$$

MWCNTs/PPy

$\mathrm{PPYP} / \mathrm{Fe}_{3} \mathrm{O}_{4}$-NPs

SWNT/PPy

rGO/PPy NT

PPy/GN

c-MWCNT/PIN

$\mathrm{Mn}_{2} \mathrm{O}_{3} / \mathrm{PIN}$
Poly(5-
carboxyindole)/c-
MWNT
Polypyrrole- $\gamma-\mathrm{Fe}_{2} \mathrm{O}_{3}-$
fly ash

PInd-Na-AlMCM-41

Ppy/AuNPs-GOx

$\mathrm{MoS}_{2}$-Pin

$\mathrm{MoO}_{3} / \mathrm{PPY}, \mathrm{VO}_{2} /$

$\mathrm{PPY}, \mathrm{SnO}_{2} / \mathrm{PPY}$

$\mathrm{SnO}_{2} / \mathrm{PPy}$

$\mathrm{PPy} / \mathrm{TiO}_{2}$

PPy-coated CNFs

PPy/Ag

PPy-Alg-CNT

graphene/

polypyrrole

Ag/polypyrrole

AgNPs/PIn-r-GO

Pd/PPY

PPy/Au

Pind/CNT

$\mathrm{PIN} / \mathrm{Au}$

One-pot One-pot method synthesis

Pt-polypyrrole modified $\mathrm{TiO}_{2}$

Solution mixing

Solution mixing

In situ In situ emulsion synthesis polymerization polymerization

In situ emulsion polymerization microemulsion

Wet-spinning technique
Wet spinning technique and Vacuum filtration Vacuum filtration In situ and interfacial

In situ polymerization In situ polymerization polymerization

In situ polymerization

Enzymatic in situ Langmuir technique

Hydrothermal method

Hydrothermal reverse Vapor deposition polymerization (VDP)

Vapor deposition polymerization (VDP)

Photo-DLICVD process

Reactive wet-spinning

Post polymerization In situ polymerization

In situ reduction process Partially deprotonated polypyrrole doped with hydroxide ions (PPyOH) in various 123 $\mathrm{PdCl}_{2}$ aqueous solutions, which differed in acidity, were studied.

In situ reduction process Polypyrrole (PPy) nanotubes are prepared by a self-degraded template method, and 124 $\mathrm{Au}$ nanoparticles are deposited in situ by the reduction of $\mathrm{HAuCl}_{4}$.

Easy and scalable electrospinning technique to fabricate high surface area elec- 126 troactive Pind nanofibers.

In situ polymerization of indole, using metal salt chloro-auric acid as an oxidant, in 127 a microemulsion system.

Titanium dioxide was modified with Pt-polypyrrole nanocomposites through the 128 in situ simultaneous reductions of $\mathrm{Pt}(\mathrm{IV})$ and the oxidative polymerization of pyrrole monomers at ambient temperature. 
Table 1 (continued)

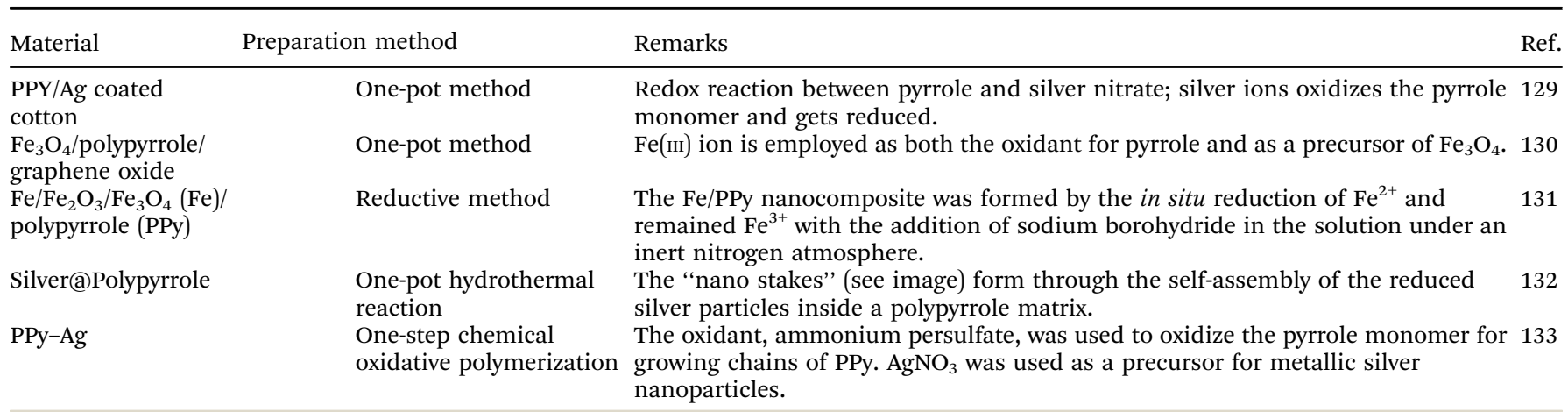

their agglomeration. Still, vigorous stirring and/or ultra-sonication of the mixture are compulsory to avoid their aggregate formation during polymerization. Notably, polymerization can be carried out not only in a homogeneous medium but also in a heterogeneous medium, i.e., in emulsion using surfactants. The surfactants can act as a template and dopant in the polymerization by forming micellar aggregates, which boost the dispersibility of nanoparticles, raise the polymerization rate, and also enhance the conductivity of the final nanocomposite. ${ }^{107}$ Such in situ emulsion polymerization uses different surfactants for the hybridization of fillers with PIN and PPY to form core-shell particle nanocomposites, such as dodecyl benzene sulphonic acid (DBSA), ${ }^{108}$ sodium dodecyl sulfate (SDS), ${ }^{109}$ cetyltrimethylammonium bromide (CTAB), and sodium lauryl sulfate (SLS). ${ }^{104}$ In addition to in situ emulsion polymerization, the enzymatic polymerization of pyrrole monomer with gold nanoparticles in the presence of glucose oxidase enzyme was also reported. ${ }^{110} \mathrm{H}_{2} \mathrm{O}_{2}$ is generated by glucose oxidase in the presence of glucose, which acted as the initiator of polymerization, and AuNPs or $\mathrm{AuCl}^{4-}$ ions facilitate the enzymatic polymerization of pyrrole. One of the routes for the in situ synthesis of conducting nanocomposites is the Langmuir technique. ${ }^{111}$ Richa Mishra et al. successfully fabricated $\mathrm{MoS}_{2}$ nanosheets in polyindole matrix at the air-water interface assisted by the Langmuir technique. Langmuir's technique can provide maximum interfacial interaction between nanoparticles and CPs at the air-water interface. Indole gets adsorbed on exfoliated nanosheets of $\mathrm{MoS}_{2}$, which act as hosts to template the controlled polymerization of indole. The hydrothermal method offers another simple approach for the synthesis of the $\mathrm{CP} / \mathrm{metal}$ oxide nanocomposite with a shorter chain length or a higher degree of conjugation. Li et al. reported a series of metal oxide/PPY composites, including $\mathrm{MoO}_{3} / \mathrm{PPY}, \mathrm{VO}_{2} / \mathrm{PPY}$, and $\mathrm{SnO}_{2} /$ PPY, via the hydrothermal reaction. ${ }^{112}$ Similarly, Libo Sun et al. synthesized $\mathrm{SnO}_{2} / \mathrm{PPY}$ nanocomposites by the hydrothermal reverse microemulsion method, which combines the merits of reverse microemulsion and hydrothermal method. ${ }^{113}$ Recently, non-liquid phase polymerization, in addition to liquid phase polymerization, is also used to synthesize nanocomposites. Chemical vapor deposition (CVD) and vapor deposition polymerization (VDP) or vapor-phase polymerization (VPP) are the two common methods used in synthesizing CPs in the vapor phase. ${ }^{92}$ The vapor deposition polymerization is a versatile approach reported for the synthesis of the nanocomposite of PPY and PIN. ${ }^{114,115}$
Jang and Bae reported the carbon nanofibers/PPY nanocomposite using such a strategy. ${ }^{114}$ The thickness of the PPY layer can be controlled through this technique and the nanocomposite exhibited superior response signal due to the presence of the thin and uniform PPY layer. The role of different co-vapors, namely, ethanol, hexane, methanol, benzene, toluene, and water, in fabricating polypyrrole polypyrrole/cellulose (PPCL) nanocomposite papers via vapor phase polymerization method was reported by Ji Eun Lee et $a .^{116}$ The oxidation level and morphology of deposited PPY are influenced by the co-vapors produced during the polymerization, and thereby the electrochemical properties of the PPCL papers are varied. The chemical vapor deposition (CVD) technique involves the deposition of CPs that occurs on a substrate through the formation of a reactive gas phase by vaporizing a liquid or solid precursor, which is transported by convection with a carrier gas. For instance, C. C. Manole et al. reported the synthesis of Ag-doped PPY films through the CVD method. ${ }^{117}$ Polymerization is accomplished by the gas-phase UV irradiation of the monomer, and the PPY films are deposited in the presence of $\mathrm{Ag}$ nanoparticles from the same monomer solution. The wet spinning process can also be used to fabricate conducting polymer nanocomposites. ${ }^{118,119}$ For example, the synthesis of reduced graphene oxide (rGO)/PPY fibers was reported by the wet-spinning process. Here, a singlecapillary needle is used to spin the mixture of pyrrole and graphene oxide into a ferric chloride solution where PY was in situ polymerized to PPY, forming the GO/PPY fibers. Then, GO/PPY fibers were chemically reduced to $\mathrm{rGO} / \mathrm{PPy}$ fibers using hydroiodic acid. Recently, the post-polymerization technique was used to prepare Ag/polypyrrole (PPY) coaxial nanocables, which involves the common ion adsorption effect. ${ }^{120}$ In this technique, the $\mathrm{Ag}^{+}$ions were adsorbed onto the closest surface of silver nanowires through the common ion adsorption effect on being disposed of from the $\mathrm{AgNO}_{3}$ aqueous solution and this silver nanowire surface is employed as the polymerization active site to form the final composition in the absence of any other oxidizing agent.

In the next strategy, namely, in situ nanoparticle synthesis in the presence of the polymer, the CPs are dissolved in a suitable solvent and then mixed with a nanofiller precursor, followed by thermal treatment or addition of reducing agents, such as hydrazine and borohydride to obtain the final nanocomposites. ${ }^{25}$ 
This strategy can be considered as a unique solution mixing process that gives uniform nanostructures with various morphologies within the polymer matrix. ${ }^{121}$ For instance, a ternary Ag NPs/ PIN-r-GO composite was prepared by mixing the aqueous solution of $\mathrm{AgNO}_{3}$ with an aqueous suspension of PIN/GO under constant stirring. ${ }^{122}$ An aqueous solution of sodium borohydride was used as a reducing agent to form the final nanocomposite, showing enhanced electrochemical properties. Pd/PPY ${ }^{123}$ and Au/PPY ${ }^{124}$ monometallic nanocomposites have been reported to be synthesized by this method for their potentiometric sensor applications. However, this technique is not widely adopted since it is difficult to control the size and distribution of the nanocomposites. ${ }^{88}$ Electrospinning offers a simple method for the synthesis of conducting polymer nanocomposites. The electrospinning technique uses an electrostatic force (direct current) of several $\mathrm{kV}$ to generate fibers of the nanocomposite from a solution or melt. ${ }^{125}$ Mike Tebyetekerwa et al. reported polyindole/carbon nanotube (PIN/CNT) nanofibers fabricated via the electrospinning process for the first time. ${ }^{126}$ In the procedure, a little percentage of CNTs were introduced into the spinning solution containing PIN and PEO. The current applied was $\sim 15 \mathrm{kV}$ and solvent evaporation at $24{ }^{\circ} \mathrm{C}$ in the vacuum solidifies the nanofiber.

4.1.1.3. One-pot synthesis. This method involves the simultaneous polymerization of monomers and synthesis of nanoparticles in a single step to produce a homogenous nanocomposite. In a study, Leela Joshi and Rajiv Prakas employed a one-pot strategy to synthesize polyindole-Au nanocomposite using the metal salt chloroauric acid as an oxidant and revealed its vast potential in electronic applications and fabrication of nanoscale organic devices. ${ }^{127}$ There are several literature reports on the one-pot synthesis of PPY nanocomposites. ${ }^{128-133}$

The major disadvantage of one-pot synthesis is the limited control over the size and morphology of the resulting nanocomposites. ${ }^{92}$

4.1.2. Electrochemical methods. Electrochemical synthesis is considered to be an advanced synthetic way of fabricating conducting polymer nanocomposites with excellent thermal and physical stability. This smooth and rapid method involves reduction-oxidation activity and a sluggish rate of degradation. The three-electrode assembly techniques such as potentiostatic, galvanostatic, or potentiodynamic are chiefly employed in electrochemical synthesis, and the morphology and properties of the nanocomposites can be controlled by the applied potential or current density. From the survey of the literature, it has been observed that mainly three procedures have been followed for the synthesis of nanocomposites of PPy and PIN: (i) ex situ synthesis (ii) in situ synthesis, and (iii) single-step synthesis. A summary of recent electrochemical methods for PIN and PPY nanocomposites described in the literature are shown in Table 2.

4.1.2.1. Ex situ (sequestered) synthesis. Layer-by-layer assembly method is one of the sophisticated ex situ methods for the synthesis of conducting polymer nanocomposites. For example, layer-by-layer assembly method was reported by Dongzhi Zhang et al. for the fabrication of polypyrrole $/ \mathrm{Zn}_{2} \mathrm{SnO}_{4}$ nanofilm and used as an ultra-high sensitive ammonia sensor $^{134}$ (Fig. 3).

Table 2 Representative examples of the electrochemical methods for the synthesis of PIN and PPY nanocomposites

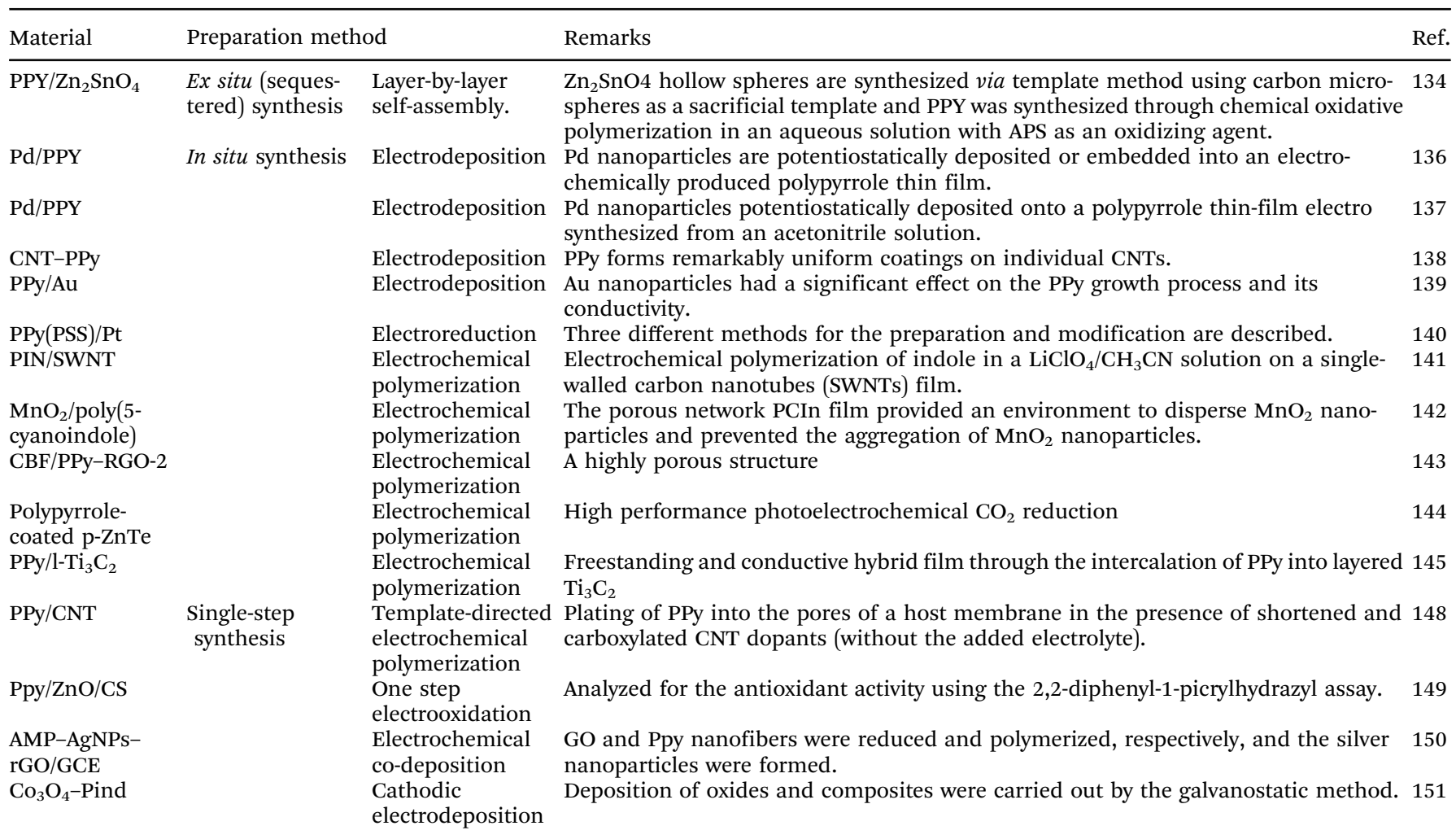


(a)
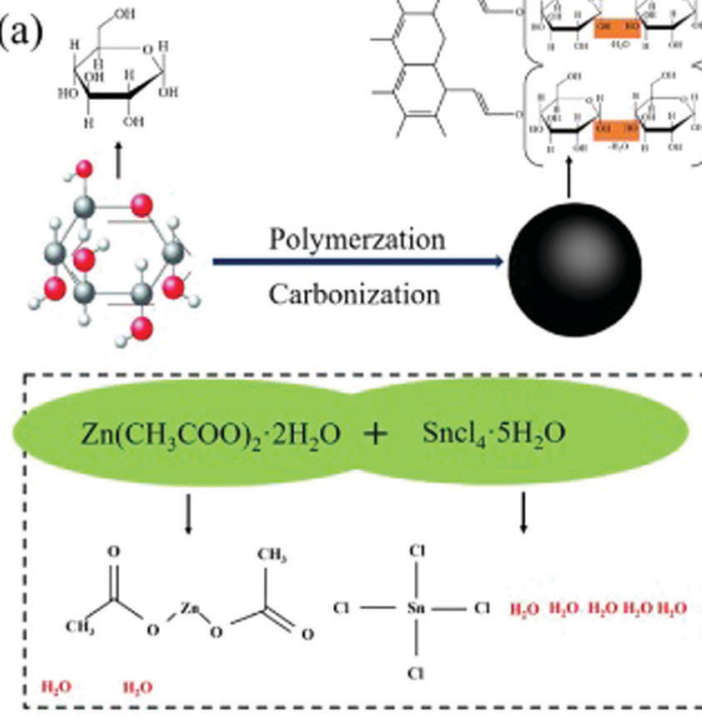

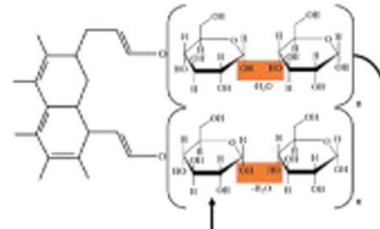

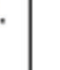

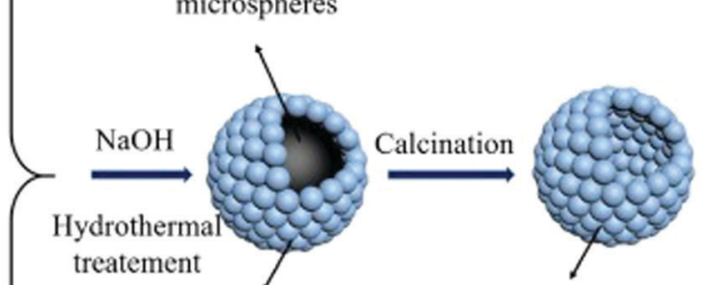

$$
\mathrm{Zn}_{2} \mathrm{SnO}_{4}
$$

$\mathrm{Zn}_{2} \mathrm{SnO}_{4}$ hollow spheres

(b)
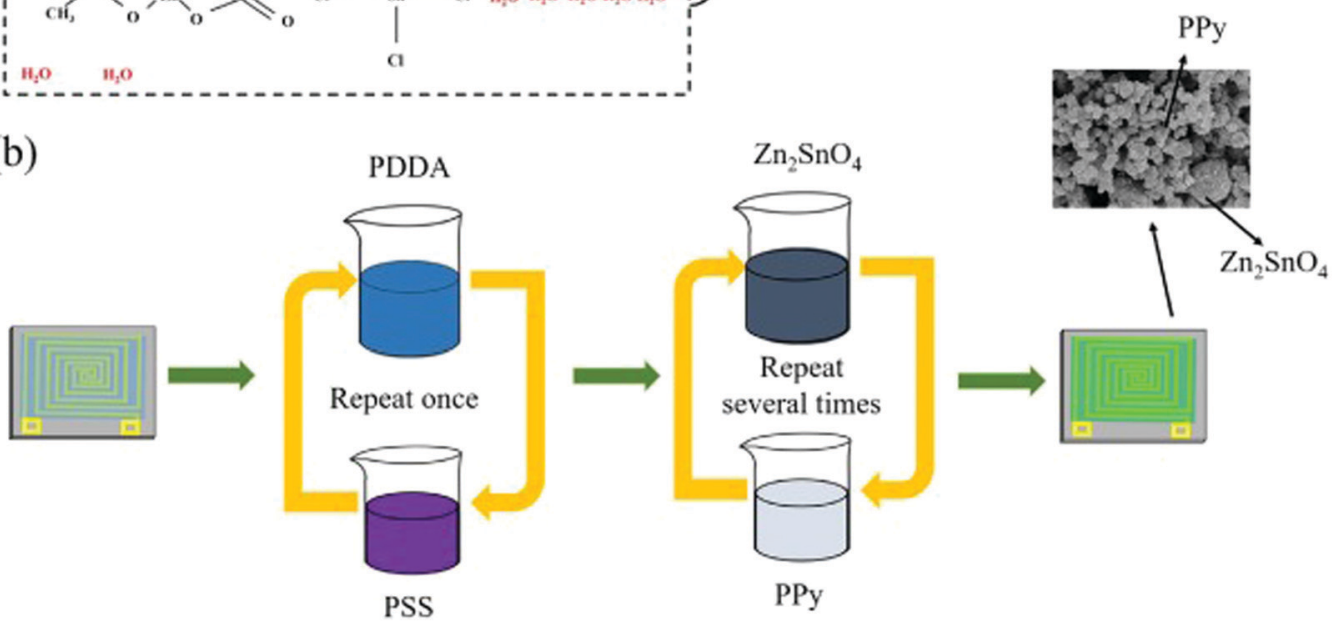

Fig. 3 Schematic representation of the synthesis of (a) $\mathrm{Zn}_{2} \mathrm{SnO}_{4}$ hollow spheres and (b) $\mathrm{PPy} / \mathrm{Zn}_{2} \mathrm{SnO}_{4}$ nanocomposite film. Reproduced with permission. ${ }^{134}$ Copyright 2018, Elsevier.

$\mathrm{Zn}_{2} \mathrm{SnO}_{4}$ hollow spheres are produced via the template method employing carbon microspheres as a sacrificial template and the chemical oxidative polymerization method was used to prepare PPY with APS as an oxidizing agent. These $\mathrm{Zn}_{2} \mathrm{SnO}_{4}$ hollow spheres and PPY nanospheres act as partners in the layer-bylayer assembly technique. Photolithographic technology is used to pattern a pair of $\mathrm{Ni} / \mathrm{Cu}$ interdigital electrodes (IDEs) on the PCB sensor substrate. In the fabrication technique, a precursor layer is first deposited on the substrate by alternately immersing in poly(diallyl dimethylammonium chloride) (PDDA) and polystyrene sulfate (PSS) solutions twice, and then the sensor was alternately immersed in $\mathrm{Zn}_{2} \mathrm{SnO}_{4}$ and PPy suspensions for several cycles. The FTIR spectra manifest the successful fabrication of the $\mathrm{PPY} / \mathrm{Zn}_{2} \mathrm{SnO}_{4}$ nanocomposite.

4.1.2.2. In situ synthesis methods. This method can be further classified based on components formed in the in situ procedure. The electrochemical deposition of fillers into PPY or PIN films is a very appropriate and convenient method for the insertion of nanostructures into the PPY- and PINmodified electrode surfaces. It has been established that the electrochemical deposition conditions can control the spatial distribution, size, and the number of fillers in the composites. ${ }^{135}$ Moreover, spatial distribution and the reduction potential of the nanoparticles depend on the initial oxidation state of the CP layer. The nucleation and growth of nanoparticles on a reduced CP film were significantly restricted and high overpotentials are required, while on the oxidized CP layer, nanoparticle deposition, especially metal deposition, will occur and the reduction of metal cations occurred at a potential close to equilibrium. ${ }^{135}$ The Pd/PPY nanocomposite has been reported to be first prepared by electrochemical deposition using platinum electrodes. The resulting composite shows good electrical conductivity and its electrochemical activity is related to both polypyrrole and palladium particles. ${ }^{136,137}$ Latter composites based on $\mathrm{CNT}^{138}$ and unimetallic composites ${ }^{139,140}$ with PPY have also been reported. These synthetic methods have been also discussed in several studies on PIN nanocomposites. For example, Ruirui Yue et al. reported 5-aminoindole (AIn) electropolymerized on graphene (GE)-modified glass carbon (GC) electrode and Pt particle electrodeposition were carried out on the synthesized PAIn/GE/GC electrode. Polymerization was conducted through the 
cyclic voltammetry method and different cyclic voltammogram (CV) circles to obtain different loading masses. Other methods focus on strategies where an array of fillers can be used as the working electrode for the electrodeposition of PIN or PPY. This technique offers control over the thickness and morphology of the CP layer deposited. The electrochemical polymerization of indole was also carried out using the conventional three-electrode one-compartment cell having an Au plate as the working electrode. ${ }^{141}$ Covalent functionalization of SWNTs with PIN in the doped state is illustrated through this electrode deposition. Weiqiang Zhou et al. tried to synthesize the $\mathrm{MnO}_{2} / \operatorname{poly}(5-$ cyanoindole (PCIn)) nanocomposite by means of PCIn and $\mathrm{KMnO}_{4}$ as a host material and a precursor, respectively. ${ }^{142}$ The porous PCIn electrode can improve the surface area and thereby the capacitive behavior of the final composite. More recently, a working electrode made of $\mathrm{CBF},{ }^{143} \mathrm{ZnTe},{ }^{144}$ and MXene was used for the electropolymerization of the pyrrole monomer. Zhu et al. synthesized the $\mathrm{Ti}_{3} \mathrm{C}_{2}$ MXene/PPy free-standing composite film through the intercalation of PPY with $\mathrm{Ti}_{3} \mathrm{C}_{2}$ MXene sheets. ${ }^{145}$ The $\mathrm{N}-\mathrm{H}$ groups of pyrrole rings and the oxygen or fluorine-containing terminal groups on $\mathrm{Ti}_{3} \mathrm{C}_{2}$ MXene sheets were strongly bonded via hydrogen bonding in this composite. An alternative route to electrodeposition includes the nanoparticles bearing the carboxylate groups, ${ }^{144}$ or DNA-wrapped ${ }^{146,147}$ with negative charges acting as both 1D templates and dopants for growing CPs. These template techniques are very flexible and simple as the deposition of the preferred materials carried within the pores of the self-assembled template molecules, followed by the template dissolution. For instance, the new PPY/CNT nanowires were grown by a template-directed electropolymerization of PPY into the pores of a host membrane in the presence of CNT dopants. This is a convenient and reproducible fabrication method for producing high-quality PPY/CNT nanowires of multiple sizes or compositions. ${ }^{148}$

4.1.2.3. Single-step synthesis. A feasible single-step electrochemical reaction between the monomer and metal salt solution occurs when the potential pulses of different polarities are applied in cycles. The electrodeposition of metal nanoparticles takes place when a negative potential is applied, whereas a positive potential is necessary for the synthesis of the conducting polymeric film. This synthetic method has been successfully discussed in the fabrication of the polypyrrole/zinc oxide/chitosan bionanocomposite. ${ }^{149}$ In another work, one step strategy was employed for the graphene oxide reduction and polymerization of PPY through cyclic voltammetry and the PPY NFs-AgNPs-rGO nanocomposite was fabricated. ${ }^{150}$ Compared with other methods, the electrochemical co-deposition of organic and inorganic components offers the possibility of deposition of thick films, shorter processing time, and higher deposition rate at room temperature. ${ }^{149}$ A notable example is the fabrication of the cobalt oxide-polyindole $\left(\mathrm{Co}_{3} \mathrm{O}_{4}-\mathrm{Pind}\right)$ composites via cathodic electrodeposition. To obtain the $\mathrm{Co}_{3} \mathrm{O}_{4}-\mathrm{Pind}$ composites, an indole monomer was added to the aqueous electrolyte containing $\mathrm{NaNO}_{3}, \mathrm{Co}\left(\mathrm{NO}_{3}\right)_{2}$, and $\mathrm{HNO}_{3}$, and the deposition of oxides and composites were carried out by the galvanostatic method. ${ }^{151}$

4.1.3. Photochemical methods. The photochemical method is a direct route for the synthesis of conducting polymer nanocomposites, which has been popularized only in the recent years. ${ }^{152}$ Photochemical methods have many advantages over chemical and/or electrochemical polymerizations methods. This environment-friendly method enables the easy fabrication of CP films and can be optimized by incorporating nanomaterials into the polymer structure on a nonconducting substrate surface. ${ }^{153}$ Moreover, this simple single pot reaction can be scaled up to fulfill the industrial necessities. Based on the mechanistic aspects, the photochemical synthesis of the conducting polymer nanocomposites has been classified into two major groups: (1) direct photopolymerization, and (2) photopolymerization in the presence of a photosensitizer. The representative examples for the photochemical methods for the synthesis of PIN and PPY nanocomposites are summarized in Table 3.

4.1.3.1. Direct photopolymerization. Here, the photoexcitation process is directly executed by the monomer without using any photosensitizer. The photopolymerization process has been carried out by exposing monomers and electron acceptors to

Table 3 Representative examples of the photochemical methods for the synthesis of PIN and PPY nanocomposites

\begin{tabular}{|c|c|c|c|c|}
\hline Material & Preparation method & & Remarks & Ref. \\
\hline $\mathrm{TiO}_{2}$-polypyrrole & & $\begin{array}{l}\text { In situ } \\
\text { photopolymerization }\end{array}$ & $\begin{array}{l}\text { Optical excitation of mesoporous } \mathrm{TiO}_{2} \text { was used to generate the } \\
\text { electronic potential necessary for the oxidation and polymerization } \\
\text { of the pyrrole monomer. }\end{array}$ & 155 \\
\hline $\mathrm{TiO}_{2} / \mathrm{PPY}$ & & $\begin{array}{l}\text { In situ } \\
\text { photopolymerization }\end{array}$ & $\begin{array}{l}\text { Oxidative polymerization of pyrrole is initiated by photoexcited } \mathrm{TiO}_{2} \\
\text { nanoparticles. }\end{array}$ & 157 \\
\hline MMT-Sil-PPyAg & & $\begin{array}{l}\text { One-pot } \\
\text { photopolymerization }\end{array}$ & $\begin{array}{l}\text { One pot photopolymerization of pyrrole using silver nitrate as a } \\
\text { photosensitizer in the presence of clay (montmorillonite, MMT) }\end{array}$ & 158 \\
\hline $\begin{array}{l}\text { PPy/Ag-coated } \\
\text { cellulose fabrics }\end{array}$ & & $\begin{array}{l}\text { One pot } \\
\text { photopolymerization }\end{array}$ & UV-induced polymerization of pyrrole in the presence of $\mathrm{AgNO}_{3}$ & 159 \\
\hline
\end{tabular}


light, where the monomeric molecules act as a photosensitizer. For example, polypyrrole-reduced graphene oxide composites were synthesized via the direct photopolymerization method. ${ }^{154}$ Pyrrole monomers absorb light and produce photoexcited pyrrole molecules. These photoexcited pyrrole molecules will be instantly quenched by the graphene oxide, followed by the formation of pyrrole radical cations. Thus, graphene oxide is reduced to reduced graphene oxide and the polymerization of pyrrole monomers is initiated by employing radical cations. Further, the pyrrole oligomer formed through the electron transfer process absorbs light at a longer wavelength and forms new radical centers to propagate the polymerization process. Evidently, the $\pi-\pi^{*}$ interaction between the pyrrole monomer and graphene oxide lowered the photoexcitation energy of the pyrrole. Notably, this PPy-RGO composite demonstrated much higher electrical conductivities than those of photopolymerized PPY-Au composites. However, this method is seldom used due to its long reaction time and low quantitative efficiency.

4.1.3.2. Photopolymerization in the presence of a photosensitizer. In this method, the polymerization of monomers proceeds very efficiently using various nanomaterials as photosensitizers. ${ }^{155-157}$ Many transition metals or metal salts can perform as photosensitizers as they can absorb light energy and transfer it to the monomer molecules. ${ }^{158-160}$ For example, pyrrole activated by cerium(III) nitrate, leading to the formation of ceria/polypyrrole nanocomposite particles, was reported for the first time using the photopolymerization method. ${ }^{158}$ The author demonstrated that cerium nitrate can be considered as a unique photocatalyst for photo-polymerization due to the reason that photopolymerization takes place very efficiently without any further materials or additives and does not occur even for $4 \mathrm{~h}$ irradiation in the absence of cerium nitrate photocatalyst. They found distinct differences in the electrical properties of the ceria/polypyrrole nanocomposite particles acquired from the photochemical polymerization technique in comparison to polypyrrole synthesized via the chemical polymerization method. This photopolymerization method was reported by numerous studies, such as PPY/ $\mathrm{WO}_{3}{ }^{153}$ and $\mathrm{PPY} / \mathrm{TiO}_{2}{ }^{155,157}$ In many photopolymerization processes, the metal ions will oxidize pyrrole and themselves reduce to metallic NPs, which remain trapped in forming polypyrrole nanocomposites. ${ }^{156}$ In a different example, free-standing flexible polypyrrole-silver nanocomposite films were synthesized by the interfacial photopolymerization method. ${ }^{161}$ In the interfacial photopolymerization process, initially, the formation of the film occurs at the organic solvent (DCM)-ater interface and later at the air-water interface. Such films exhibit much-improved conjugation length and crystalline structure because of the slow polymerization process. Moreover, the ordered PPY-Ag films are achieved through the low feeding of pyrrole and reducing the availability of $\mathrm{Ag}^{+}$. Ternary hybrid systems based on PPY are also fabricated by photopolymerization methods; ${ }^{158,159}$ Khouloud Jlassi et al. investigated the heterostructure formation via photopolymerization by polymerizing pyrrole in situ in the presence of montmorillonite clay using $\mathrm{AgNO}_{3}$ as a photosensitizer. Polypyrrole and silver nanoparticles are simultaneously synthesized under UV-light irradiation in the form of a composite coating on silanized clay nanosheets.

4.1.4. Other novel trends for synthesis. Recently, photoelectrochemical polymerization methods have been devoted to assembling polypyrrole on a $\mathrm{TiO}_{2}$ nanotube array. ${ }^{162} \mathrm{Here}$, the concept of light-induced electrodeposition of PPY onto $\mathrm{TiO}_{2}$ nanotubes has been utilized by making use of photogenerated holes, which directly oxidize the monomer molecule. Interestingly, pulsed potential methods and pulsed light methods can assist in improved monomer availability within the nanotubular matrix. E. Ngaboyamahina et al. employed pulsed-potential and pulsed light methods to fabricate polypyrrole in $\mathrm{TiO}_{2}$ nanotube arrays. ${ }^{163}$ By alternating the oxidation phase with rest time, better control over the electrodeposition rate can be realized. Other advantages include the higher electropolymerization yields by regulating the deposition rate using pulses of light. Jianhang Huang et al. investigated ultrasound-assisted polymerization in the synthesis of $\mathrm{ZnO} /$ polypyrrole composites for zinc/nickel rechargeable battery. ${ }^{164}$ Compared with conventional magnetic stirring, polymerization using ultrasound could provide improved $\mathrm{ZnO}$ particles distribution as well as faster dissociation of pyrrole. Hence, an enhanced quantum of radicals generated can facilitate better polymerization efficiency.

\section{Multifunctions of PIN and PPY and their nanocomposites}

Among the CPs, PIN and PPY can be economically and conveniently synthesized at a large scale through electrochemical or chemical methods. Many of the interesting properties of PIN and PPY, such as tunable bandgaps, ionic and electronic conductivity, optical response, surface tension, volume change, environmental and thermal stability, biocompatibility, and electrochemical properties, have been exploited for many technological applications. The effect of nanoparticle-induced moderations in PPY and PIN, which possess the most effective colligative electronic, magnetic, and optical properties, has been widely explored. These tailoring of these conducting polymers to have proper electrical conductivity, mechanical properties, as well as processability has been the main challenge in the application for electrochromic displays, supercapacitors, sensors, thin-film transistors, organic LED, environmental remediation, etc. Fig. 4 shows an illustration of the applications of PIN, PPY, and their nanocomposites. Compared to conventional materials, PIN, PPY, and their nanocomposites possess many advantages in sensing and environmental remediation application fields. The key mechanisms assisted by these CPs and nanocomposites under an applied potential include pollutant uptake and release and electrocatalytic reduction/oxidation. ${ }^{165}$ The involvement of amino and hydroxyl groups attached to the polymer backbone of PPY and PIN and its surface roughness aid in pollutant adsorption. Toxic metal ions can attach to the $\pi$-electrons at the backbone of these polymers, resulting in strong interaction. In photocatalysis, PIN and PPY could be used as a sensitizer to support a metal oxide photocatalyst and the degradation of selected dyes under visible 


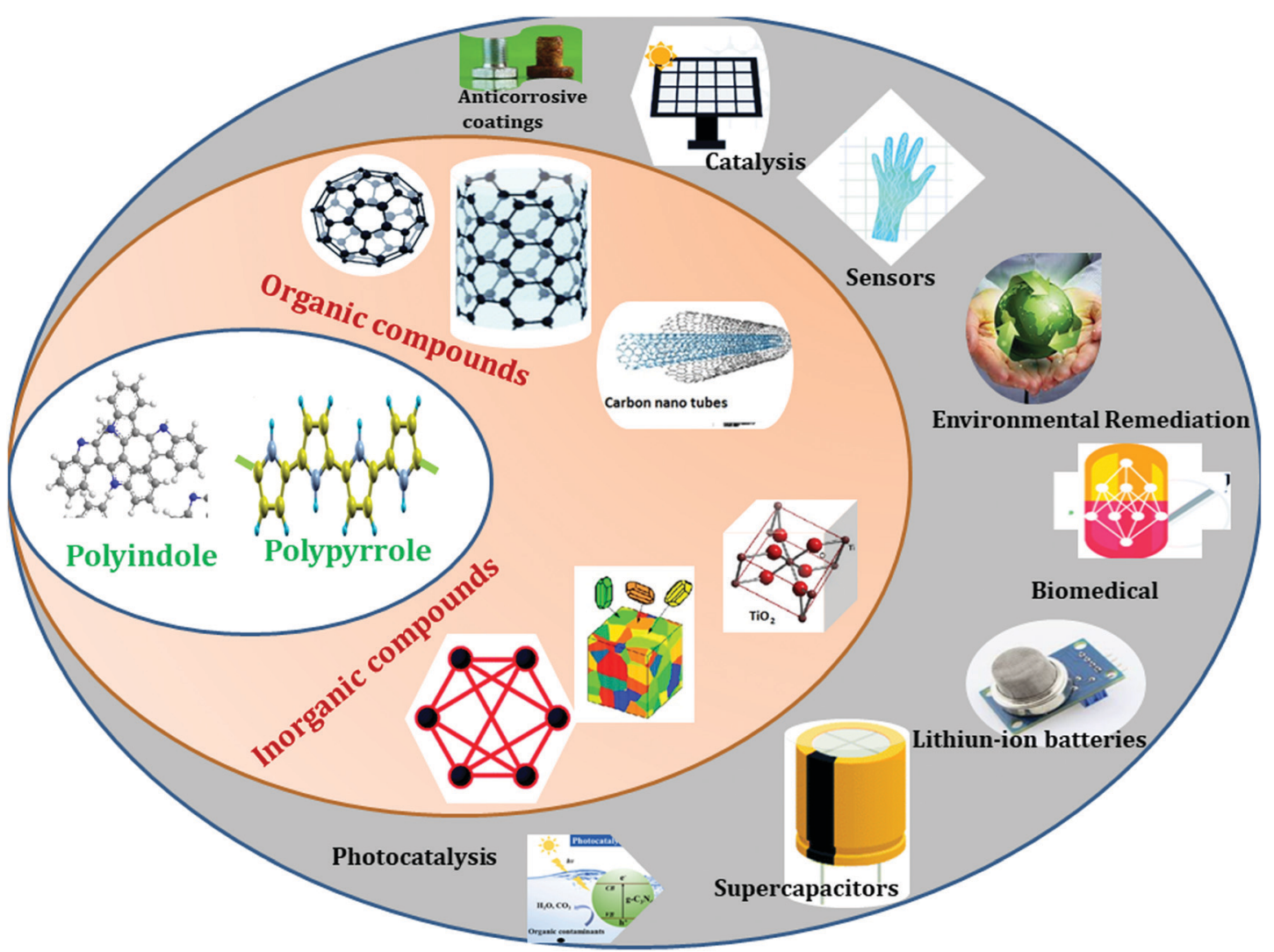

Fig. 4 An illustration of the applications of PIN, PPY, and their nanocomposites.

light irradiation. PIN and PPY possess high charge carrier mobility, and their nanocomposites can be designed to promote efficient charge separation during the photodegradation of pollutants, under simulated sunlight irradiation. Similarly, the limitations faced by conventional biosensors include slow response, high detection limit, and low selectivity, which opens the opportunities of using nanobiosensors based on CP nanomaterials since these CPs have unique characteristics that enable their customization for specific needs.

In the next section, we will concisely discuss the selected applications of PPY and PIN and its nanocomposites, mainly in environmental remediation and sensors application. This perspective gives an outline of the contributions of PPY and PIN in these interesting and important fields.

\subsection{Applications of PPY and PIN to environmental remediation}

The inherent electrochemical activity, high hydrophobicity, stability, and tunable bandgap make PPY and PIN promising avenues for environmental remediation technologies. These state-of-the-art materials can support the detection and removal of pollutants in multiple ways. The mechanisms such as adsorption, membrane separation, photocatalysis, ion exchange, and chemical or electrochemical reactions involving complexation or redox processes are responsible for their environmental applications. ${ }^{76,166-169}$ This section discusses the growing fame of PIN and PPY and their nanocomposites in environmental remediation applications, starting with air purification (i.e., $\mathrm{NO}_{x}$ and volatile organic compound (VOC) conversions, and $\mathrm{CO}_{2}$ adsorption) and extending to wastewater treatment, with the last section attributed to green chemistry to reduce the release of wastes into the environment.

\subsubsection{Air purification}

5.1.1.1. $\mathrm{CO}_{2}$ removal. Rapid industrial growth and changes in lifestyles are associated with the emission of hazardous gases into the atmosphere. The combustion of fossil fuels to meet energy demands results in a rapid rise of atmospheric $\mathrm{CO}_{2}$ concentrations, which is a major greenhouse gas. ${ }^{166}$ As per the Intergovernmental Panel on Climate Change (IPCC), carbon capture and storage (CCS) can effectively reduce $\mathrm{CO}_{2}$ concentrations in the atmosphere. ${ }^{170}$ Among the variety of solid-state adsorbent materials, activated carbons have been considered as a good choice for $\mathrm{CO}_{2}$ capture due to their recycling ability, simple production, availability, low cost, the ability to tune their ultramicroporosity, and high adsorption capacity. ${ }^{170-172}$ However, they suffer from the serious drawbacks of decreasing adsorption capacity at high temperatures. These drawbacks can be tackled by enhancing the interaction between the gas molecules and adsorbents by customizing the heteroatom doping or pore size/volume. ${ }^{170}$ The functional groups such as nitrogen can be integrated into the carbon framework for the improved attraction of acidic $\mathrm{CO}_{2}$ molecules toward the electron-donating species in the micropores.

Recently, there have been some reports concerning $\mathrm{CO}_{2}$ capture by conducting polymers. PPY and PIN have been 
functioning as precursor materials for the fabrication of nitrogen-doped porous activated carbons for $\mathrm{CO}_{2}$ adsorption. These conducting polymeric precursors can generate uniform pores during self-assembly, and the possibility of tuning the micropore size is achieved by controlling the extent of cross-linking. ${ }^{172}$ Moreover, they can produce more uniform nitrogen doping in the carbon framework in the absence of any other reagents during fabrication. In this context, Arpita Adhikari et al. developed N-doped porous activated carbons for $\mathrm{CO}_{2}$ capture using PPY as the precursor and $\mathrm{KOH}$ as an activating agent. ${ }^{171}$ In addition, Sevilla and co-workers reported $\mathrm{CO}_{2}$ adsorption on the $\mathrm{KOH}$-activated PPY-derived carbons under various activation conditions. ${ }^{173}$

To further improve the performance of $\mathrm{CO}_{2}$ adsorption, Arosha C. Dassanayake and Mietek Jaroniec ${ }^{172}$ newly synthesized activated polypyrrole-derived carbon spheres that can survive high gas pressure without dropping the sorption capacity when employed in circulating bed reactors as compared to non-spherical sorbents. The higher $\mathrm{CO}_{2}$ uptake at ambient conditions is attributed to the spherical morphology of the sorbents that reduce the attrition of materials and facilitate mass penetration and equilibration. The carbon spheres produced by the carbonization and controlled activation of PPY spheres using carbon/KOH showed $\mathrm{CO}_{2}$ uptakes of $7.73 \mathrm{mmol} \mathrm{g}^{-1}$ and $5.42 \mathrm{mmol} \mathrm{g}^{-1}$ at $0{ }^{\circ} \mathrm{C}$ and $25{ }^{\circ} \mathrm{C}$, respectively. Porous polypyrrole nanostructures can also function as active materials for $\mathrm{CO}_{2}$ adsorption. ${ }^{171}$ PPY nanostructure with better morphological features was synthesized using sodium cholate biosurfactant and was activated by heating at $70{ }^{\circ} \mathrm{C}$ with simultaneous degassing for $8 \mathrm{~h}$. The adsorption of $\mathrm{CO}_{2}$ molecules proceeds via acid-base interactions. The composite sorbents obtained by coupling PPY or PIN with GO revealed the active adsorption capacity at ambient conditions ${ }^{174,175}$ Ultramicropores $(<0.7 \mathrm{~nm})$ of porous carbons produced by the activation of composites are mainly responsible for the large $\mathrm{CO}_{2}$ uptake at ambient pressure due to enhanced gas-solid interactions within fine micropores.

Owing to the presence of basic $\mathrm{N}$ groups, microporous carbon materials derived from polyindole nanofibers and their composites were applied as sorbents for $\mathrm{CO}_{2}$ capture. ${ }^{170,174}$ Muhammad Saleh et al. explored polyindole-based hybrid material as an adsorbent for $\mathrm{CO}_{2}$ capture for the first time. ${ }^{174}$ Generally, the flue gases produced from power plants contain $\mathrm{CO}_{2}(20 \%)$ and $\mathrm{N}_{2}(70 \%)$ under normal pressure. The $\mathrm{N}$ content in the adsorbent gives competitive adsorbents that display good selectivity, fast adsorption kinetics, more ideal high $\mathrm{CO}_{2}$ uptake, and easy regeneration at low pressure.

Photocatalytic technologies using conducting polymer nanocomposites as a catalyst have been used as an efficient green method for reducing $\mathrm{CO}_{2}$ to produce organic substances. ${ }^{167}$

The conducting polymer PPY can act as a stable photosensitizer to enhance the photocatalytic activity and solar light conversion efficiency of $\mathrm{TiO}_{2}$. Fei Gao et al. reported improved photocatalytic activity of PPY-modified $\mathrm{TiO}_{2}\left(\mathrm{PPY} / \mathrm{TiO}_{2}\right)$ nanocomposites fabricated through the facile chemical oxidation of pyrrole in a $\mathrm{TiO}_{2}$ sol solution. ${ }^{167}$ The light adsorption range and separation efficacy of the hole-electron pairs from $\mathrm{TiO}_{2}$ can be enhanced by the introduction of PPY.
5.1.1.2. Volatile organic compounds' (VOCs) removal. The presence of VOCs in the atmosphere is harmful to the health of humans. ${ }^{176}$ Photocatalysis is an active tool among various technologies for air purification. Xiaojing Yuan et al. developed $\mathrm{TiO}_{2}$-Polypyrrole nanostructures for the highly active photodegradation of toluene. ${ }^{177}$ The recombination of photogenerated charge carriers is reduced by developing a $\mathrm{p}-\mathrm{n}$ heterojunction between the PPY nanostructures and $\mathrm{TiO}_{2}$, thereby enhancing the photocatalytic degradation of toluene. In addition, the high surface area, fewer defects in the nanostructure, and broad light absorption aid in enhancing the photocatalytic performance of the composite. PPYNS can be photoexcited under visible light irradiation, and acts as a photosensitizer.

Unfortunately, very less consideration has been given to the development of CPs-based adsorbents for volatile organic compounds (VOCs) mainly due to the harmfulness of VOCs and time-consuming complex measurements. ${ }^{178}$ Barbara Szczéśniak et al. reported the one-step carbonization and activation process for the fabrication of polypyrrole/ reduced graphene oxide composite derived from highly porous carbon materials, which can act as a benzene adsorbent material. ${ }^{178}$ The ultramicroporous carbon obtained exhibits large BET surface areas ranging from 1650 to $2780 \mathrm{~m}^{2} \mathrm{~g}^{-1}$, and the high micropore volumes in the range of $0.43-0.78 \mathrm{~cm}^{3} \mathrm{~g}^{-1}$ aid in benzene adsorption. Recently, Bowen Li developed a green and simple way for the large production of the material for the adsorption of toluene from paraffin liquid using polypyrrolebased porous carbon (PPC) material through $\mathrm{ZnCl}_{2}$ activation. ${ }^{179}$ The presence of more functional groups on the PPC surface and high $\mathrm{N}$-doped content are beneficial for the enhanced adsorption of nearly $7.00-8.82 \%$.

5.1.1.3. $\mathrm{NO}_{x}$ removal. $\mathrm{NO}_{x}$, including nitric oxide and nitrogen dioxide, are responsible for atmospheric pollution in even infinitesimal amounts, including ozone depletion, acid rain, and photochemical smog. The emission limitation of $\mathrm{NO}_{x}$ is a crucial task for thermal power plants in the field of air pollution control. Conventional methods such as selective non-catalytic reduction (SNCR), selective catalytic reduction (SCR), adsorption or absorption, and thermocatalysis have been widely applied for $\mathrm{NO}_{x}$ removal at relatively higher concentrations (i.e., $\left.\mathrm{mg} \mathrm{L}^{-1}\right) \cdot{ }^{180-182}$ However, these techniques are uneconomical at a low $\mathrm{NO}_{x}$ concentration (i.e., $\mathrm{g} \mathrm{L}^{-1}$ ) level. Chemical absorption biological reduction (CABR) systems and chemical absorptionbioelectrochemical reduction (CABER) systems are considered to be promising technologies for highly efficient $\mathrm{NO}_{x}$ removal in the flue gas due to non-secondary pollution effects, high efficiency, and low cost. ${ }^{183}$

Tianjiao Guo et al. applied the conducting polymer PPy onto the surface of carbon electrode in the biofilm electrode reactor (BER) and tested its performance in a CABER system. ${ }^{183}$ The core part of the CABER technology is BER, which is used to enhance system operation by reinforcing the reduction process. Higher current density produced by PPY on the electrode of the bioelectrochemical reactor (BER) results in an improved NO removal rate in the system. Further, the 
fabricated PPY-microbial electrolysis cell (MEC) showed excellent faradaic efficiency and improved reduction rate of $\mathrm{Fe}(\mathrm{III})$ EDTA and Fe(II)EDTA-NO in the solution in comparison to the original Carbon MEC. This established the benefit of the PPY-modified electrode(s) in the CABER system.

5.1.1.4. Quinone extraction. Atmospheric particulate matter is a complex matrix comprising both inorganic compounds such as metals, salts, elemental carbon, and organic substances including alcohols, alkanes, polycyclic aromatic hydrocarbons (PAH), and fatty acids. ${ }^{184}$ Among these diverse groups of organic substances, oxygenated $\mathrm{PAH}$ (oxy-PAH) quinones take part in redox cycling and form reactive oxygen species.

Zhe Jiao et al. reported polypyrrole-coated $\mathrm{Fe}_{3} \mathrm{O}_{4}$ $\left(\mathrm{Fe}_{3} \mathrm{O}_{4} @ \mathrm{PPy}\right)$ nanoparticles as an extraction adsorbent in a magnetic solid phase extraction method and utilized it for the analysis of five oxy-PAH quinones in fine atmospheric particulate matter. ${ }^{184}$ The composite material takes the advantage of high porosity and availability of $\pi$ electrons in PPy for the good extraction capacity toward quinones. The interactions such as $\pi-\pi$ interactions and hydrophobic interactions between quinones and PPy can enhance the functioning of $\mathrm{PPy} / \mathrm{Fe}_{3} \mathrm{O}_{4}$ in the extraction of quinones. This method offered the benefits of less organic solvent consumption and less preparation time.

5.1.2. Soil remediation. Polycyclic aromatic hydrocarbons (PAHs) are considered hazardous soil contaminants, which are produced mainly by the incomplete combustion of fossil fuels. ${ }^{185}$ Solid-phase microextraction (SPME) is one of the most familiar modern techniques to detect and quantify PAHs in contaminated soils ${ }^{186}$ because it is an effortlessly automated solvent-free, fast, and effective sample preparation technique. However, SPME fibers are also faced with some weaknesses such as high cost, fragility, limited sorption capacity, and swelling in organic solvents. Needle trap devices (NTD) is a robust and effective extraction strategy, which has greater functionality, more control over the capacity of the sorbent, and more extraction power. Unfortunately, the probability of needle clogging and improved memory effect makes them unfit for extraction.

Mina Behfar et al. reported the microextraction of PAHs from contaminated soil samples using an in-needle coated fiber (INCF) with a platinized fiber coated by a PPY/GO nanocomposite film. ${ }^{186} \mathrm{PPY} / \mathrm{GO}$ thin film was coated on the platinized surface of stainless-steel fiber employing an appropriate electropolymerization method. One of the major difficulties in analyzing natural solid samples such as sediments and soils is the strong attachment of the analytes to active sites and existence as complex matrices. Cooling-assisted microextraction (CA-ME) can effectively overcome this problem by enhancing the sample matrix temperature and simultaneously cooling the extraction phase. The reinforced in-needle coated fiber (Re-INCF) method employs the advantages of cooling-assisted microextraction and also compensates for the drawbacks of SPME and NTD techniques by coupling them into one setup. In the Re-INCf setup, the sample matrix is heated for more effective discharges of the attached molecules and simultaneously, the cooled fiber can entrap them efficiently. The PPY/GO composite with a porous structure can provide a better loading capacity and higher surface area. In addition, they interact efficiently with PAHs through polar-polar and $\pi-\pi$ interactions.

5.1.3. Wastewater treatment. Regarding wastewater treatment/ decontamination, PPY and PIN (or their nanocomposites) can act as sorbents, ion exchangers, membranes, photocatalysts, chemical/electrochemical reactors, or filters. Such a variety of applications in environmental remediation are considered in the next section.

5.1.3.1. Adsorption of pollutants. Adsorption techniques are commonly used as one of the most operative and easy techniques for removing poisonous pollutants. Among the CPs, PPY and PIN can function as efficient pollutant adsorbers due to their unique structure, which can comprise both amine and imine functional groups. ${ }^{187,188}$ The lone pairs of electrons on nitrogen atoms can facilitate the chelation and adsorption of pollutants.

Despite their practical usage in textile, paper, and printing industries, dyes pose a severe risk to the ecosystem and cause water pollution. PPY and PIN (or their composites) adsorb bulky amounts of dyes from aqueous solutions. The FTIR spectra were aided to establish the intermolecular hydrogen bonding between NH groups in PPY or PIN and nitrogen- or oxygen-containing groups in dyes. ${ }^{27}$ Unfortunately, the electronic conducting properties of CPs are not exploited in this dye adsorption application. Dye removal is conveniently tested by spectrophotometric techniques.

Among CPs, PPY and PIN have shown outstanding profiles as an adsorbent for the dye from contaminated aqueous solution. $^{23}$ PPY proved to be a useful adsorbent for methyl orange, the maximum capacity being $237 \mathrm{mg} \mathrm{g}{ }^{-1} \cdot{ }^{189}$ The adsorption capacity for other dyes, such as Acid Orange 10, malachite green, Congo red, amaranth, or indigo carmine is marginal at $10-20 \mathrm{mg} \mathrm{g}^{-1} \cdot{ }^{190}$ The enhanced adsorption of dyes by PPy nanocomposites has been typically observed due to synergistic effects. The composites containing magnetic particles have the benefit of adsorbents separation by the magnetic field. ${ }^{191}$ A better adsorption capacity of $1000 \mathrm{mg} \mathrm{g}^{-1}$ was obtained with polypyrrole-coated with mesoporous silica SBA15. ${ }^{192}$ PPy deposited on natural polymers such cellulose, ${ }^{193}$ chitosan, ${ }^{190}$ and saw dust ${ }^{194}$ represents excellent forms of adsorbents. For instance, the polypyrrole/cotton composite showed enhanced adsorption capacity compared to cotton itself.

Heavy metal pollution is another most dangerous environmental problem threatening human life due to the non-degradable and persistent nature of the pollutants. PPY and PIN are effective adsorbents because of their biocompatibility, environmental stability, chemical versatility, presence of nitrogen atoms that can chelate metal ions, designable structure, and simplicity. Recent publications extensively describe the adsorption characteristics, physicochemical properties, and mechanism of diverse PPY-based adsorbents as well as their application in the elimination of heavy metal ions. ${ }^{195}$ 
$\mathrm{Cu}$ (II) ions commonly occur as heavy metal ions in wastewater. Zhijiang Cai et al. reported polyindole nanofibers synthesized via the electrospinning technique to adsorb $\mathrm{Cu}$ (II) from an aqueous solution. ${ }^{197}$ Fibers having a uniform diameter, exceptionally long length, high porosity, interstitial, interconnectivity, and large specific surface ratio are usually prepared from the electrospinning technique, which can be effectively applied to metal-ion adsorption technique. FTIR spectroscopy confirms the chemisorption mechanism by the chelation of the $\mathrm{N}-\mathrm{H}$ groups of the PIN nanofibers with $\mathrm{Cu}(\mathrm{II})$. A large specific surface area stably combined with a recycling adsorption capacity makes PIN nanofibers a potent adsorbent compared to other nanofibers conducting polymer. More complex nanohybrids of PIN and multiple nanoparticle materials thereof can also be intended for sorbents. For instance, polyindole-based $\mathrm{ZnO} / \mathrm{MgO}$ nanocomposite for the removal of $\mathrm{Pb}$ (II) heavy metal ion. ${ }^{188}$ Composites offer a greater number of reaction sites available for $\mathrm{Pb}^{2+}$ adsorption.

To improve the chelating capability toward a broad range of heavy metal ions such as $\mathrm{Pd}(\mathrm{II}), \mathrm{UO}_{2}(\mathrm{II}), \mathrm{Cu}(\mathrm{II})$, and $\mathrm{Cd}(\mathrm{II})$, certain chelating functional groups such as carboxyl, amino, amidoxime, and sulfhydryl can be chemically bonded onto the adsorbents' surface. ${ }^{196}$ An amidoxime surface-functionalized polyindole (ASFPI) nanofiber synthesized via the electrospinning of poly(5cyanoindole) was applied for the removal of Pd(II) and Cd(II) from waste water bodies (Fig. 5). An adequate selection of experimental conditions such as temperature, $\mathrm{pH}$ value, contact time, and metal ions concentration allows the better binding property to the adsorbent. The complexation ability toward metal ions will be lost at low $\mathrm{pH}$ due to high protonation while better dissociation of oxime-hydroxyl-groups and more negative oxygen-ion of the oxime-hydroxyl-groups are produced at high $\mathrm{pH}$, facilitating adsorption. The selectivity of the metal ion depends upon the relative stability of the complexes and the ionic radii of the metal ions. In line with this report, Zhijiang et al. investigated amidoxime-modified polyindole (SAMPI) nanofiber membrane for the adsorption of hexavalent chromium ( $\mathrm{Cr}(\mathrm{vI})$ ) from wastewater. ${ }^{198}$ The SAMPI nanofibers contain more amine functional groups, which have better active sites for $\mathrm{HCrO}_{4}{ }^{-}$ adsorption. In addition, the interchange between doped $\mathrm{Cl}^{-}$in the SAMPI nanofiber and $\mathrm{HCrO}_{4}{ }^{-}$in the solution resulted in a higher adsorption capacity of $404.86 \mathrm{mg} \mathrm{g}^{-1} 45{ }^{\circ} \mathrm{C}$.

PPY and its nanocomposites exhibited appreciable adsorption capacity for defluorination from wastewater compared to other CPs. ${ }^{199,200}$ Defloration through adsorption in PPY composites involves both ion-exchange and physical adsorption mechanisms. Maximum fluoride ion removal occurred at higher temperatures, indicating the endothermic nature of the process. Studies also showed the effective removal of fluoride ions in the presence of other common anions such as $\mathrm{Cl}^{-}, \mathrm{NO}^{3-}, \mathrm{SO}_{4}{ }^{2-}$, and $\mathrm{HCO}_{3}{ }^{-}$.

5.1.3.2. Use of $3 D P P Y$ materials. Due to the small surface area and lack of a porous structure, PIN or PPY powders do not display much higher dye adsorption capacity. Also, aggregation can occur very easily in the powder form and incurs a very difficult post-separation process. Since pollutants are often present at low concentration levels, 3D materials with a high surface area were employed as highly efficient dye

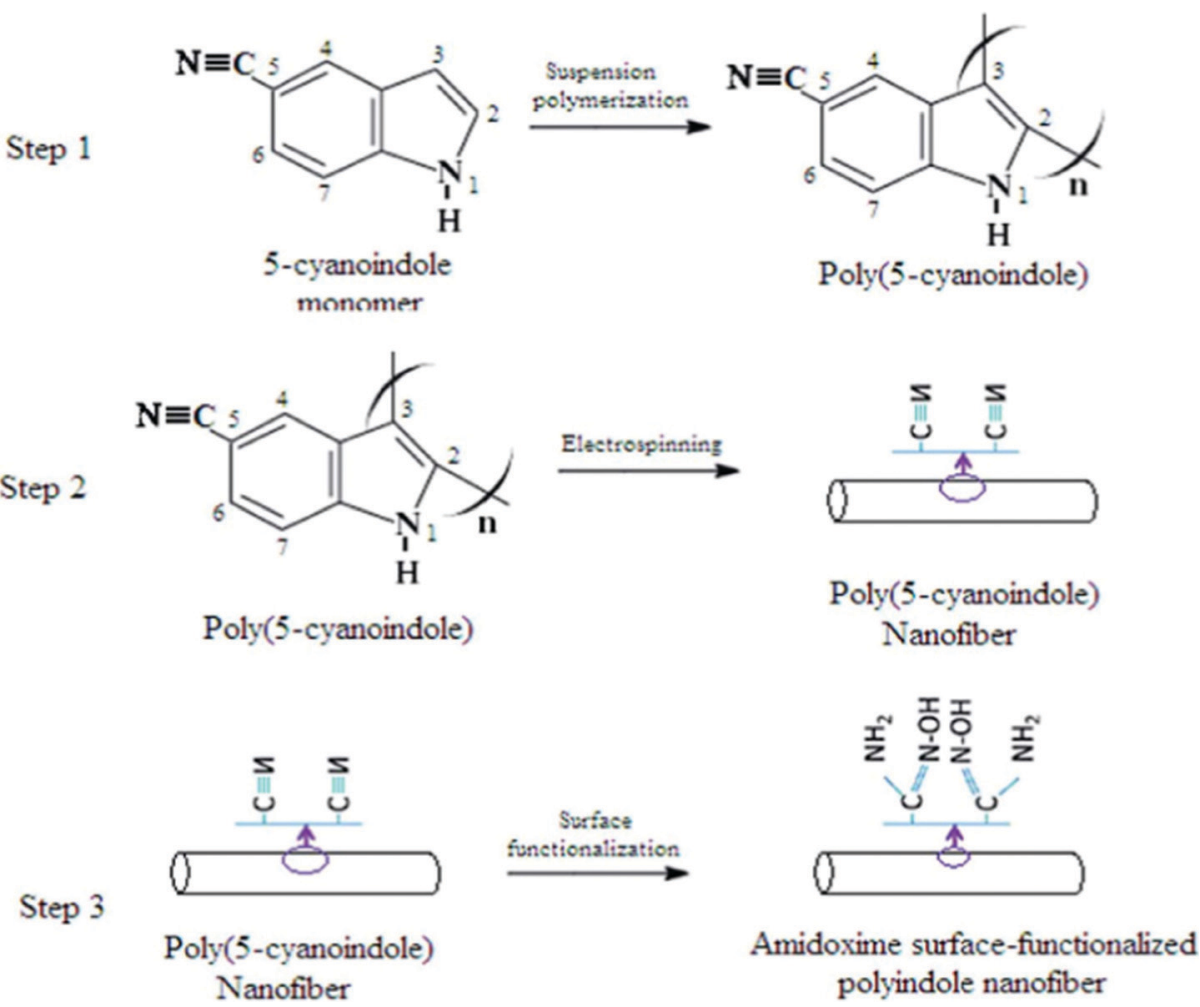

Fig. 5 Representation of the synthetic process of ASFPI nanofibers. Reproduced with permission. ${ }^{196}$ Copyright 2015, Royal Society of Chemistry. 
absorbents. $^{201}$ Xi Ye et al. fabricated pure PPY hydrogel beads for dye adsorption via an oxidant-templating strategy for the first time. ${ }^{189}$ The methyl orange adsorption capacity of PPY hydrogel beads was $236.9 \mathrm{mg} \mathrm{g}^{-1}$, which was significantly much higher than that of PPY powder. Hydrogels with enhanced adsorption properties are prepared by the reactive-template method. ${ }^{202}$ The reactive-template method is a substitute for the traditional soft-template and hard-template approaches where the one-step removal of templates and formation of final nanostructure were furnished simultaneously. These 3D hierarchical porous structures developed by the assembly of $0 \mathrm{D}$ PPY nanobeads into macroscopic frameworks offer a desirable combination of high surface area, fast mass transport through broad interpenetrated channels, and low density. The presence of high active surface areas thus obtained normally increases the target reaction rates.

The recyclable composite hydrogels of PPY with a threedimensional network exhibits excellent removal capability for heavy metal ion removal through simultaneous chemical reduction and adsorption. ${ }^{203}$ The participation of CPs in the chemical reduction of pollutants is further discussed below. Easy separation, regeneration, and reuse can be also accompanied due by a stable network in the composite hydrogel. Composite hydrogels of PPY can also participate in the most efficient and economical removal of antibiotics from an aqueous solution. ${ }^{203}$ For instance, Thayyath et al. developed polypyrrole-coated irondoped titania-based hydrogel for the adsorption of tetracycline hydrochloride $(\mathrm{TCH})$ from waste water. $^{203}$ The maximum adsorption occurs at $\mathrm{pH} 5.0$ due to the occurrence of zwitter ionic species of TCH and its electrostatic well as H-bonding interactions with the negatively charged adsorbent surface.

5.1.3.3. Membrane separation of pollutants. Membrane separation is a practical route for purifying wastewater that exploits to separate freshwater from contaminated waste water. ${ }^{168}$ Such barriers should have high flux, high selectivity, stability, antifouling, and chlorine-like chemicals. The sensitive membranes that respond to external stimuli such as magnetic forces, light, electrical voltage, ionic strength, specific molecules/ions, vibration, $\mathrm{pH}$, pressure, temperature, or reduction/oxidation reactions, can offer tunable self-cleaning and better removal efficacy. Antifouling is one of the main difficulties in the membrane separation technology. ${ }^{168}$ Membrane fouling can be effectively alleviated if the pore size of a membrane is switched between the micropore mode and macropore mode during the filtration and cleaning process, respectively. An electrically responsive ultrafiltration membrane (UF) of a polypyrrole-dodecylbenzenesulfonate (PPY-DBS) within the pores of a polyvinylidene fluoride (PVDF) membrane is a promising candidate for fouling alleviation and selective separation. ${ }^{168}$ Under an oxidation potential, the membrane size will be enhanced and then backwashed to remove foulants in the pores. Conversely, a reduction voltage is applied to recover the membrane pore size. The redox reaction in PPY-DBS was truly an electrochemical doping/ undoping process. The molecular weight distribution of the solute in the membrane could be tuned during filtration via this response mechanism. In addition to ultrafiltration, the methods such as membrane adsorption, ${ }^{204}$ cation exchange membrane, ${ }^{205}$ and nanofiltration ${ }^{206}$ were also detected for PPYand PIN-based membranes. For instance, Nasim Haghighat et al. fabricated polypyrrole-functionalized multiwalled carbon nanotubes-blended polyvinyl chloride nanofiltration (NF) membranes for the separation of Reactive Blue 50 dye in wastewater. $^{206}$ In NF, the membrane has a pore size of about 1-3 nm and properties between ultrafiltration and reverse osmosis. The $-\mathrm{N}-\mathrm{H}$ groups and aromatic ring of pyrrole on the membrane exhibit a repulsive interaction with the aromatic ring and amine functional groups on dye and results in the improved rejection of the dye. ${ }^{206}$ Besides this, the presence of PPY-MWCNTs content in the membrane improves the hydrophilicity by facilitating the formation of the hydrogen bond with water molecules.

5.1.3.4. Electrochemical treatment. Most of the pollutants in wastewater can be effectively degraded to non-toxic materials by electrochemical treatment, including electrochemical reduction, electrochemical oxidation, electrocoagulation/flotation, electrocoagulation, electrochemical advanced oxidation processes, and electrodialysis. $^{207}$ Such electrochemical technologies are most attractive due to their environmental compatibility and high efficiency, which use the electron, a clean reagent, as the main reagent. CPs display high stability, hydrophobicity, and fast electron transfer, and can be used favorably for electrochemical pollutant removal.

5.1.3.4.1. Electrochemical reduction. The electrochemical reduction dechlorination methods with PPY have been established to be very effective and alternative method for the detoxification of various polychlorophenols, chlorinated volatile organic compounds (VOCs), and polychlorinated hydrocarbons ${ }^{208-210}$ Electrocatalytic hydrogenolysis (ECH) is a promising approach proposed for electrochemically reductive dechlorination. ${ }^{211}$ In this technology, the electrolysis of $\mathrm{H}^{+}$ions produces chemisorbed hydrogen atoms $\left(\mathrm{H}_{\text {ads }}\right)$ on the electrode surface, which attack the chemisorbed PPY molecules. Thus, the reductive cleavage of $\sigma$ bonds or the addition of hydrogen to $\pi$ bonds occurs, following which the removal of halogen atoms successfully occurred at the electrodes loaded with noble metal under mild experimental conditions. Phenol will be the final product in the reductive elimination of such polychlorophenols. $^{212,213}$

PPY deposited on different types of conducting electrode substrates such as aluminum, stainless steel mesh, and reticulated vitreous carbon substrate ${ }^{214,215}$ and its composites with $\mathrm{Fe}_{3} \mathrm{O}_{4}{ }^{216}$ carbon nanotubes, ${ }^{217}$ and cellulose fiber ${ }^{218}$ can electrochemically degrade hexavalent chromium to less toxic and immobilize trivalent state due to its redox potential and ability to exchange anions with the solution. The reaction proceeds via a spontaneous electron transfer between PPY and chromate ion and an anion exchange process to accomplish charge compensation. ${ }^{219}$ The efficiency of PPY films to reduce $\mathrm{Cr}(\mathrm{vI})$ ions is strongly dependent upon the polymerization conditions. ${ }^{219}$ Reduction in presence of anions with larger hydrated radii such as $\mathrm{SO}_{4}{ }^{2-}, \mathrm{F}^{-}$, and $\mathrm{ClO}^{4-}$ showed lower yields than ions with smaller radii $\left(\mathrm{Br}^{-}, \mathrm{Cl}^{-}, \mathrm{I}^{-}\right.$, $\mathrm{NO}^{3-}$ ). This demonstrates that anodic potential induces a 
channeling process for anions by the relaxation of the PPY network. It is noteworthy that the pollutant itself restores the active form of the conductive polymer and a regeneration step can be avoided.

The integration of reduction and adsorption for the purification of Cr(vi) by PPY composites may deliver obvious benefits over the existing methods. ${ }^{218}$ Research findings confirmed that $\mathrm{Cr}(\mathrm{VI})$ was reduced to $\mathrm{Cr}$ (III) by the conductive PPY matrix and adsorbed onto the composite of PPY with cellulose fiber. The negatively charged hydroxyl/carboxyl groups in the cellulose fiber matrixes are responsible for $\mathrm{Cr}(\mathrm{III})$ adsorption. Thus, additional treatment procedures to remove $\mathrm{Cr}$ (III) can be eliminated.

Electrochemical reduction methods are utilized for dioxygen removal from aqueous solutions, which resist corrosion. S. Biallozor et al. checked the possibility of dioxygen electroreduction using PPY as the cathodic material in solutions of $\mathrm{pH}$ close to $7 .^{221}$ Nickel electrodes deposited with a polypyrrole film were applied for electroreduction and the reaction yielded $\mathrm{OH}^{-}$ as the final product via a $4 \mathrm{e}^{-}$path.

The electroreduction of $\mathrm{NO}_{3}{ }^{-}$ions is also of main concern from the environmental remediation perspective. The nitrate ion itself is nontoxic; however, the nitrite ion formed upon reduction by bacteria results in water pollution. Thus, the choice of the right electrode material that converts nitrate to ammonia without forming nitrite plays a very important role in electroreduction. For example, PPY-coated copper electrodes directly produce ammonia from nitrates by maintaining the applied potentials as small as possible. The coating of $\mathrm{Cu}$ surface with PPy causes controlled $\mathrm{H}_{\text {ads }}$ formation at the electrode, which accelerates the reduction to ammonia and direct electron transfer remains secondarily in a competition reaction ${ }^{220}$ (Fig. 6).

5.1.3.4.2. Electrochemical oxidation. The complete degradation of organic pollutants cannot be achieved through electrochemical reduction methods; however, organic contaminants are completely converted to $\mathrm{CO}_{2}$ and $\mathrm{H}_{2} \mathrm{O}$ by electrochemical oxidation method. ${ }^{222}$ Electrochemical oxidation occurs either by electrochemical combustion or electrochemical conversion into smaller fragments. The electrocatalysts such as $\mathrm{PbO}_{2}{ }^{223}$ can be integrated into the PPY matrix to provide better catalytic performance. $\mathrm{PbO}_{2}$ is preferred in the electrochemical oxidation of organic pollutants (such as 2-chlorophenol) due to its large dioxygen overpotential, high electrical conductivity, relative chemical inertness, and low cost. Here, PPY is converted into its reduced (neutral) state and then regenerated by electrochemical oxidation for reuse. Catalysts may act as either counter ions to balance the positive charge on the oxidized PPY polymer, or as microparticles or pendant groups that are attached to the PPY matrix. Oxygen evolution occurs as a side reaction in electrochemical oxidation when the reaction potential reaches the oxygen evolution overpotential, and this increases the energy consumption. Thus, the selection of an anode material is crucial. In a different example, ferrocenyl alkylammonium $\mathrm{N}$-substituted PPY-containing Pt and Pd involves the oxidation of As(III) to As(v) at lower potentials. ${ }^{224}$

5.1.3.4.3. Electrically switched ion exchange. Here, the uptake of charged pollutants through ion entrapping with a PPy matrix and subsequent release is stimulated by an electric field. The removal of both cationic (e.g., $\mathrm{Zn}^{2+}, \mathrm{Hg}^{2+}, \mathrm{Ni}^{2+}, \mathrm{Pb}^{2+}$, $\mathrm{Cr}^{6+}$, and $\left.\mathrm{Cd}^{2+}\right)^{76}$ or anionic $\left(\text { e.g., } \mathrm{F}^{-}\right)^{200}$ species can be done based on the type of ion dynamics leading the system. This electrochemical ion exchange occurs in an uncharged PPY matrix through complexation with amine or imine nitrogen, while in a charged matrix, the exchange is based on the necessity for charge compensation. For example, the anion entrapping and liberating property of PPY films is exploited for the green treatment method of a model azo dye, Acid Red $1 .^{225}$ During oxidation, polypyrrole $+\bullet$ electrostatically entraps the dye to the PPY matrix to maintain the electroneutrality, while during reduction, polypyrrole $+\bullet$ becomes neutral, and thereby Acid Red 1 from the film to the solution can be removed.

In cationic pollutant dynamics, usually, a dopant anion $\left(\mathrm{A}^{-}\right)$ is incorporated in the polymer bulk for initial charge compensation. The dopant anions such as poly(styrene sulfonate) (PSS), ${ }^{226}$ dodecyl benzenesulfonate (DBS), ${ }^{227}$ and catechol anions $^{228}$ are bulky to remain entrapped in the polymer matrix and electroactive in the whole working potential range.

For instance, $\mathrm{PPy} / \mathrm{PSS}^{-}$film reduction results in the incorporation of $\mathrm{Ni}^{2+}$ ions to balance the negative charge on the irreversibly incorporated large $\mathrm{PSS}^{-}$anions and are released on

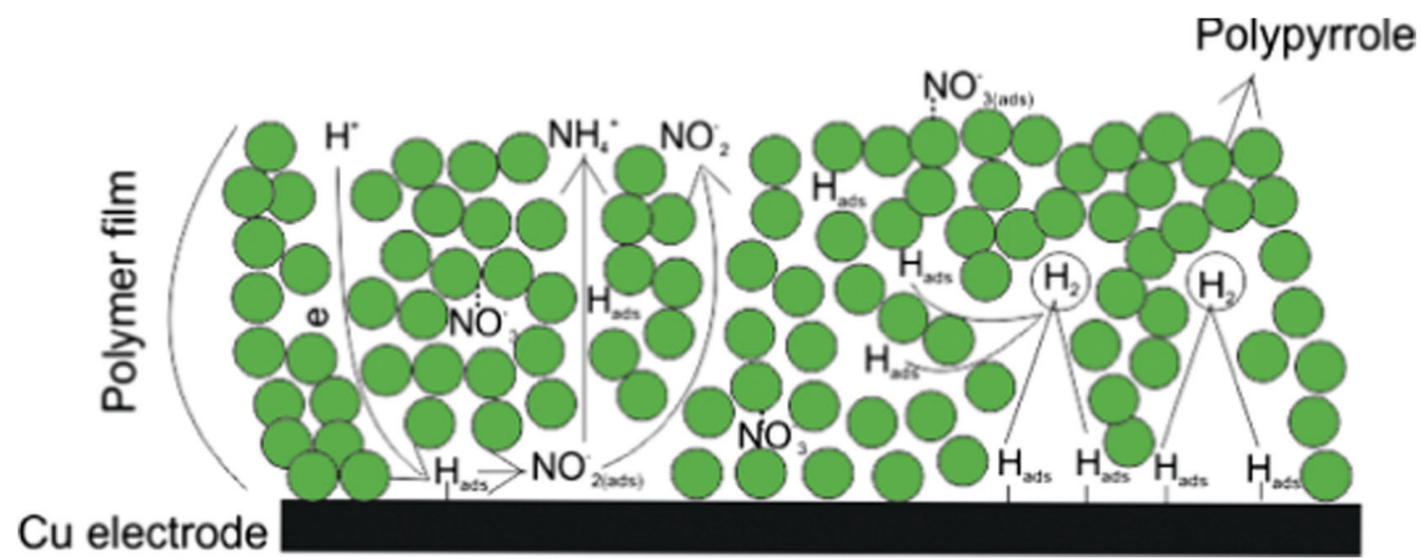

Fig. 6 An illustration of different reactions on the PPY-Cu electrode. Reproduced with permission. ${ }^{220}$ Copyright 2015 , Elsevier. 
the application of reverse potential. ${ }^{226}$ Likewise, M. A. Olatunji et al. reported the removal of radioactive ${ }^{57} \mathrm{Co}$ by PPY-sawdust composite. $^{229}$ The nature and size of the dopants anion can influence the electrical conductivity, porosity, hydrophobicity/ hydrophilicity, cross-linking degree, density, isotropy/anisotropy, mechanical properties, and permeability of the polymer. ${ }^{226}$ In a related way, bulky anions in the PPY matrix yield smaller pore diameters in comparison to smaller inorganic dopants. ${ }^{226}$

Electrically switched ion exchange technique shows ion selectivity based on charge, size, acid/base, complexation, electroactivity characteristics, or mobility. ${ }^{228,230}$ Crown-etherfunctionalized bithiophene-PPY composite showed metal chelation property specifically for $\mathrm{Ba}(\mathrm{II})$ ions. ${ }^{231}$

The diffusion of dopant anions in and out of the PPY matrix may be restricted by the poor mass transfer properties of the PPY films. Thus, the improvement in mass transfer properties and thereby the ion-exchange capability of PPY films can be achieved by increasing the surface area by depositing on a porous matrix. Yuehelin et al. reported the fabrication of perchlorate electrically switched ion exchange (ESIX) for perchlorate removal utilizing PPy deposited on carbon nanotubes. ${ }^{232}$ The X-ray photoelectron spectroscopy (XPS) and cyclic voltammetry techniques demonstrate the selectivity of PPY/CNTs films for the perchlorate ion. The technique is considered a green one since the elution of perchlorate ions is controlled by the applied potential.

Interestingly, the brine disposal problem occurred by the use of regeneration agents in the classical ion-exchange technique, and the rate of chemical uptake is tackled in the ESIX method by adjusting the applied potential. Other advantages include (a) minimizing secondary waste production, (b) avoidance of the additional chemicals, (c) drastic $\mathrm{pH}$ change prevention, (d) ligand-independent, (e) cost-effective, and (f) green procedure.

5.1.3.5. Photocatalysts. Photocatalysis technology is a broad prospect to alleviate water pollution. ${ }^{176}$ The mechanism involves (i) the migration of $\mathrm{e}^{-}$from the valence band to the conduction band of the photocatalyst under illumination and forms e-hole $\left(\mathrm{h}^{+}\right)$pairs. (ii) Organic contaminants are directly oxidized to $\mathrm{CO}_{2}$ and $\mathrm{H}_{2} \mathrm{O}$ by $\mathrm{h}^{+}$or ${ }^{\bullet} \mathrm{OH}$ radicals created, which can indirectly oxidize the pollutants. ${ }^{176} \mathrm{In}$ an aerobic environment, $\mathrm{O}_{2}$ reacts with the $\mathrm{e}^{-}$and generates ${ }^{\bullet} \mathrm{O}^{2-}$ and other reactive species, which can also oxidize organic pollutants. However, narrow light absorption region and photogenerated electron-hole pair recombination limit the efficiency of the catalyst.

CPs have narrow bandgaps and undergo $\pi-\pi^{*}$ electron transition by absorbing ultraviolet and visible lights. ${ }^{10}$ Yuan et al. reported pristine PPy nanostructures as a promising photocatalyst for the degradation of MO and phenol. ${ }^{233}$ PPy, synthesized as hexagonal mesophases by the chemical polymerization technique, had the highest degradation ability toward phenol under UV light, while PPY-NS synthesized via radiolysis showed enhanced photocatalytic activity under visible light. Since pristine PIN and PPY undergo fast photoelectron-holes recombination and possess low specific surface areas, very few studies are reported for the photocatalytic activity of pristine PPY and PIN.
The incorporation of inorganic semiconducting materials with excellent photocatalytic activity such as $\mathrm{TiO}_{2}$ to a conducting polymer matrix (e.g., PPY or PIN) can reduce the fast recombination of photoexcited charge carriers and CPs act as a photosensitizer. ${ }^{234}$ This is also beneficial for reducing the harmful release of $\mathrm{TiO}_{2}$ nanoparticles into the environment. $^{235}$ For example, PPY is used as a sensitizer in the $\mathrm{PPY} / \mathrm{TiO}_{2}$ nanocomposite structure for selected dye degradation such as Rhodamine $\mathrm{B}$ and methyl orange under visible light irradiation. ${ }^{235}$ This $\mathrm{PPY} / \mathrm{TiO}_{2}$ nanocomposite can degrade methylene blue by $100 \%$ in $1 \mathrm{~h}$ and Rhodamine B by $97 \%$ in $8 \mathrm{~h}$ under visible light. In these composites, $\mathrm{TiO}_{2}$ is photocatalytically inactive under visible light, whereas PPY undergoes visible-light-induced $\pi-\pi^{*}$ electron transition. Since the LUMO of PPY ( $\pi^{*}$-orbital) has less reductive potential compared to that of the conduction band of $\mathrm{TiO}_{2}$, the excited electrons were transferred into the conduction bands of $\mathrm{TiO}_{2}$. Subsequently, these electrons were adsorbed onto the surface to react with water and oxygen, forming superoxide and hydroxyl radicals that degrade organic pollutants. The efficient electron-hole pair separation and fast charge transfer between PPY and $\mathrm{TiO}_{2}$ can be achieved by the effective harmonization of the valence band (VB) of $\mathrm{TiO}_{2}$ and the HOMO of pristine PPY. ${ }^{10}$ Here, PPy can act as an effective hole carrier and an outstanding electron trapper. ${ }^{235}$ The performances of PPY can be also greatly improved by incorporating other semiconducting metal compounds such as CdS, ${ }^{169}$ modified $\mathrm{Fe}_{2} \mathrm{O}_{3},{ }^{236} \mathrm{BiOI},{ }^{237} \mathrm{ZnIn}_{2} \mathrm{~S}_{4},{ }^{238}$ $\mathrm{BiOBr}-\mathrm{Ag},{ }^{239} \mathrm{~B}_{2} \mathrm{WO}_{6},{ }^{240}$ and $\mathrm{AgPMo}_{12}{ }^{241}$

Except for inorganic semiconductors material, graphitic carbon nitride $\left(\mathrm{gC}_{3} \mathrm{~N}_{4}\right)$ has also been made a composite with PPY to fabricate efficient photocatalysts that degrade Rhodamine $\mathrm{B}$ (RhB). ${ }^{242}$ The PPY-g- $\mathrm{C}_{3} \mathrm{~N}_{4}$ composite photocatalyst was fabricated by a sonochemical approach. Such a modification with g- $\mathrm{C}_{3} \mathrm{~N}_{4}$ reveals alternative pathways for organic pollutant degradation. The incorporation of PPY aids the separation and passage of photogenerated carriers. The CB offset of $0.94 \mathrm{eV}$ $(1.0 \mathrm{eV})$ results in the transfer of photogenerated electrons rapidly from $\mathrm{g}-\mathrm{C}_{3} \mathrm{~N}_{4}$ to PPY. whereas the VB offset of $1.1 \mathrm{eV}$ $(0.31 \mathrm{eV})$ causes the transfer of photogenerated holes from Ppy to $g-\mathrm{C}_{3} \mathrm{~N}_{4}$. To realize efficient charge separation and transfer, the potential difference between the VB of $g-\mathrm{C}_{3} \mathrm{~N}_{4}$ and the HOMO of PPY or CB of $g-\mathrm{C}_{3} \mathrm{~N}_{4}$ and LUMO of PPY is very important. By this charge transfer, the dissociation barrier of the Frenkel exciton can be tackled, thereby stabilizing the electrons and holes. The hole will be redistributed on one side of the heterojunction $\left(\mathrm{g}-\mathrm{C}_{3} \mathrm{~N}_{4}\right)$ and electrons on the opposite side (PPY), which demonstrates a steady internal electric field.

Recently, simultaneous $\mathrm{H}_{2}$ production and degradation of organic pollutants have been attained using various visiblelight-driven (VLD) photocatalyst systems based on CPs. ${ }^{37} \mathrm{~A}$ typical example is the generation of photocatalytic hydrogen and Bisphenol A (BPA) removal using photocatalysts based on sulfonated PIN (SPID) coated with magnetic zinc oxysulfide in $\mathrm{Na}_{2} \mathrm{~S} / \mathrm{Na}_{2} \mathrm{SO}_{3}$ solution. ${ }^{37}$ Here, $\mathrm{Na}_{2} \mathrm{~S} / \mathrm{Na}_{2} \mathrm{SO}_{3}$ was used as sacrificial reagents, which enhance both BPA degradation and photocatalytic $\mathrm{H}_{2}$ production by preventing electron-hole 
recombination. Impressively, the best approach for $\mathrm{H}_{2}$ production could be evidenced later in 180 min by employing a BPA solution of $60 \mathrm{mg} \mathrm{L}^{-1}$ concentration. The mechanism suggests that BPA molecules cannot work as a photosensitizer. However, intermediates and products formed on BPA degradation play the role of hydrogen production improvement. At the same time, the secondary intermediates of BPA degradation can delay $\mathrm{H}_{2}$ production.

In application, water pollutants, such as herbicides, can also be effectively removed using the photocatalyst based on CPs. Take the work by Sameer Ahmad et al. as an example. ${ }^{38}$ In this case, graphene-polyindole nanocomposites (Gr-PIn NC) were chosen as a cost-effective photocatalyst to degrade the herbicide 2,4-dichlorophenoxyacetic acid (2,4-D). This nanocomposite (NC) was synthesized by a simple sol-gel technique. The graphene sheet loaded with PIN showed significant improvement in the photocatalytic activity of about two times that of pristine PIN. It is suggested that the synergetic effect formed via the intimate contact of PIN and graphene sheets ease the transfer and separation of photoexcited charge carriers; thus, the photocatalytic degradation of 2,4-D is enhanced.

5.1.3.6. Reductive dechlorination. Halogenated organic compounds are prevalent organic pollutants detected in ground and surface water, wastewaters, as well as in soils. Incineration, adsorption, biological methods, chemical methods, and electrochemical method have been employed for the remediation processes of these persistent pollutant. ${ }^{22}$ However, these methods may result in the production of toxic intermediates as secondary pollutants during remediation. Since the presence of halogens makes halogenated organics more toxic, methods such as reductive chlorination are an alternative approach. ${ }^{243}$ The reductive dechlorination of 3,3,4,4-tetrachlorobiphenyl (PCB77) using palladium-based nanoparticles immobilized in polypyrrole matrices is an example. ${ }^{243}$ The exchange of perchlorate for tetrachloropalladate and further reduction to $\operatorname{Pd}(0)$ by PPY in the film occurred by incubating PPY film in $\mathrm{K}_{2} \mathrm{PdCl}_{4}$ solution. Further, the Pd nanoparticles in PPY films were used for dechlorination in the presence of hydrogen. The removal of chlorine from PCB77 through reductive dechlorination ultimately produces biphenyl; thereby, the proinflammatory activity of PCB77 is markedly reduced.

5.1.4. Green chemistry. CPs can be used as a catalyst to regulate the selectivity, activity, and stability of chemical reactions, and are thereby expected to eliminate wasteful secondary reactions, energy consumption, and minimize the use and production of toxic substances. Kalpana N. Handore et al. reported the use of PIN-ZnO nanocomposite as a heterogeneous green catalyst for the solvent-free synthesis of 3,4-dihydropyrimidinone compounds. PIN-ZnO composites are synthesized in a one-step procedure without using a high amount of organic solvents and templates. ${ }^{244}$ The insolubility of $\mathrm{PIN}-\mathrm{ZnO}$ nanocomposites is exploited for easy separation from the reaction mixture and further reused many times without damaging the catalytic property. Likewise, catalysts based on PPY can act as green, cheap, and recoverable solid acid catalysts in many organic synthesis $^{245,246}$ For example, sulfonated PPY nanospheres and $\mathrm{N}$-functionalized PPY acetic acid was used as recyclable and efficient catalysts for the single-step synthesis of highlyfunctionalized $4 H$-pyrano $(2,3-c)$ pyrazoles. ${ }^{245}$ However, the ordinary approaches for the synthesis of $4 H$-pyrano $(2,3-c)$ pyrazoles were faced with several drawbacks such as the presence of hazardous and/or costly catalysts and solvents, harsh reaction conditions, low yield, and prolonged reaction time.

A further environment friendly chemical reaction of PPY-derived catalyst involves transfer hydrogenation and dehydrogenation reactions with formic acid, a promising liquid hydrogen storage medium with $4.4 \mathrm{wt} \%$ hydrogen capacity. ${ }^{247}$ Here, atomic cobaltnitrogen (Co-N)-anchored mesoporous carbon (Co-N@NC) catalyst prepared via straightforward and scalable melamine-assisted pyrolysis of $\mathrm{Co}^{2+}$-chelated hyper-cross-linked polypyrrole (HPPY) mixture. The Co-N@NC catalyst demonstrated the formylation of quinolones through transfer hydrogenation and formic acid dehydrogenation, revealing an enhanced $\mathrm{H}_{2}$ production rate along with selectivity and stability for transfer hydrogenation.

The "produced water" formed as a byproduct during oil production is becoming an environmental problem by threatening public health. ${ }^{248}$ This produced water contains several poisonous materials such as polycyclic aromatic hydrocarbons, organic acids, volatile hydrocarbons, bacteria, naturally occurring radioactive material (NORM), and heavy metals. Polyindole nanoparticlebased electrorheological fluid (ER) proved the feasibility for reducing water production via conformance control technique, which makes the oil production operation more green, economical, and clean. ${ }^{248}$ PIN nanoparticles were preferred due to the need for some unusual features regarding the size, synthesis method, and morphology to be applicable in an oil reservoir. The ER fluid-based conformance control technique involves the formation of a solidlike structure from ER fluid by the application of an electrical field, which obstructs the pore throat in porous media and reduces water production. Meanwhile, cleaner oil can be manufactured at low cost and in an environment friendly manner.

Enzymatic biofuel cell (EBFC) is a recent greener technology that utilizes redox enzymes in the form of electrocatalysts. ${ }^{109}$ Presently, a novel electrocatalyst based on ZnO nanoparticlesmodified polyindole (PIn) multi-walled carbon nanotube (MWcnt) immobilized with glucose oxidase (Gox) enzyme and ferritin as mediator reported enhanced electrocatalytic activity in glucose oxidation. The outcomes of the study showed that the as-synthesized $\mathrm{ZnO} / \mathrm{PIn}$-MWCNTs/Frt/GOx biocomposite is a favorable bioanode for assembling electrochemical biofuel cells. In addition, PPY and PIN-based catalysts may also be applied in oxygen reduction reactions (ORR) occurring in fuel cells ${ }^{249-254}$ Fuel cells are considered a sustainable and renewable energy source with an environment friendly nature compared to fossil fuels. Studies show that PIN and PPYderived catalysts can act as a substitute for the standard $\mathrm{Pt} / \mathrm{C}$ in ORR in terms of cost and efficiency. ${ }^{255-257}$

\subsection{Application of PPY and PIN as chemical sensors}

The utilization of PPY and PIN as the sensor is a desirable choice to material scientists due to its high sensitivity, short 
response time, biocompatibility, economical synthesis procedure, fast charge transfer with the target analytes at room temperature, and the chance for the modification of physical and chemical properties for sensing purpose. ${ }^{31,258}$ When exposed to an analyte, the interactions may influence the color, mass, work function, solvation effects, electrical conductivity, conformations of backbone, and the attraction of dopant counter ions or electrons in CP films. ${ }^{29,31}$ Electrical signals are produced as a result of the changes in electron mobility and the concentration of analyte in solution or gas can be quantified. ${ }^{31}$ This is the basic principle that permits CPs to function as chemical sensors. ${ }^{5,31}$ Among different types of chemical sensors, electrochemical sensors have attracted great attention, mainly because of the ease and low cost of manufacturing, accuracy, and ease in the analysis of results. ${ }^{259}$ The critical parameters for evaluating a sensor include its sensitivity, selectivity, response rate, and stability. ${ }^{10}$ The sensitivity of a CP-based sensor depends on its specific surface area, catalytic activity, device configuration, and conductivity. ${ }^{10}$ Various strategies are reported in the literature to customize CPs for analytical purposes.

The suitable selection of experimental conditions such as the solvent, $\mathrm{pH}$, supporting electrolyte, the dopant, and the amount of charge passed, permits the adjustment in porosity, thickness, viscoelastic properties, binding properties, and morphology for the final CP films. ${ }^{260}$ For instance, surface morphology performs a noteworthy role in the gas sensing activity of PPY nanostructures. ${ }^{261,262}$ When the size of the materials is reduced to the nanoscale level, many new or enhanced properties emerge. However, pristine PPY or PIN films have feeble activities toward many analyte molecules due to their poor selectivity and weak sensitivity. ${ }^{115}$ In such sensors, the linear range of response will be restricted and the recorded values of potential interfere with both ionic and redox species present in the system. ${ }^{88}$ Nanoscale hybridization with graphene, carbon nanotubes, metal, biological materials, and metal oxide nanoparticles can address the above issues by improving the molecular interaction, transport performance, and electrocatalytic reactivity. Nanomaterialmodified PIN and PPY sensors demonstrate a remarkable gain in terms of the selectivity, sensitivity, and versatility since nanomaterials empower novel optical, electrical, surface increment, catalytic properties, and functional ability. These sensors are employed for the measurement and amplification of signals in several fields, including the environmental monitoring of trace metals, medical diagnosis, and food analysis.

The most common methods to incorporate recognition elements within the conducting polymer matrix include covalent attachment, doping, affinity interactions, and physical adsorption. ${ }^{263}$ Doping is the most used approach in electroanalysis due to reproducibility in the sensing of several targets. Unlike chemical sensors, a biosensor involves the immobilization of biological recognition agents such as enzymes, oligonucleotides, aptamer, or antibodies/antigen into conducting polymers that recognize the presence of an analyte. ${ }^{264}$ The biorecognition technique can be categorized into five major classes based on the transduction mechanism: (i) optical-detection biosensors, (ii) resonant biosensors, (iii) thermal detection biosensors, (iv) electrochemical biosensors, and (v) ion-sensitive field-effect transistor-based biosensors. ${ }^{265}$ Various electrochemical biosensors based on PIN and PPY films have been developed for sensing analytes such as cholesterol, glucose, dopamine, hydrogen peroxide, hydrazine, cysteine, and kanamycin. ${ }^{265}$ The biocompatibility and biodegradability of PPY and PIN can be improved via nanomaterial modification; thus, they can be utilized in tissue engineering, bioelectrodes, and drug delivery in addition to biorecognition. ${ }^{88}$

Applications of PPY- and PIN-based materials for the sensing and detection of various chemical species utilizing electrical sensing at electrode interfaces include potentiometric, amperometric, impedimetric, chemoresistance, electrochemical luminescent, field-effect transistors, and photoelectrochemical sensors, which give quick response to change in the current, voltage, and resistance. ${ }^{24}$ In addition, fluorescence sensors have also attracted considerable attention in sensing applications. ${ }^{266}$ Stimuli-responsive, self-healing, and conductive hydrogels of PPY and PIN have also been developed in the recent years for their metal-like electrical conductivity and hydrogel-like flexible mechanical properties. ${ }^{267-269}$ Zexing Deng et al. designed multifunctional conductive hydrogels with self-healing ability and desirable mechanical property using $\beta$-cyclodextrin ( $\beta$-CD), $N$-isopropylacrylamide (NIPAM), CNT, and PPY, and exploited their potential applications in pressure-dependent sensors, bicipital muscle of arm motion sensing, large-scale human index finger motion sensing, and self-healable electrical devices. ${ }^{270}$ Many recent publications reviewed the ability of PPY-modified materials as sensors. ${ }^{29-31,258}$ Accordingly, this review is not concentrated on the in-depth discussions of sensing aspects of PPY-based materials but on the recent developments in PIN modified materials for sensing and detecting various chemical analytes in the liquid and gas phases (Table 4). The article from Zhou et al. tried to overview the advancement in PIN research concerning its polymerization mechanisms, synthesis, properties, and applications. The article did not emphasize most of the remarkable recent works and failed in-depth analysis with regards to expressing the innovation of PIN-based sensor applications.

\subsubsection{PIN-based chemical sensors for analytes in solution}

5.2.1.1. Glucose. The interest behind accurate glucose sensing not only counts on diabetes diagnosis but also on satisfying the necessities in environmental protection, and food industry. The literature reports various glucose biosensing platforms based on amperometric methods, polarimetric techniques, surfaceenhanced Raman scattering, and surface plasmon resonance techniques (SPR). ${ }^{271}$ Among these technologies, SPR-based sensors, especially ATR-SPR sensors, are found to have more sensitive measurements and are the foremost technology in the field of the real-time analysis for interactions in biomolecules. Lalit Kumar et al. reported polyindole-modified metal (Au) as a glucose sensor employing surface plasmon resonance (SPR) technique. ${ }^{271}$ The spin coating technique was utilized to deposit glucose oxidase (GOD) immobilized polyindole film on a gold surface. The interaction of glucose analyte with GOD results in changes in the refractive index of the sensor surface and results in signal 
Table 4 PIN nanocomposite-based sensors

\begin{tabular}{|c|c|c|c|c|c|}
\hline Sensor composition & Target gas & Detection limit & Concentration & Selectivity & Ref. \\
\hline $\mathrm{PIn} / \mathrm{Au}$ & Glucose & - & $0.075-0.5 \mu \mathrm{M}$ & - & 271 \\
\hline $\mathrm{PIn} / \mathrm{Au}$ & Glucose & - & $0.1-0.5 \mu \mathrm{M}$ & - & 272 \\
\hline GOD/PIN & Glucose & - & - & - & 273 \\
\hline Over oxidized polyindole & Dopamine & - & - & - & 274 \\
\hline Graphene/oxidized polyindole & Dopamine & & $10 \mu \mathrm{M}^{-1} \mathrm{mM}$ & $\begin{array}{l}\text { More selective to dopamine than ascor- } \\
\text { bic acid }\end{array}$ & 275 \\
\hline PIn/GQDs@MIPs & Dopamine & $1 \times 10^{-10} \mathrm{M}$ & $\begin{array}{l}5 \times 10^{-10}-1.2 \times \\
10^{-6} \mathrm{M}\end{array}$ & $\begin{array}{l}\text { More selective to dopamine than ascor- } \\
\text { bic acid }\end{array}$ & 276 \\
\hline $\mathrm{Ag}-\mathrm{PIn}$ & Dopamine & & $40 \mathrm{nM}-12 \mu \mathrm{M}$ & $\begin{array}{l}\text { More selective to dopamine than ascor- } \\
\text { bic acid }\end{array}$ & 277 \\
\hline Poly(indole-6-carboxylic acid) & Dopamine & $4 \mu \mathrm{M}$ & $18 \mu \mathrm{A} \pm 6 \mathrm{nA} \mathrm{mM}^{-1}$ & & 278 \\
\hline Poly(indole-3-acetic acid) & Dopamine & $6.0 \times 10^{-8} \mathrm{~mol} \mathrm{~L}^{-1}$ & - & $\begin{array}{l}\text { More selective to dopamine than ascor- } \\
\text { bic acid }\end{array}$ & 281 \\
\hline $\begin{array}{l}\text { Poly(5-carboxyindole)/horseradish } \\
\text { peroxidase (HRP) }\end{array}$ & Dopamine & - & - & - & 282 \\
\hline Poly(indole-5-carboxylic acid)/Au & Triglycerides & $20 \mathrm{mg} \mathrm{dl}^{-1}$ & $50-700 \mathrm{mg} \mathrm{dL} \mathrm{L}^{-1}$ & - & 283 \\
\hline PIN/WC/SSPE & Cholesterol & $1.23 \times 10^{-6} \mathrm{~mol} \mathrm{~L}^{-1}$ & & - & 284 \\
\hline $\begin{array}{l}\text { Poly(indole-5-carboxylic acid)/zinc } \\
\text { sulfide }\end{array}$ & D-amino acid & $0.001 \mathrm{mM}$ & $0.001-2.0 \mathrm{mM}$ & - & 285 \\
\hline $\begin{array}{l}\text { MWNT-doped poly(indole-6- } \\
\text { carboxylic acid) }\end{array}$ & DNA & $2.0 \mathrm{fmol} \mathrm{L}^{-1}$ & - & - & 286 \\
\hline $\begin{array}{l}\text { Poly(indole-6-carboxylic acid)/ } \\
\text { ODN }\end{array}$ & DNA & $5.79 \mathrm{pmol} \mathrm{L}^{-1}$ & $\begin{array}{l}3.5 \times 10^{-10}-2.0 \times \\
10^{-8} \mathrm{~mol} \mathrm{~L}^{-1}\end{array}$ & - & 287 \\
\hline Poly(5-formylindole)/ODN & Ramos cells & 300 cells $\mathrm{mL}^{-1}$ & $\begin{array}{l}500 \text { to } 1.0 \times \\
10^{5} \text { cells } \mathrm{mL}^{-1}\end{array}$ & - & 59 \\
\hline P5FIn/SWNTs/Au & $\begin{array}{l}\text { alpha-fetoprotein }(\alpha- \\
\text { FP) }\end{array}$ & $200 \mathrm{fg} \mathrm{mL}^{-1}$ & & - & 288 \\
\hline AuNP/GQDs--PEI-GO & $\begin{array}{l}\text { Prostate-specific } \\
\text { antigen (PSA) }\end{array}$ & $0.44 \mathrm{pg} \mathrm{mL} \mathrm{m}^{-1}$ & 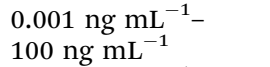 & - & 289 \\
\hline PIn-5-COOH/MWCNTs-COOH & $\begin{array}{l}\text { alpha fetoprotein }(\alpha- \\
\text { FP) }\end{array}$ & $0.33 \mathrm{pg} \mathrm{mL}-1$ & $\begin{array}{l}0.001 \mathrm{ng} \mathrm{mL}^{-1}- \\
100 \mathrm{ng} \mathrm{mL}^{-1}\end{array}$ & - & 290 \\
\hline $\begin{array}{l}\mathrm{AO} / \mathrm{AuNPs}-\mathrm{PtNPs} \text { onto PIN5- } \\
\mathrm{COOH} / \mathrm{Au}\end{array}$ & $\begin{array}{l}\text { Glycated hemoglobin } \\
\text { (HbA1c) }\end{array}$ & $0.2 \mu \mathrm{M}$ & $0.1-1000 \mu \mathrm{M}$ & 然 & 291 \\
\hline $\mathrm{Au}-\mathrm{PIn}-\mathrm{RGO}$ & Caffeine & $0.26 \mu \mathrm{M}$ & $\begin{array}{l}0.8-40 \text { to } 40- \\
1000 \mu \mathrm{M}\end{array}$ & $\begin{array}{l}\text { More selective to caffeine than } \mathrm{K}^{+}, \mathrm{Na}^{+} \text {, } \\
\mathrm{Cu}^{2+}, \mathrm{NO}_{3}{ }^{-}, \mathrm{PO}_{4}{ }^{3-} \text {, glucose, sucrose, } \\
\text { cholic acid and citric acid }\end{array}$ & 292 \\
\hline $\begin{array}{l}\text { PICA/F-Au/graphene quantum } \\
\text { dots/gold nanorods (AuNRs) }\end{array}$ & Aflatoxin (AFB1) & $0.00375 \mathrm{ng} \mathrm{mL}^{-1}$ & $0.01-100 \mathrm{ng} \mathrm{mL}^{-1}$ & $\begin{array}{l}\text { More sensitive to AFB1 than Aflatoxin B2 } \\
\text { (AFB2), Ochratoxin A (OTA), Aflatoxin M1 } \\
\text { (AFM1) }\end{array}$ & 293 \\
\hline $\mathrm{Fe}_{3} \mathrm{O}_{4} \mathrm{NPs} / \mathrm{Pin} 5 \mathrm{COOH}$ & $\begin{array}{l}\text { Malathion and } \\
\text { chlorpyrifos }\end{array}$ & - & $\begin{array}{l}0.1-60 \text { and } 1.5- \\
70 \mathrm{nM}\end{array}$ & - & 46 \\
\hline Siloxane/polyindole/gold & $\begin{array}{l}\text { Chloride ion and } \\
\text { potassium ion }\end{array}$ & - & - & 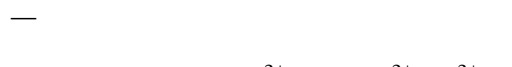 & 295 \\
\hline Undoped-polyindole & $\mathrm{Cu}^{2+}$ & $8 \times 10^{-6} \mathrm{M}$ & $10^{-4}-10^{-3} \mathrm{M}$ & $\begin{array}{l}\text { More sensitive to } \mathrm{Cu}^{2+} \text { than } \mathrm{Pb}^{2+}, \mathrm{Ni}^{2+} \text {, } \\
\mathrm{Co}^{2+}, \mathrm{Fe}^{2+} \text {, and } \mathrm{Zn}^{2+}\end{array}$ & 296 \\
\hline PIn-CSA & Calcium ion & $5 \mu \mathrm{M}$ & $2 \times 10^{5}$ to $1 \times 10^{2} \mathrm{M}$ & & 287 \\
\hline PIN/CdS & Picric acid & - & - & $\begin{array}{l}\text { More sensitive to picric acid in the } \\
\text { presence of } \mathrm{Li}^{+}, \mathrm{Ca}^{2+}, \mathrm{Cd}^{2+}, \mathrm{Pb}^{2+}, \mathrm{Cr}^{2+} \\
\mathrm{Hg}^{2+}, \mathrm{Co}^{2+}, \mathrm{Ni}^{2+}, \mathrm{Cu}^{2+} \text {, and } \mathrm{Zn}^{2+}\end{array}$ & 298 \\
\hline $\begin{array}{l}\text { Polyindole (PIn)-substrate inte- } \\
\text { grated waveguide (SIW) }\end{array}$ & Methanol gas & - & - & - & 35 \\
\hline Poly(indole-cothiophene) $/ \mathrm{Fe}_{3} \mathrm{O}_{4}$ & $\mathrm{H}_{2} \mathrm{O}_{2}$ & $0.54 \mu \mathrm{M}$ & Upto $350 \mu \mathrm{M}$ & - & 302 \\
\hline Pind composite nanofibers & Humidity & - & - & - & 303 \\
\hline $\begin{array}{l}\text { Nickel oxide@polyindole/ } \\
\text { phenothiazine }\end{array}$ & Ammonia & - & - & - & 299 \\
\hline $\mathrm{PIN} / \mathrm{ZnFe}_{2} \mathrm{O}_{4}$ & Ammonia & - & - & - & 60 \\
\hline $\mathrm{PIN} / \mathrm{Cu}-\mathrm{Al}_{2} \mathrm{O}_{3}$ & Ammonia & - & - & - & 300 \\
\hline
\end{tabular}

enhancement in the association phase. The sensor exhibited excellent stability, fast response, high reproducibility, high sensitivity, and specific detection of very low concentrations of glucose. The electrode showed glucose response in the linear dynamic range of 0.075$0.5 \mu \mathrm{M}$. A larger specific surface area can increase the number of sites for the adsorption of GOD in the GOD/polyindole/Au electrode and thereby result in enhanced sensitivity. Recently, Vishal Gupta and Lalit Kumar investigated the kinetic study of a surface plasmon resonance-based glucose sensor using polyindole. ${ }^{272}$
Most of the studies reported on glucose-sensing utilize glucose oxidase (GOD) enzyme as an electrocatalytic element that was immobilized within the CP matrix. Such an immobilization can be done by physical adsorption, covalent bonding, and electrochemical codeposition. ${ }^{263}$ For example, GOD was directly immobilized into the PIN films during electrochemical polymerization in one step and functioned as an amperometric glucose sensor. ${ }^{273}$ The one-step electrodeposition procedure could be employed for the development of a sensor in the $\mathrm{CH}_{3} \mathrm{CN}$ solution comprising 
indole and Aspergillus niger. The sensor showed a rapid response time (25-40 s) with excellent storage and operational stability (>35 days).

5.2.1.2. Dopamine. Recently, a considerable variety of electrode materials have been developed using polyindole and its derivatives to monitor dopamine (DA). Inherent polyindole was reported to be insensitive to dopamine through the electrochemical method. Meanwhile, over-oxidized polyindole modified (OPIn) glassy carbon electrodes (GCE) have exhibited excellent sensitivity toward DA in the presence of ascorbate. ${ }^{274} \mathrm{~A}$ major challenge in DA sensing is the oxidation of ascorbic acid (AA) at nearly the same potential and coexistence of dopamine with ascorbic acid in high relative concentrations. Thus, the capability of the electrode to selectively sense DA in the presence of excess AA is very crucial. The cation permselectivity character of the OPIn film allows the intake of the cationic DA into the film while discarding the anionic AA. Thus, OPIn-modified electrodes could show excellent selectivity toward DA oxidation. However, the modified electrodes displayed fouling either due to the production of melanin-like compounds at the electrode surface, the cation binding capacity saturation of the film, or variation in the binding ability of the OPIn films on persistent buffer solution immersion.

Moreover, a composite based on graphene (Gr) and oxidized polyindole has been used for the electrochemical detection of dopamine. ${ }^{275}$ In situ oxidation polymerization was employed for the coating of oxidized PIN over graphene surfaces. The synthesis route provided a homogeneous graphene-polymer composite that exhibited enhanced sensing properties with better processibility. The assessment of the permselective behavior and the electrocatalytic performance was done using differential pulse voltammetry (DPV) and impedance spectroscopy (EIS). This sensor showed a detection limit of $0.05 \mathrm{mM}$ and $0.5 \mathrm{mM}$ in the lower and higher range region, respectively. Zhou et al. utilized the fluorescence property of polyindole/ graphene quantum dots molecularly imprinted polymers (PIn/ GQDs@MIPs) in the fabrication of the fluorescence sensor ${ }^{276}$ (Fig. 7). This sensor based on PIn/GQDs@MIPs displayed an outstanding sensitivity with a linear range of $5 \times 10^{-10}$ to $1.2 \times$ $10^{-6} \mathrm{M}$ toward DA with an extremely low limit of detection $\left(1 \times 10^{-10} \mathrm{M}\right)$. In this case, hydrogen bonds are formed between amino groups of DA and oxygen-containing groups of the composite in the imprinted cavities provided by the sensor. The author demonstrated a distinctive affinity modifiable dualtype binding mechanism, where non-covalent interaction is off and on at low affinity and high-affinity types, respectively. Further, the rebinding interface can be adjusted by varying the $\mathrm{pH}$, while keeping the specificity. Likewise, V. Divya et al. also constructed a nanomolar fluorescence sensor for dopamine based on silver-polyindole nanocomposite, ${ }^{277}$ and the linear range for the sensor was found to be in the range from $40 \mathrm{nM}$ to $12 \mathrm{mM}$.

Polyindoles substituted by carboxylic acids, such as poly (5-carboxyindole) and poly(6-carboxyindole) coated on glassy carbon electrodes demonstrated significant reactivity and excellent sensitivity in the oxidation of DA and AA. The hybridization of certain redox mediators, namely, tetracyanoquinodimethane (TCNQ), ferrocene (Fc), and dimethyl ferrocene $(\mathrm{dmFc})^{278-280}$ with

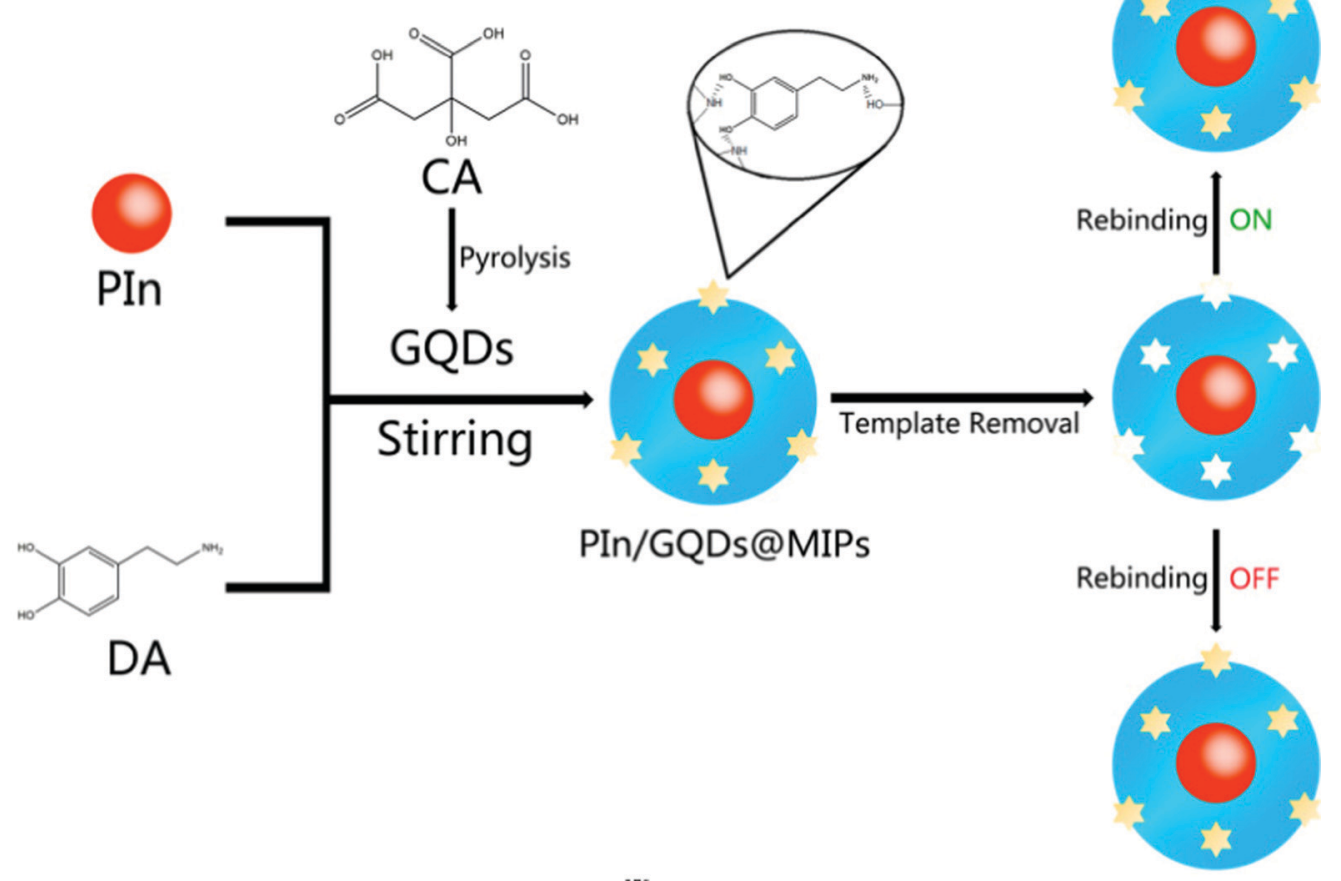

Fig. 7 Schematic of PIn/GQDs@MIPs synthesis. Reproduced with permission. ${ }^{276}$ Copyright 2015, American Chemical Society. 
the polymer matrix could enhance the electron transfer between the polymer and the target analyte. Nafion ${ }^{\mathbb{R}}$ was used to solubilize these redox mediators as well as to provide permselectivity to the blend. Such electrodes displayed sensitivity of $18 \mu \mathrm{A} \pm 6$ $\mathrm{nA} \mathrm{mM}{ }^{-1}, 14 \mu \mathrm{A} \pm 11 \mathrm{nA} \mathrm{mM}^{-1}$, and $16 \mu \mathrm{A} \pm 9 \mathrm{nA} \mathrm{mM}^{-1}$ for TCNQ, Fc, and dmFc, respectively. Similarly, poly(indole-3-acetic acid)-modified GCD electrode offers ample enhancements in voltammetric sensitivity and selectivity toward dopamine (DA). ${ }^{281}$ This coating significantly weakens the voltammetric response of AA, while the DA oxidation peak current is greatly improved. Even at a higher concentration of AA (3 order), any interference was not detected and the detection limit for dopamine is ca. $6.0 \times 10^{-8} \mathrm{~mol} \mathrm{~L}^{-1}$. Such higher sensitivity and selectivity for DA are attributed to the charge refinement and the accumulation of analyte.

The enzymes entrapped CP matrices can be also employed for the selective detection of dopamine. For example, a conducting poly(5-carboxyindole)-based covalently-entrapped rice peroxidase biosensor showed an impressive relative activity with dopamine as the substrate than immobilized horseradish peroxidase (HRP). ${ }^{282}$ Rice peroxidase is a cheaper and more convenient enzyme system for immobilizing in a conducting matrix. The experimental results showed that the conducting poly(5-carboxyindole) can function as a suitable matrix for the covalent immobilization of the enzyme through an amide linkage (as shown in Fig. 8). Certain linkage reagents such as EDC and NHS are employed to covalently link the free carboxyl groups present at the surface of the conducting poly(5-carboxyindole) through an amide bond. This economical and facile method of immobilization is an added benefit in the fabrication of RP-based sensors over conventional sensor electrodes. Fabricated electrodes exhibited ultrasensitivity and fast response to dopamine and enables RP as a suitable enzyme system for dopamine detection in an aqueous solution.

5.2.1.3. Triglycerides and cholesterol. Triglycerides (TG) are key constituents of very-low-density lipoprotein (VLDL) and chylomicrons, which perform a vital role in energy source metabolism and dietary fat transport. The determination of TG is important to bioscience and clinical diagnosis since a high level of TG in the bloodstream can cause atherosclerosis, heart disease, and stroke.
An amperometric biosensor for TG was developed by electrodepositing gold polypyrrole nanocomposite-decorated poly(indole-5carboxylic acid) on the surface of the gold electrode. The electrode was further modified by covalently co-immobilizing the biomolecules such as lipase, glycerol kinase, and glycerol-3phosphate oxide on the surface. ${ }^{283}$ For TG concentrations in the range of $50-700 \mathrm{mg} \mathrm{dL}{ }^{-1}$, a linear response was observed. The detection limit of the biosensor was $20 \mathrm{mg} \mathrm{dL}{ }^{-1}$. The $\mathrm{H}_{2} \mathrm{O}_{2}$ produced enzymatically could generate electrons through electrochemical reactions and potential differences created through the flow of electrons can effectively sense the presence of TG. It was found that the electrode was unaffected by several serum substances and could be active for the direct quantification of TG in biological materials other than serum.

Low cholesterol levels in the blood can cause anemia and hepatopathy while high cholesterol levels in humans can lead to fatal diseases. Polyindole/tungsten carbide nanocompositebased ingenious non-enzymatic cholesterol electrochemical sensor was reported by Shubham Sharma et al. ${ }^{284}$ The quality of the sensor was evaluated by exposing it to human blood serum, which exhibited an excellent recovery of 95.5-97.4\%. The sensor showed excellent sensitivity and high selectivity to cholesterol with a low detection limit of $1.23 \times 10^{-6} \mathrm{~mol} \mathrm{~L}^{-1}$.

5.2.1.4. D-Amino acid. The variation of the D-amino acid level in the brain is connected with several neurological and psychiatric diseases; thus. its determination in biological materials is very important. Suman Lata et al. constructed a d-amino acid biosensor-based poly(indole-5-carboxylic acid)/zinc sulfide hybrid film immobilized with d-amino acid oxidase. ${ }^{286}$ The enzyme was immobilized onto the electrode surface through EDC/NHS activation chemistry. The biosensor exhibited excellent sensitivity of $58.85 \mu \mathrm{A} \mathrm{cm} \mathrm{cm}^{-2} \mathrm{mM}^{-1}$ with a detection limit of 0.001 $\mathrm{mM}(\mathrm{S} / \mathrm{N}=3)$. In this case, the biosensor response $(\mathrm{mA})$ and $\mathrm{d}-$ alanine were linearly related within the range of $0.001-2.0 \mathrm{mM}$. The protective layer of polyindole-5-carboxylic acid film can solve the leakage issue of the enzyme and other external environmental disturbances. The author also assessed the sensor to quantity the d-amino acid level in fruits and vegetables.

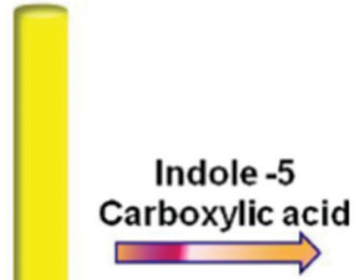

Electrodeposition
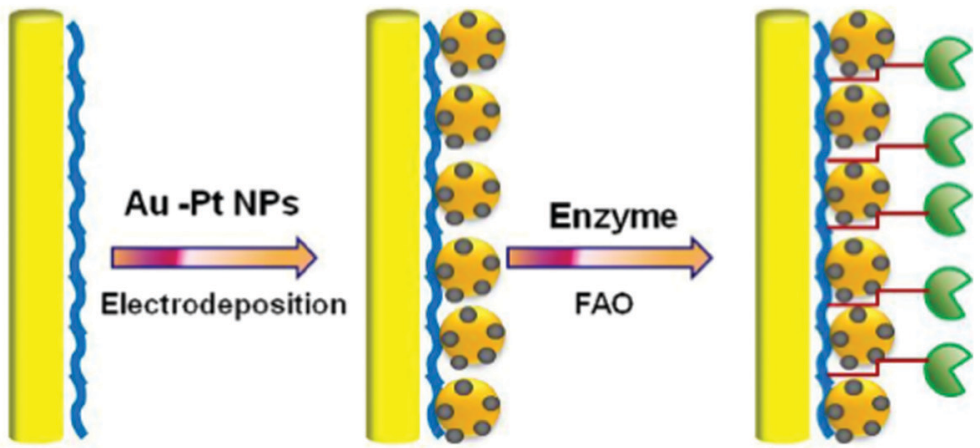

\section{Au electrode}

Fig. 8 Schematic of the working electrode for DA sensing. Reproduced with permission. ${ }^{285}$ Copyright 2017, Elsevier. 
5.2.1.5. DNA. As DNA plays an important role in genetic information storage, its determination is crucial to bioscience and clinical diagnosis. Guangming Nie et al. developed a simple labelfree femtomolar sensor for the recognition of target DNA related to hepatitis B virus (HBV) based on MWNT-doped poly(indole-6carboxylic acid) (PICA) composite. ${ }^{287}$ With a larger surface area and quite a few functionalized carboxylic acid groups, PICAMWNT exhibited a detection limit is $2.0 \mathrm{fmol} \mathrm{L}^{-1}$ enhances and improved sensitivity. In addition, another simple label-free electrochemical DNA sensor based on poly(6-carboxyindole) was fabricated by Zhang groups. ${ }^{288}$ A one-step synthetic route was employed to covalently graft the 18-mer amino-substituted oligonucleotide (ODN) probe onto the polymer. Such sensors can distinguish one-base mismatched and non-complementary ODN sequences. It is also evidenced that the sensor can be redeveloped after a dehybridization step. The sensor exhibited a detection limit of $5.79 \mathrm{pmol} \mathrm{L}^{-1}$ and a dynamic detection range for complementary target ODN from $3.5 \times 10^{-10} \mathrm{~mol} \mathrm{~L}^{-1}$ to $2.0 \times$ $10^{-8} \mathrm{~mol} \mathrm{~L}^{-1}$.

5.2.1.6. Ramos cells. The research on the accurate sensing of cancer cells is of great importance to the primary diagnosis and prompt exactitude therapy. A novel signal-on ECL biosensor for Ramos cell is based on the gold nanoparticles (AuNPs)-enhanced poly(5-formylindole) (P5FIn) film tagged with $\mathrm{Ru}(\mathrm{bpy})_{2}$ used as a target recognition element as well as a tool of amplification. ${ }^{59}$ Here, an aldimine condensation pathway is utilized to covalently immobilize an 18-mer amino-substituted oligonucleotide (ODN) probe to the surface of the solid substrates (Fig. 9). The aptamers and probe DNA S1 are hybridized for the recognition, followed by the binding of the labeled probes. resulting in the detection of ECL signals. The unique recognition and distinctive binding capacity between aptamers and target cells, and P5Fin induced
ECL quenching made the Burkitt's lymphoma (Ramos) detection highly sensitive and selective. The linear range of this biosensor was from 500 to $1.0 \times 10^{5}$ cells $\mathrm{mL}^{-1}$ and showed a detection limit of 300 cells $\mathrm{mL}^{-1}$. The reason for the high sensitivity and selectivity can be further explained by (1) the large surface area and improved hydrophilicity offered by P5FIn films so that a large number of biomolecules can be entrapped onto the surface of the electrode; (2) the enhanced conductivity of the P5FIn films during the ECL measurement on applying a potential of $+1.30 \mathrm{~V}$ versus $\mathrm{Ag} / \mathrm{AgCl}$.

5.2.1.7. Bio-markers. Tumor markers are biochemical substances produced by human tumor tissues, which reveal the presence and progress of tumors in the human body. As a tumor marker, $\alpha$-fetoprotein sensing has critical clinical significance. Two simple label-free electrochemical immunosensor for the tumor marker $\alpha$-fetoprotein based on poly(5-formylindole)/ single-walled carbon nanotubes (P5FIn/SWNTs) composite or polyindole-6-carboxylic acid (ICA)/multiwall carbon nanotubes (PICA/MWNT) composite with 2-aminoethanethiol-modified CdSe QDs were fabricated by the Guangming Nie and Lin Zhang groups. ${ }^{289}$ Such label-free electrochemical biosensors are simple, low-cost, specific, reproducible, and sensitive analytical methods for the detection of tumor markers. The role of MWNTs/SWNTs is to reduce the injection barrier of the electrons to QDs while the PICA-MWNT or poly(5-formylindole)/SWNTs composite film provides a high surface area and better conductivity to enhance the ECL performance. Similarly, Taotao Yang et al. reported another highly sensitive label-free electrochemical immunosensor based on poly(indole-5-carboxylic acid)/MWCNTs-COOH with ultra-high redox stability. ${ }^{290}$ Such a nanocomposite could exhibit $96.03 \%$ redox stability after 500 cyclic voltammetry (CV) cycles in buffer solution with a $\mathrm{pH}$ of 6.2 and is attributed to the

(a)
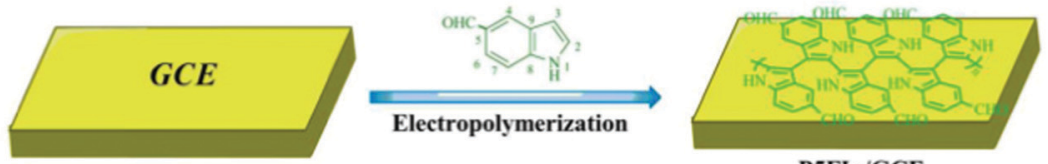

P5FIn/GCE

(b)

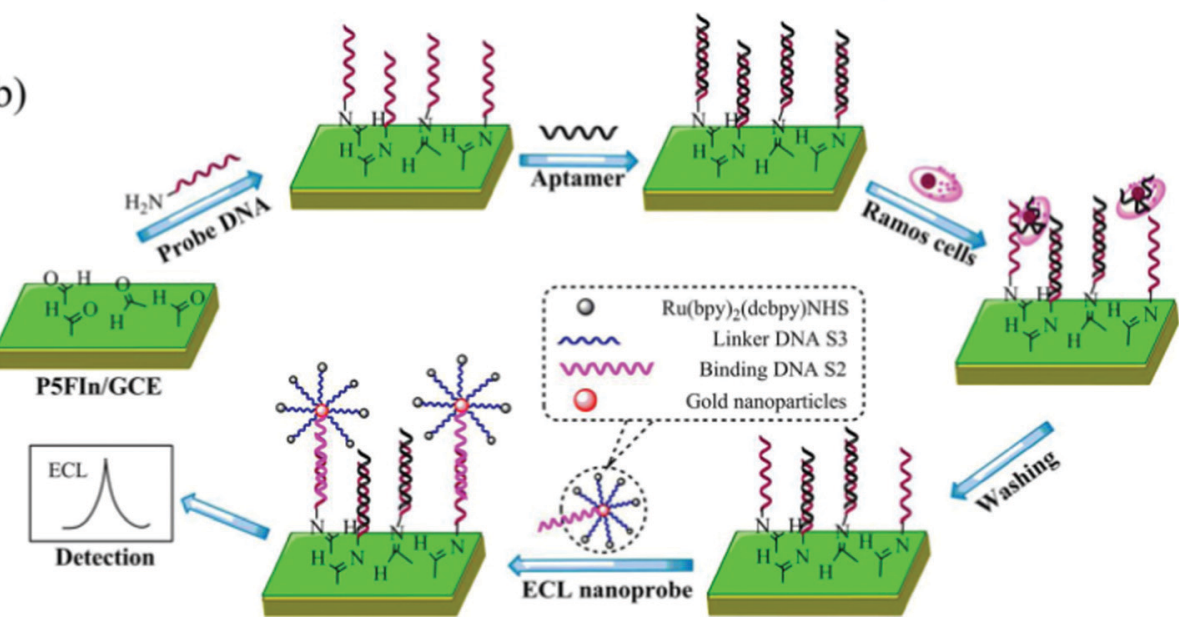

Fig. 9 Electropolymerization of P5FIn films on GCE (a) and the developed ECL biosensor based on P5FIn films (b). Reproduced with permission. ${ }^{59}$ Copyright 2013, American Chemical Society. 
stable structure of poly(indole-5-carboxylic acid). This hybrid film exhibited a broad linear range from $0.001 \mathrm{ng} \mathrm{mL}^{-1}$ to $100 \mathrm{ng} \mathrm{mL} \mathrm{m}^{-1}$ and a small detection limit of $0.33 \mathrm{pg} \mathrm{mL}{ }^{-1}$ for alpha-fetoprotein detection. Prostate-specific antigen (PSA) is yet another tumor marker mainly for detecting prostate cancer synthesized by the human prostate gland. An ultrasensitive, easy to make, reproducible sandwich "signal-on" electrochemiluminescence immunosensor made of poly(indole-6-carboxylic acid)/ flowerlike $\mathrm{Au}$ nanoparticles (PICA/FGNs) as the electrode modified material and $\mathrm{Au}$ nanoparticle/graphene quantum dots-poly(ether imide)-graphene oxide (AuNP/GQDs-PEI-GO) composite as the probe. ${ }^{291}$ The unique structure of PICA/FGNs can facilitate fast electron transport during redox processes and improve the loading of Ab1 to further enhance the ECL signal. Similarly, Haiyan Jia reported poly(indole-5-carboxylic acid) @ poly(3,4-ethylene dioxythiophene) (PIn-5-COOH@PEDOT) composite with a core structure as a label-free immunosensing platform for PSA with $3.4 \mathrm{pg} \mathrm{mL}^{-1}(\mathrm{~S} / \mathrm{N}=3)$ detection limit and a wide linear range of $0.01-25 \mathrm{ng} \mathrm{mL}^{-1}$.

Glycated hemoglobin (HbA1c) is a biomarker for monitoring the glycine level in the blood. A composite made from $\mathrm{Au}-\mathrm{Pt}$ bimetallic nanoparticles and poly(indole-5-carboxylic acid)modified Au electrode can act as a novel amperometric glycated hemoglobin biosensor. ${ }^{285}$ The sensor presents excellent storage stability and $50 \%$ of its initial activity was maintained for 12 weeks at $4{ }^{\circ} \mathrm{C}$.

5.2.1.8. Caffeine. The unnecessary use of caffeine may aid in kidney malfunction, heart disease, cancer, and even death. Highly sensitive electrochemical sensors based on goldpolyindole-reduced graphene oxide ternary nanocomposites (Au/Pin/RGO) for the detection of caffeine (up to $0.26 \mu \mathrm{M}$ ) demonstrated fast response as well as $97.6 \%$ to $104.1 \%$ recovery. $^{292}$ These nanohybrids can selectively detect CAF even at a 100 -fold concentration of $\mathrm{K}^{+}, \mathrm{Na}^{+}, \mathrm{Cu}^{2+}, \mathrm{NO}^{3-}$, $\mathrm{PO}_{4}{ }^{3-}$, 50-fold glucose, sucrose, and 10-fold cholic acid and citric acid. The presence of Au NPs and RGO in the PIN matrix could synergistically enhance the rate of electron transfer, electrocatalytic activity, reproducibility, and selectivity for the sensitive detection of CAF.

5.2.1.9. Aflatoxin. A class I carcinogen, aflatoxin B1 (AFB1) may be found in agricultural and animal products. A hybrid electrode, active for the ultrasensitive detection of aflatoxin B1, was designed based on gold nanorods/graphene quantum dots-modified poly(indole-6-carboxylic acid)/flower-gold nanocomposite, as reported by Yan Lu et al. ${ }^{293}$ Under the optimal conditions, this simple electrochemiluminescence (ECL) aptasensor displays a broad dynamic linear range from 0.01 to $100 \mathrm{ng} \mathrm{mL}{ }^{-1}$ with a small detection limit of $0.00375 \mathrm{ng} \mathrm{mL}^{-1}$. A large specific surface area, provided by this nanocomposite, can raise the loading capability of bioactive substances.

5.2.1.10. Pesticides and insecticides. Electrochemical methods are useful to monitor several pesticides and insecticides. Recently, N. Chauhan et al. constructed a biosensor for malathion and chlorpyrifos detection by employing iron oxide nanoparticles and poly(indole-5-carboxylic acid) composite films. ${ }^{46}$ Such amperometric acetylcholinesterase was developed by immobilizing the enzyme (AChE) covalently on Pin5COOH/ $\mathrm{Fe}_{3} \mathrm{O}_{4}$ NP-modified GCE and cyclic voltammogram (CV) platforms are used for sensing. Under optimized conditions, the enzyme inhibition by pesticides displayed detection limits of 0.1-60 and 1.5-70 $\mathrm{nM}$ for malathion and chlorpyrifos, respectively. The recovery (almost 97.9\%) time for the enzymatic activity of the sensor was found to be $10 \mathrm{~min}$. Similarly, organophosphorus insecticides are detected by impregnating rat brain acetylcholinesterase on poly(indole-5-carboxylic acid) and ZnS-modified Au electrode. ${ }^{294}$

5.2.1.11. Diverse cations and anions. Potentiometric ion sensors or solid-state ion-selective electrodes are one of the chief members of the electrochemical sensor group. For example, self-assembled siloxane-polyindole-gold nanoparticle polymeric nanofluid-based membranes can be used as a potentiometric ion sensor for both cations and anions. ${ }^{295}$ Sodium tetraphenylborate (TPB), a non-specific ion-exchange molecule, was impregnated in the polyindole-siloxane-gold nanofluid to monitor chloride ions in solution. Furthermore, a dibenzo-18-crown-6impregnated polyvinyl chloride matrix membrane-based solidstate ion sensor was fabricated to sense various potassium ion concentrations.

The neutral polyindole matrix formed via the undoing process may have vacant interstices, which could be made accessible for other ions existing in the aqueous solution. A host-guest linkage may be formed in this accessible interstice and result in the development of an ion sensor. These undoped PIN-modified electrodes are reported as $\mathrm{Cu}^{2+}$ ion sesors. ${ }^{296}$ The lowest detection limit for this sensor is $8 \times 10^{-6} \mathrm{M}$. Moreover, the dimensions of $\mathrm{Cu}^{2+}$ ions and geometry of the interstices probably aids in the selective and fast detection of the sensor. Pandey et al. developed another polyindole-based ion-selective sensor for calcium ions. The developed calcium sensor can function even in the absence of any calcium selective ionophore/chemical/ion carrier. ${ }^{297}$ They reported that the ionexchange property is developed within the polymeric domains of $\mathrm{Ca}^{2+}$ ions due to the presence of sulfonic acid-doped indole residue and the fabricated electrode exhibited a limit of detection of $5 \mu \mathrm{M}$ and negligible interference with other cations.

5.2.1.12. Picric acid. Pollution due to picric acid in groundwater, soil, and other security applications has become a serious concern due to its explosivity and high toxicity. The in situ chemical oxidative polymerization of polyindole with CdS nanoparticles produces PIN/Cds nanocomposites, which were applied to picric acid detection at room temperature. ${ }^{298}$ This fluorescence sensor works based on a static/dynamic quenching mechanism, where an electron-rich PIN/CdS nanocomposite is warranting some donor-acceptor interaction with electron-deficient picric acid. The comparison of the fluorescence intensities with diverse metal ions such as $\mathrm{Li}^{+}, \mathrm{Ca}^{2+}, \mathrm{Cd}^{2+}, \mathrm{Pb}^{2+}$, $\mathrm{Cr}^{2+}, \mathrm{Hg}^{2+}, \mathrm{Co}^{2+}, \mathrm{Ni}^{2+}, \mathrm{Cu}^{2+}$, and $\mathrm{Zn}^{2+}$ ions has confirmed the picric acid selectivity of the PIN/CdS nanocomposite and has a 
Stern-Volmer constant $\left(K_{\text {sv }}\right)$ value of $30 \times 10^{3} \mathrm{M}^{-1}$ for the detection of picric acid.

5.2.2. PIN-based chemical sensors for analyses in gas phase. The variation in the measurable physical signals such as current, acoustic variables, or absorbance may occur on exposure of the vapor of target analyte to the sensing material and these sensors can be used to monitor the environment.

5.2.2.1. Volatile organic compounds (VOC). Methanol gas is one of the hazardous VOC gases produced from industrial processes, agricultural waste, and fossil fuels, which can cause disturbances in the metabolism of the human body. ${ }^{35}$ Excellent work is reported by Alok Kumar et al., where a substrateintegrated waveguide (SIW) sensor developed by depositing polyindole (PIN) can be used for methanol sensing quantitatively and qualitatively at room temperature. ${ }^{35}$ The deposited polyindole was placed at the intensified electric field region of the microwave-based cavity resonator and the changes in the high-frequency conductivity and dielectric property activated by the adsorption and desorption of methanol gas enables fast methanol sensing. The sensor exhibited quick response and recovery at room temperature. The PIN-integrated SIW sensor showed a large $Q$ factor and high filling factor, which aided in obtaining good sensitivity in terms of frequency shift (3.33 $\left.\mathrm{kHz} \mathrm{ppm}^{-1}\right)$, amplitude shift $\left(0.005 \mathrm{~dB} \mathrm{ppm}^{-1}\right)$, bandwidth broadening (3.66 kHz $\mathrm{ppm}^{-1}$ ), and loaded $Q$ factor variation (10.60 $Q$ value $\mathrm{ppm}^{-1}$ ).

5.2.2.2. Ammonia. The development of selective, responsive, sensitive, and economical ammonia sensors is preferred in various applications such as medical diagnosis, explosives, fertilizer industries, environmental analysis, as well as in security systems. PIN composites fabricated by in situ oxidation in the presence of metal oxides such as $\mathrm{NiO},{ }^{299} \mathrm{ZnFe}_{2} \mathrm{O}_{4},{ }^{60}$ and $\mathrm{Cu}-\mathrm{Al}_{2} \mathrm{O}_{3}{ }^{300}$ showed ammonia sensing behavior. The encapsulation of metal oxides greatly improved the electrical conductivity and dielectric properties in comparison to that of the pristine PIN matrix. Moreover, the sensing response of the nanocomposite toward ammonia gas depends on the number of filler particles in the polymer matrix.

5.2.2.3. $\mathrm{H}_{2} \mathrm{O}_{2}$. Hydrogen peroxide $\left(\mathrm{H}_{2} \mathrm{O}_{2}\right)$ from industrial processes is a poisonous and destructive gas. Mehdi Baghayeri et al. reported an electrochemical biosensor based on arrested hemoglobin onto a GCD modified with magnetic poly(indolecothiophene) nanocomposite for the detection of hydrogen peroxide in environmental and food samples. ${ }^{301}$ The composite electrode exhibited a pore structure with large surface areas and excellent biocompatibility. In addition, the chains of the PIT@Fe $\mathrm{O}_{4}$ nanocomposite present an appropriate matrix for the immobilization of hemoglobin, resulting in direct electrocatalytic performances of hemoglobin with a low detection limit of $0.54 \mu \mathrm{M}$ and a linear range up to $350 \mu \mathrm{M} .^{302}$

5.2.2.4. Humidity. Polyindole composite nanofibers synthesized via electrospinning can be used as humidity sensors by tracking their electrical resistance under different relative humidity $(\mathrm{RH})$ environments $\left(25{ }^{\circ} \mathrm{C}\right) .^{303}$ The dissociation of water into $\mathrm{H}_{3} \mathrm{O}^{+}$and $\mathrm{OH}^{-}$species, and thus doping the polymer produces conductivity changes. Thus, the variation in relative humidity (\% RH atmosphere) is recorded as a function of changes in the resistance of the nanocomposite. The response time and recovery time to the equilibrium condition of the sensor were less than $5 \mathrm{~min}$, and could be effectually and competently employed in biomedical applications.

\section{Conclusion and future perspective}

As has been discussed in this review, tunable bandgaps, ionic and electronic conductivity, optical response, surface tension, volume change, environmental and thermal stability, biocompatibility, and electrochemical properties are among the unique features of PPY and PIN-based nanocomposites, which are being exploited for environmental remediation and sensing applications. In addition, the chemical, electrochemical, and photochemical methods along with other novel trends can be utilized for the large-scale synthesis of these materials more economically. The doping level is crucial as it strongly affects the electrochemical properties of PIN- and PPY-based materials. Recent developments in materials science have unlocked an extensive range of opportunities to synthesize and manipulate the morphology and structure of PIN- and PPY-based composites. These state-of-the-art materials can support pollutant recognition and elimination in different means. The high sensitivity, short response time, biocompatibility, economical synthesis procedure, and easy charge transfer properties of nanomaterial-modified PIN and PPY open up an appropriate choice for material scientists to utilize these materials as a sensor. However, the applications of PIN, PPY, and its nanocomposites in sensing and environmental remediations remain challenging. The response and recovery time of sensors based on PIN and PPY have shown remarkable enhancement with great advances in nanotechnology. However, the selectivity toward specific analytes is still a challenge. Thus, it is essential to wisely functionalize these CPs with suitable receptors. An additional concern is that PIN and PPY materials may degrade over time, even in dry, oxygen-free surroundings. Novel efforts should be directed at refining the stability of the sensor response. Accordingly, future research into PPY and PIN-based sensors will offer great potential for the production of next-generation sensor devices. In short, it is expected that wearable or flexible high-performance sensors will be constructed using these CPs shortly.

The applications of PIN- and PPY-based nanocomposites to remediate environmental problems are just the tip of the iceberg and many of the concepts discussed in this review aid further investigation to achieve their full progress. Optimizing the synthetic pathways to alter the chain length of the polymer, and the customization of the dispersity and processability of the dopants with the preferred morphology are critical requirements to achieve suitable materials for environmental and sensing applications. Doping and undoping of PIN and PPY involving anion or cation dynamics may be a foundation of the 
motivation for new methodologies in environmental remediation, especially for metallic ions that are difficult to eliminate. The capability of PIN and PPY to integrate catalysts into their structures can also be exploited for efficient pollutant sensing and removal. The photoelectrocatalytic processes can be conducted by employing PIN and PPY nanocomposites, which can harness visible light to produce pollutant oxidation or reduction.

Modern materials such as 3D materials and dendrimers support selectivity and enhanced mass transfer. It will be essential to utilize these materials, especially for environmental remediation applications. PIN with nanobelts, nanorod, nanowire, and nanofibers morphologies can ably provide higher surface area, improved conductivities, continuous charge transfer compared to nanospheres, and the next effort should exploit 1D, $2 \mathrm{D}$, and 3D PIN structures of a virgin nature and composite environments for efficient sensing and removal of pollutants. All of these concepts are in good accordance with modern green chemistry trends where more well-organized and environment friendly chemical treatments for pollutants are needed for a sustainable future. This research field is very lively and can be a source of inventions for solving many issues and industrial applications in the environmental arena. Sufficient knowledge of the interactions among polymer components and their bulk properties will allow their better construction. Theoretical methods to predict and explain the interaction of pure PIN, PPY, and their composites with analytes also merit exploration with modern computational tools. In conclusion, PIN, PPY, and their nanocomposites hold potential for use in sensing and environmental remediation applications. Fast developments in CP synthesis and property characterizations will permit the development of innovative applications based on these CPs with properties tuned by careful material selection.

\section{Conflicts of interest}

“There are no conflicts to declare".

\section{Acknowledgements}

Anjitha. T. is grateful to CSIR for her CSIR-JRF fellowship.

\section{References}

1 T. Nezakati, A. Seifalian, A. Tan and A. M. Seifalian, Chem. Rev., 2018, 118, 6766-6843.

2 A. Dyer, J. Reynolds and J. Skotheim, Handbook of Conducting Polymers, CRC Press, Boca Raton, FL, 2007, vol. 2, p. 1680.

3 T. M. Swager, Macromolecules, 2017, 50, 4867-4886.

4 H. Shirakawa, E. J. Louis, A. G. MacDiarmid, C. K. Chiang and A. J. Heeger, J. Chem. Soc., Chem. Commun., 1977, 578-580.

5 M. Ansari, S. Ansari, M. Cho, S. Ansari, M. Abdel-wahab and A. Alshahrie, Functional Polymers, Springer, Berlin, Germany, 2019, pp. 911-940.

6 Y. Shi, L. Peng and G. Yu, Nanoscale, 2015, 7, 12796-12806.
7 U. Lange, N. V. Roznyatovskaya and V. M. Mirsky, Anal. Chim. Acta, 2008, 614, 1-26.

8 R. Kumar, S. Singh and B. Yadav, Int. J. Adv. Res., J. Sci., Eng. Technol., 2015, 2, 110-124.

9 O. Ala and Q. Fan, Res. J. Text. Apparel, 2009, 13, 51-68.

10 Q. Zhou and G. Shi, J. Am. Chem. Soc., 2016, 138, 2868-2876.

11 Y. Wang and X. Jing, Polym. Adv. Technol., 2005, 16, 344-351.

12 E. Brinkman, Journal, 2015, 25-31.

13 P. P. Deshpande, N. G. Jadhav, V. J. Gelling and D. Sazou, J. Coat. Technol. Res., 2014, 11, 473-494.

14 G. Inzelt, J. Solid State Electrochem., 2016, 20, 1507-1508.

15 A. R. Murad, A. Iraqi, S. B. Aziz, S. N. Abdullah and M. A. Brza, Polymers, 2020, 12, 2627.

16 W. Hou, Y. Xiao, G. Han and J.-Y. Lin, Polymers, 2019, 11, 143.

17 A. A. Ansari and S. Islam, 2nd International Conference on Emerging Trends in Engineering \& Technology, 2013, pp. 1-4.

18 P.-C. Wang, L.-H. Liu, D. A. Mengistie, K.-H. Li, B.-J. Wen, T.-S. Liu and C.-W. Chu, Displays, 2013, 34, 301-314.

19 Q. Meng, K. Cai, Y. Chen and L. Chen, Nano Energy, 2017, 36, 268-285.

20 S. Tajik, H. Beitollahi, F. G. Nejad, I. S. Shoaie, M. A. Khalilzadeh, M. S. Asl, Q. Van Le, K. Zhang, H. W. Jang and M. Shokouhimehr, RSC Adv., 2020, 10, 37834-37856.

21 G. Wang, A. Morrin, M. Li, N. Liu and X. Luo, J. Mater. Chem. B, 2018, 6, 4173-4190.

22 H. D. Tran, D. Li and R. B. Kaner, Adv. Mater., 2009, 21, 1487-1499.

23 A. Taghizadeh, M. Taghizadeh, M. Jouyandeh, M. K. Yazdi, P. Zarrintaj, M. R. Saeb, E. C. Lima and V. K. Gupta, J. Mol. Liq., 2020, 113447.

24 R. Gangopadhyay and A. De, Chem. Mater., 2000, 12, 608-622.

25 C. Zhan, G. Yu, Y. Lu, L. Wang, E. Wujcik and S. Wei, J. Mater. Chem. C, 2017, 5, 1569-1585.

26 D. Duraibabu and Y. Sasikumar, Green Photocatalysts, Springer, 2020, pp. 189-208.

27 J. Stejskal, Chem. Pap., 2020, 74, 1-54.

28 J. G. Ibanez, M. E. Rincón, S. Gutierrez-Granados, M. H. Chahma, O. A. Jaramillo-Quintero and B. A. FrontanaUribe, Chem. Rev., 2018, 118, 4731-4816.

29 Q. Ameer and S. B. Adeloju, Sens. Actuators, B, 2005, 106, 541-552.

30 Y. C. Wong, B. C. Ang, A. Haseeb, A. A. Baharuddin and Y. H. Wong, J. Electrochem. Soc., 2019, 167, 037503.

31 Y. Wang, A. Liu, Y. Han and T. Li, Polym. Int., 2020, 69, 7-17.

32 A. Ramanavičius, A. Ramanavičienè and A. Malinauskas, Electrochim. Acta, 2006, 51, 6025-6037.

33 G. Nie, L. Wang and C. Liu, J. Mater. Chem. C, 2015, 3, 11318-11325.

34 J. Li, Q. Guo, Y. Lu and G. Nie, Eur. Polym. J., 2019, 113, 29-35.

35 A. Kumar, C. Wang, F.-Y. Meng, C.-P. Jiang, G.-F. Yan, M. Zhao, C.-Q. Jing and L. Wang, ACS Sens., 2020, 5, 3939-3948. 
36 S. Sharma, P. Joshi, S. Mehtab, M. G. H. Zaidi, K. Singhal and T. I. Siddiqi, J. Anal. Test., 2020, 1-10.

37 A. D. Ali, S. H. Ammar and E. M. Khudhair, Environ. Nanotechnol., Monit. Manage., 2020, 14, 100359.

38 S. Ahmad, V. U. Siddiqui, A. Ansari, W. A. Siddiqi and M. K. Akram, AIP Conf. Proc., 2020, 2276, 020016.

39 A. Kumar, L. Joshi and R. Prakash, Ind. Eng. Chem. Res., 2013, 52, 9374-9380.

40 S. R. Nayak, K. N. S. Mohana, M. B. Hegde, K. Rajitha, A. M. Madhusudhana and S. R. Naik, J. Alloys Compd., 2021, 856, 158057.

41 M. Mobin, F. Ansar, M. Shoeb, M. Parveen and J. Aslam, Nano Select, 2021, 2, 293-302.

42 P. S. Abthagir and R. Saraswathi, Org. Electron., 2004, 5, 299-308.

43 S. A. Yeriskin, H. I. Unal and B. Sari, J. Appl. Polym. Sci., 2011, 120, 390-396.

44 H. Mudila, P. Prasher, M. Kumar, A. Kumar, M. Zaidi and A. Kumar, Mater. Renewable Sustainable Energy, 2019, 8, 1-19.

45 I. Marriam, Y. Wang and M. Tebyetekerwa, Energy Storage Mater., 2020, 33, 336-359.

46 N. Chauhan, J. Narang and U. Jain, J. Exp. Nanosci., 2016, 11, 111-122.

47 P. C. Pandey, D. S. Chauhan and V. Singh, Mater. Sci. Eng., C, 2012, 32, 1-11.

48 H. L. Youmans, J. B. Rush and V. H. Brown, J. Heterocycl. Chem., 1976, 13, 949-953.

49 P. S. Abthagir, K. Dhanalakshmi and R. Saraswathi, Synth. Met., 1998, 93, 1-7.

50 J. Xu, G. Nie, S. Zhang, X. Han, J. Hou and S. Pu, J. Polym. Sci., Part A: Polym. Chem., 2005, 43, 1444-1453.

51 E. B. Maarouf, D. Billaud and E. Hannecart, Mater. Res. Bull., 1994, 29, 637-643.

52 N. Wadatkar and S. Waghuley, Egypt. J. Basic Appl. Sci., 2015, 2, 19-24.

53 B. Purty, R. B. Choudhary, A. Biswas and G. Udayabhanu, Polym. Bull., 2019, 76, 1619-1640.

54 Q. Guo, J. Li, B. Zhang, G. Nie and D. Wang, ACS Appl. Mater. Interfaces, 2019, 11, 6491-6501.

55 D. Billaud, E. Maarouf and E. Hannecart, Synth. Met., 1995, 69, 571-572.

56 A. Eftekhari, L. Li and Y. Yang, J. Power Sources, 2017, 347, 86-107.

57 J. G. Mackintosh, C. R. Redpath, A. C. Jones, P. R. Langridge-Smith and A. R. Mount, J. Electroanal. Chem., 1995, 388, 179-185.

58 W. Zhou and J. Xu, Polym. Rev., 2017, 57, 248-275.

59 G. Nie, Z. Bai, W. Yu and J. Chen, Biomacromolecules, 2013, 14, 834-840.

60 T. Anjitha, T. Anilkumar, G. Mathew and M. Ramesan, Polym. Compos., 2019, 40, 2802-2811.

61 P. Chhattise, K. Handore, A. Horne, K. Mohite, A. Chaskar, S. Dallavalle and V. Chabukswar, J. Chem. Sci., 2016, 128, 467-475.

62 S. An, T. Abdiryim, Y. Ding and I. Nurulla, Mater. Lett., 2008, 62, 935-938.
63 S. Koiry, V. Saxena, D. Sutar, S. Bhattacharya, D. Aswal, S. Gupta and J. Yakhmi, J. Appl. Polym. Sci., 2007, 103, 595-599.

64 S.-k. Kim, N. Miyagawa, H. Seki, T. Ishikawa and K. Hoshino, J. Electroanal. Chem., 2008, 615, 12-18.

65 R. B. Choudhary, S. Ansari and B. Purty, J. Energy Storage, 2020, 29, 101302.

66 T. Livache, H. Bazin and G. Mathis, Clin. Chim. Acta, 1998, 278, 171-176.

67 S. Morsi, M. Abd El-Aziz, R. Morsi and A. Hussain, J. Coat. Technol. Res., 2019, 16, 745-759.

68 Y. Huang, H. Li, Z. Wang, M. Zhu, Z. Pei, Q. Xue, Y. Huang and C. Zhi, Nano Energy, 2016, 22, 422-438.

69 S. Oliveira, J. Luzardo, L. Silva, D. Aguiar, C. Senna, R. Verdan, A. Kuznetsov, T. Vasconcelos, B. Archanjo and C. Achete, Thin Solid Films, 2020, 699, 137875.

70 P. Gahlout and V. Choudhary, Synth. Met., 2020, 266, 116414.

71 S. Aznar-Cervantes, M. I. Roca, J. G. Martinez, L. MeseguerOlmo, J. L. Cenis, J. M. Moraleda and T. F. Otero, Bioelectrochemistry, 2012, 85, 36-43.

72 J.-K. Kim, J. Manuel, M.-H. Lee, J. Scheers, D.-H. Lim, P. Johansson, J.-H. Ahn, A. Matic and P. Jacobsson, J. Mater. Chem., 2012, 22, 15045-15049.

73 J. Xia, L. Chen and S. Yanagida, J. Mater. Chem., 2011, 21, 4644-4649.

74 J.-Y. Hong, S. O. Jeon, J. Jang, K. Song and S. H. Kim, Org. Electron., 2013, 14, 979-983.

75 P. Yang and W. Mai, Nano Energy, 2014, 8, 274-290.

76 H. N. M. E. Mahmud, A. O. Huq and R. Binti Yahya, RSC Adv., 2016, 6, 14778-14791.

77 P. Camurlu, RSC Adv., 2014, 4, 55832-55845.

78 G. Kaur, R. Adhikari, P. Cass, M. Bown and P. Gunatillake, RSC Adv., 2015, 5, 37553-37567.

79 S. Rasmussen, Bull. Hist. Chem., 2015, 40, 45-55.

80 V. A. Pedrosa, X. Luo, J. Burdick and J. Wang, Small, 2008, 4, 738-741.

81 X.-G. Li, F. Wei, M.-R. Huang and Y.-B. Xie, J. Phys. Chem. B, 2007, 111, 5829-5836.

82 H. Ashassi-Sorkhabi and A. Kazempour, J. Mol. Liq., 2020, 113085.

83 Z. Chen, W. Yang, B. Xu, Y. Guo, Y. Chen, X. Yin and Y. Liu, Prog. Org. Coat., 2018, 122, 159-169.

84 N. Balint, Acta Biomater., 2014, 10, 2341.

85 L. Dai, Intelligent macromolecules for smart devices: from materials synthesis to device applications, 2004, 41-80.

86 A. L. Pang, A. Arsad and M. Ahmadipour, Polym. Adv. Technol., 2021, 32, 1428-1454.

87 V. V. Tat'yana and O. N. Efimov, Russ. Chem. Rev., 1997, 66, 443.

88 G. Kaur, A. Kaur and H. Kaur, Polym.-Plast. Technol. Mater., 2020, 1-18.

89 S. B. Kondawar and P. T. Patil, Conducting Polymer Hybrids, Springer, 2017, pp. 223-267.

90 H. Wei, H. Wang, A. Li, D. Cui, Z. Zhao, L. Chu, X. Wei, L. Wang, D. Pan and J. Fan, ChemNanoMat, 2020, 6, 174-184. 
91 C. Tang, N. Chen and X. Hu, Conducting Polym. Hybrids, 2017, 1-44.

92 D. N. Nguyen and H. Yoon, Polymers, 2016, 8, 118.

93 C. Zhao, X. Jia, K. Shu, C. Yu, G. G. Wallace and C. Wang, J. Mater. Chem. A, 2020, 8, 4677-4699.

94 A. Mane, S. Navale and V. Patil, Org. Electron., 2015, 19, 15-25.

95 V. Bhugul and G. Choudhari, Int. J. Adv. Innov. Res., 2013, 2, $2278-7844$.

96 A. Muñoz-Bonilla, J. Sánchez-Marcos and P. Herrasti, Conducting Polym. Hybrids, 2017, 45-80.

97 E. Temizel, E. Ayan, M. Şenel, H. Erdemi, M. S. Yavuz, H. Kavas, A. Baykal and R. Öztürk, Mater. Chem. Phys., 2011, 131, 284-291.

98 M. Alvi, A. Al-Ghamdi and M. Husain, Phys. B, 2014, 454, 31-34.

99 O. Jiyoung, M. E. Kozlov, D. M. Novitski and R. H. Baughman, 2010.

100 C. Yang, L. Zhang, N. Hu, Z. Yang, H. Wei and Y. Zhang, J. Power Sources, 2016, 302, 39-45.

101 P. Rejania and B. Beenab, Indian J. Adv. Chem. Sci., 2013, 2, 244-248.

102 L. Joshi, B. Gupta and R. Prakash, Thin Solid Films, 2010, 519, 218-222.

103 L. Joshi, A. K. Singh and R. Prakash, Mater. Chem. Phys., 2012, 135, 80-87.

104 S. Varshney, A. Ohlan, V. K. Jain, V. P. Dutta and S. K. Dhawan, Ind. Eng. Chem. Res., 2014, 53, 14282-14290.

105 S. M. Imran, G. N. Shao, M. S. Haider, N. Abbas, M. Hussain and H. T. Kim, J. Appl. Polym. Sci., 2015, 132, 41800.

106 M. B. G. Costa, J. M. Juárez, M. L. Martínez, J. Cussa and O. A. Anunziata, Microporous Mesoporous Mater., 2012, 153, 191-197.

107 A. Ohlan, K. Singh, A. Chandra and S. K. Dhawan, ACS Appl. Mater. Interfaces, 2010, 2, 927-933.

108 M. Irfan, A. Shakoor, N. A. Niaz, N. Anwar and G. Ali, J. Mater. Sci.: Mater. Electron., 2020, 31, 22365-22374.

109 N. Shakeel, M. I. Ahamed, S. Kanchi and H. A. Kashmery, Sci. Rep., 2020, 10, 1-10.

110 N. German, A. Ramanaviciene and A. Ramanavicius, Polymers, 2019, 11, 377.

111 R. Mishra, N. R. Nirala, R. K. Pandey, R. P. Ojha and R. Prakash, Langmuir, 2017, 33, 13572-13580.

112 J. Xu, X. Li, J. Liu, X. Wang, Q. Peng and Y. Li, J. Polym. Sci., Part A: Polym. Chem., 2005, 43, 2892-2900.

113 L. Sun, Y. Shi, X. Li, K. Ding, Z. He and B. Li, J. Inorg. Organomet. Polym. Mater., 2014, 24, 395-400.

114 J. Jang and J. Bae, Sens. Actuators, B, 2007, 122, 7-13.

115 X. Lu, Q. Zhao, X. Liu, D. Wang, W. Zhang, C. Wang and Y. Wei, Macromol. Rapid Commun., 2006, 27, 430-434.

116 J. E. Lee, Y. Lee, K.-J. Ahn, J. Huh, H. W. Shim, G. Sampath, W. B. Im, Y. I. Huh and H. Yoon, Sci. Rep., 2015, 5, 1-8.

117 C. C. Manole, F. Maury and I. Demetrescu, Phys. Proc., 2013, 46, 46-55.

118 J. Foroughi, G. M. Spinks and G. G. Wallace, J. Mater. Chem., 2011, 21, 6421-6426.
119 X. Ding, Y. Zhao, C. Hu, Y. Hu, Z. Dong, N. Chen, Z. Zhang and L. Qu, J. Mater. Chem. A, 2014, 2, 12355-12360.

120 A. Chen, H. Xie, H. Wang, H. Li and X. Li, Synth. Met., 2006, 156, 346-350.

121 J. N. Coleman, U. Khan and Y. K. Gun'ko, Adv. Mater., 2006, 18, 689-706.

122 P. Dubey, A. Kumar and R. Prakash, Appl. Surf. Sci., 2015, 355, 262-267.

123 M. Hasik, A. Bernasik, A. Adamczyk, G. Malata, K. Kowalski and J. Camra, Eur. Polym. J., 2003, 39, 1669-1678.

$124 \mathrm{~J} . \mathrm{Xu}, \mathrm{J} . \mathrm{Hu}, \mathrm{B}$. Quan and Z. Wei, Macromol. Rapid Commun., 2009, 30, 936-940.

125 A. Kausar, J. Plast. Film Sheeting, 2020, 8756087920937344.

126 M. Tebyetekerwa, S. Yang, S. Peng, Z. Xu, W. Shao, D. Pan, S. Ramakrishna and M. Zhu, Electrochim. Acta, 2017, 247, 400-409.

127 L. Joshi and R. Prakash, Mater. Lett., 2011, 65, 3016-3019. 128 T. A. Kandiel, R. Dillert and D. W. Bahnemann, Photochem. Photobiol. Sci., 2009, 8, 683-690.

129 K. F. Babu, P. Dhandapani, S. Maruthamuthu and M. A. Kulandainathan, Carbohydr. Polym., 2012, 90, 1557-1563.

130 Z. Yang, Q. Sheng, S. Zhang, X. Zheng and J. Zheng, Microchim. Acta, 2017, 184, 2219-2226.

131 R. Peymanfar, F. Norouzi and S. Javanshir, Mater. Res. Express, 2018, 6, 035024.

132 D. Muñoz-Rojas, J. Oró-Solé, O. Ayyad and P. GómezRomero, Small, 2008, 4, 1301-1306.

133 M. H. Ullah and C.-S. Ha, J. Mater. Sci., 2016, 51, 7536-7544.

134 D. Zhang, Z. Wu, X. Zong and Y. Zhang, Sens. Actuators, B, 2018, 274, 575-586.

135 C. Li, H. Bai and G. Shi, Chem. Soc. Rev., 2009, 38, 2397-2409.

136 N. Cioffi, L. Torsi, L. Sabbatini, P. Zambonin and T. BleveZacheo, J. Electroanal. Chem., 2000, 488, 42-47.

137 N. Cioffi, L. Torsi, I. Losito, L. Sabbatini, P. Zambonin and T. Bleve-Zacheo, Electrochim. Acta, 2001, 46, 4205-4211.

138 G. Z. Chen, M. S. Shaffer, D. Coleby, G. Dixon, W. Zhou, D. Fray and A. Windle, Adv. Mater., 2000, 12, 522-526.

139 W. Chen, C. M. Li, P. Chen and C. Sun, Electrochim. Acta, 2007, 52, 2845-2849.

140 K. Jüttner, K.-M. Mangold, M. Lange and K. Bouzek, Russ. J. Electrochem., 2004, 40, 317-325.

141 M. Baibarac, I. Baltog, M. Scocioreanu, S. Lefrant and J. Mevellec, Synth. Met., 2009, 159, 2550-2555.

142 W. Zhou, X. Ma, F. Jiang, D. Zhu, J. Xu, B. Lu and C. Liu, Electrochim. Acta, 2014, 138, 270-277.

143 H. A. A. Bashid, H. N. Lim, S. Kamaruzaman, S. A. Rashid, R. Yunus, N. M. Huang, C. Y. Yin, M. M. Rahman, M. Altarawneh and Z. T. Jiang, Nanoscale Res. Lett., 2017, 12, 1-10.

144 J. Chung, S. H. Park, E.-H. Kim and S. I. Woo, J. Mater. Chem. A, 2015, 3, 1089-1095.

145 M. Zhu, Y. Huang, Q. Deng, J. Zhou, Z. Pei, Q. Xue, Y. Huang, Z. Wang, H. Li and Q. Huang, Adv. Energy Mater., 2016, 6, 1600969. 
146 K. Ghanbari, S. Bathaie and M. Mousavi, Biosens. Bioelectron., 2008, 23, 1825-1831.

147 S. Ko and J. Jang, Ultramicroscopy, 2008, 108, 1328-1333.

148 J. Wang, J. Dai and T. Yarlagadda, Langmuir, 2005, 21, 9-12.

149 S. Ebrahimiasl, A. Zakaria, A. Kassim and S. N. Basri, Int. J. Nanomed., 2015, 10, 217.

150 P. M. Nia, F. Lorestani, W. P. Meng and Y. Alias, Appl. Surf. Sci., 2015, 332, 648-656.

151 R. P. Raj, P. Ragupathy and S. Mohan, J. Mater. Chem. A, 2015, 3, 24338-24348.

152 H. R. Heydarnezhad and B. Pourabbas, J. Mater. Sci.: Mater. Electron., 2013, 24, 4378-4385.

153 P.-G. Su and Y.-T. Peng, Sens. Actuators, B, 2014, 193, 637-643.

154 H. D. Pham, V. H. Pham, E.-S. Oh, J. S. Chung and S. Kim, Korean J. Chem. Eng., 2012, 29, 125-129.

155 N. C. Strandwitz, Y. Nonoguchi, S. W. Boettcher and G. D. Stucky, Langmuir, 2010, 26, 5319-5322.

156 C. Martins, Y. De Almeida, G. Do Nascimento and W. De Azevedo, J. Mater. Sci., 2006, 41, 7413-7418.

157 Z. Weng and X. Ni, J. Appl. Polym. Sci., 2008, 110, 109-116.

158 K. Jlassi, A. Singh, D. K. Aswal, R. Losno, M. Benna-Zayani and M. M. Chehimi, Colloids Surf., A, 2013, 439, 193-199.

159 M. F. Attia, T. Azib, Z. Salmi, A. Singh, P. Decorse, N. Battaglini, H. Lecoq, M. Omastová, A. A. Higazy and A. M. Elshafei, J. Colloid Interface Sci., 2013, 393, 130-137.

160 P.-G. Su and Y.-P. Chang, Sens. Actuators, B, 2008, 129, 915-920.

161 A. Singh, Z. Salmi, P. Jha, N. Joshi, A. Kumar, P. Decorse, H. Lecoq, S. Lau-Truong, D. K. Aswal and S. K. Gupta, RSC $A d v .$, 2013, 3, 13329-13336.

162 C. Janáky, W. Chanmanee and K. Rajeshwar, Electrochim. Acta, 2014, 122, 303-309.

163 E. Ngaboyamahina, C. Debiemme-Chouvy, A. Pailleret and E. Sutter, J. Phys. Chem. C, 2014, 118, 26341-26350.

164 J. Huang, Z. Yang, B. Yang, R. Wang and T. Wang, J. Power Sources, 2014, 271, 143-151.

165 M. Hepel, Z. Xingmin, R. Stephenson and S. Perkins, Microchem. J., 1997, 56, 79-92.

166 R. Balasubramanian and S. Chowdhury, J. Mater. Chem. A, 2015, 3, 21968-21989.

167 F. Gao, X. Hou, A. Wang, G. Chu, W. Wu, J. Chen and H. Zou, Particuology, 2016, 26, 73-78.

168 X. Tan, C. Hu, Z. Zhu, H. Liu and J. Qu, Adv. Funct. Mater., 2019, 29, 1903081.

169 Y. Shan, J. Zhao, W. Li, Q. Huang and C. Xiao, J. Mater. Sci., 2018, 53, 2065-2076.

170 M. Saleh, J. N. Tiwari, K. C. Kemp, M. Yousuf and K. S. Kim, Environ. Sci. Technol., 2013, 47, 5467-5473.

171 A. Adhikari, S. De, A. Halder, S. Pattanayak, K. Dutta, D. Mondal, D. Rana, R. Ghosh, N. K. Bera and S. Chattopadhyay, Synth. Met., 2018, 245, 209-222.

172 A. C. Dassanayake and M. Jaroniec, Colloids Surf., A, 2018, 549, 147-154.

173 M. Sevilla, P. Valle-Vigón and A. B. Fuertes, Adv. Funct. Mater., 2011, 21, 2781-2787.
174 M. Saleh, V. Chandra, K. C. Kemp and K. S. Kim, Nanotechnology, 2013, 24, 255702.

175 V. Chandra, S. U. Yu, S. H. Kim, Y. S. Yoon, D. Y. Kim, A. H. Kwon, M. Meyyappan and K. S. Kim, Chem. Commun., 2012, 48, 735-737.

176 J. Luo, S. Zhang, M. Sun, L. Yang, S. Luo and J. C. Crittenden, ACS Nano, 2019, 13, 9811-9840.

177 X. Yuan, M. P. Kobylanski, Z. Cui, J. Li, P. Beaunier, D. Dragoe, C. Colbeau-Justin, A. Zaleska-Medynska and H. Remita, J. Environ. Chem. Eng., 2020, 8, 104178.

178 B. Szczęśniak, Ł. Osuchowski, J. Choma and M. Jaroniec, J. Porous Mater., 2018, 25, 621-627.

179 B. Li, J. Hu, H. Xiong and Y. Xiao, ACS Omega, 2020, 5, 9398-9407.

180 M. T. Javed, N. Irfan and B. Gibbs, J. Environ. Manage., 2007, 83, 251-289.

181 L. Chen, X. Wang, Q. Cong, H. Ma, S. Li and W. Li, Chem. Eng. J., 2019, 369, 957-967.

182 R. Pandey and B. Chandrashekhar, Crit. Rev. Environ. Sci. Technol., 2014, 44, 34-96.

183 T. Guo, C. Zhang, J. Zhao, C. Ma, S. Li and W. Li, Sci. Rep., 2019, 9, 1-11.

184 F. Mirante, C. Alves, C. Pio, O. Pindado, R. Perez, M. A. Revuelta and B. Artiñano, Atmos. Res., 2013, 132, 345-361.

185 M. Markiewicz, Y. Zhang, A. Bösmann, N. Brückner, J. Thöming, P. Wasserscheid and S. Stolte, Energy Environ. Sci., 2015, 8, 1035-1045.

186 M. Behfar, A. R. Ghiasvand and F. Yazdankhah, J. Sep. Sci., 2017, 40, 2975-2983.

187 A. A. Khan, M. Q. Khan and R. Hussain, Mater. Res. Express, 2017, 4, 095024.

188 D. Devadathan, V. Baiju, J. Deepa and R. Raveendran, Nanosyst.: Phys., Chem., Math., 2020, 11, 666-671.

189 X. Ye, Q. Xu and J. Xu, RSC Adv., 2019, 9, 5895-5900.

190 J. Zhou, Q.-F. Lü and J.-J. Luo, J. Cleaner Prod., 2017, 167, 739-748.

191 A. Karamipour, N. Rasouli, M. Movahedi and H. Salavti, Phys. Chem. Res., 2016, 4, 291-301.

192 I. Akbartabar, M. E. Yazdanshenas, H.-A. Tayebi and N. Nasirizadeh, Phys. Chem. Res., 2017, 5, 659-679.

193 V. M. Ovando-Medina, P. E. Díaz-Flores, H. MartínezGutiérrez, L. A. Moreno-Ruiz, I. D. Antonio-Carmona and M. Hernández-Ordoñez, Polym. Compos., 2014, 35, 186-193.

194 S. Supriya and P. Palanisamy, Desalination and Water Treatment, 2017, 78, 281-291.

195 H. N. Muhammad Ekramul Mahmud and A. Huq, RSC Adv., 2016, 6, 14778-147791.

196 C. Zhijiang, J. Jianru, Z. Qing and Y. Haizheng, RSC Adv., 2015, 5, 82310-82323.

197 Z. Cai, X. Song, Q. Zhang and T. Zhai, Fibers Polym., 2017, 18, 502-513.

198 C. Zhijiang, S. Xianyou, Z. Qing and L. Yuanpei, J. Mater. Sci., 2017, 52, 5417-5434.

199 M. Karthikeyan, K. S. Kumar and K. Elango, Desalination, 2011, 267, 49-56. 
200 M. Karthikeyan, K. Satheesh Kumar and K. Elango, Environ. Technol., 2012, 33, 733-739.

201 S. Li, J. Liu, X. Zhang, L. Li, X. Yu and Z. Huang, Polym. Bull., 2015, 72, 2891-2902.

202 T. Yao, W. Jia, X. Tong, Y. Feng, Y. Qi, X. Zhang and J. Wu, J. Colloid Interface Sci., 2018, 527, 214-221.

203 S. Gao, Z. Liu, Q. Yan, P. Wei, Y. Li, J. Ji and L. Li, J. Inorg. Organomet. Polym. Mater., 2021, 1-9.

204 Y. Li, Y. Gao, Q. Zhang, R. Wang, C. Li, J. Mao, L. Guo, F. Wang, Z. Zhang and L. Wang, Sep. Purif. Technol., 2021, 258, 117981.

205 R. A. Tufa, T. Piallat, J. Hnat, E. Fontananova, M. Paidar, D. Chanda, E. Curcio, G. di Profio and K. Bouzek, Chem. Eng. J., 2020, 380, 122461.

206 N. Haghighat and V. Vatanpour, Mater. Today Commun., 2020, 23, 100851.

207 Y. Feng, L. Yang, J. Liu and B. Logan, J. Roy. Soc. Chem., 2016, 41.

208 J. Li, H. Liu, X. Cheng, Y. Xin, W. Xu, Z. Ma, J. Ma, N. Ren and Q. Li, Ind. Eng. Chem. Res., 2012, 51, 15557-15563.

209 Z. Sun, H. Ge, X. Hu and Y. Peng, Sep. Purif. Technol., 2010, 72, 133-139.

210 Z. Sun, K. Wang, X. Wei, S. Tong and X. Hu, Int. J. Hydrogen Energy, 2012, 37, 17862-17869.

211 Z. Sun, X. Wei, X. Hu, K. Wang and H. Shen, Colloids Surf., A, 2012, 414, 314-319.

212 Z. Sun, X. Wei, Y. Han, S. Tong and X. Hu, J. Hazard. Mater., 2013, 244, 287-294.

213 Z. Sun, H. Shen, X. Wei and X. Hu, Chem. Eng. J., 2014, 241, 433-442.

214 Y. Tian and F. Yang, J. Cleaner Prod., 2007, 15, 1415-1418.

215 K. G. Conroy and C. B. Breslin, J. Appl. Electrochem., 2004, 34, 191-195.

216 M. Bhaumik, K. Setshedi, A. Maity and M. S. Onyango, Sep. Purif. Technol., 2013, 110, 11-19.

217 M. Bhaumik, S. Agarwal, V. K. Gupta and A. Maity, J. Colloid Interface Sci., 2016, 470, 257-267.

218 Y. Lei, X. Qian, J. Shen and X. An, Ind. Eng. Chem. Res., 2012, 51, 10408-10415.

219 F. J. Rodríguez, S. Gutiérrez, J. G. Ibanez, J. L. Bravo and N. Batina, Environ. Sci. Technol., 2000, 34, 2018-2023.

220 D. Çirmi, R. Aydın and F. Köleli, J. Electroanal. Chem., 2015, 736, 101-106.

221 S. Biallozor, T. Zalewska and A. Lisowska-Oleksiak, J. Appl. Electrochem., 1996, 26, 1053-1057.

222 M. Zhang, Q. Shi, X. Song, H. Wang and Z. Bian, Environ. Sci. Pollut. Res., 2019, 26, 10457-10486.

223 B. Hwang and K. Lee, J. Appl. Electrochem., 1996, 26, 153-159.

224 J. Sánchez, B. L. Rivas, J.-C. Moutet and D. P. Oyarzún, J. Chil. Chem. Soc., 2016, 61, 3277-3280.

225 M. M. Haque, W. T. Smith and D. K. Wong, J. Hazard. Mater., 2015, 283, 164-170.

226 A. Hallik, A. Alumaa, H. Kurig, A. Jänes, E. Lust and J. Tamm, Synth. Met., 2007, 157, 1085-1090.

227 M. Careem, Y. Velmurugu, S. Skaarup and K. West, J. Power Sources, 2006, 159, 210-214.
228 M. Hepel and L. Dentrone, Electroanalysis, 1996, 8, 996-1005.

229 M. Olatunji, M. Khandaker, Y. Amin and H. E. Mahmud, 2015.

230 J. Tamm, A. Alumaa, A. Hallik and V. Sammelselg, J. Electroanal. Chem., 1998, 448, 25-31.

231 A. Glidle, A. R. Hillman, K. S. Ryder, E. L. Smith, J. M. Cooper, R. Dalgliesh, R. Cubitt and T. Geue, Electrochim. Acta, 2009, 55, 439-450.

232 Y. Lin, X. Cui and J. Bontha, Environ. Sci. Technol., 2006, 40, 4004-4009.

233 X. Yuan, D. Floresyona, P.-H. Aubert, T.-T. Bui, S. Remita, S. Ghosh, F. Brisset, F. Goubard and H. Remita, Appl. Catal., B, 2019, 242, 284-292.

234 S. L. Lee and C.-J. Chang, Polymers, 2019, 11, 206.

235 U. Riaz, S. Ashraf and A. Ruhela, J. Environ. Chem. Eng., 2015, 3, 20-29.

236 X. Yang, L. Zhang, Z. Chen, H. Jing, Y. Chen and Q. Li, Sci. Eng. Compos. Mater., 2016, 23, 269-275.

237 J. Xu, Y. Hu, C. Zeng, Y. Zhang and H. Huang, J. Colloid Interface Sci., 2017, 505, 719-727.

238 B. Gao, W. Chen, S. Dong, J. Liu, T. Liu, L. Wang and M. Sillanpää, J. Photochem. Photobiol., A, 2017, 349, 115-123.

239 X. Liu and L. Cai, Appl. Surf. Sci., 2018, 445, 242-254.

240 Z. Zhang, W. Wang and E. Gao, J. Mater. Sci., 2014, 49, 7325-7332.

241 Y.-G. Wang, P.-P. Zhu, X. Li, K.-F. Zhou, J.-B. Yang, X.L. Ma and J.-Q. Sha, J. Coord. Chem., 2017, 70, 3353-3362.

242 S. Hu, L. Ma, H. Wang, L. Zhang, Y. Zhao and G. Wu, RSC Adv., 2015, 5, 31947-31953.

243 K. Venkatachalam, X. Arzuaga, N. Chopra, V. G. Gavalas, J. Xu, D. Bhattacharyya, B. Hennig and L. G. Bachas, J. Hazard. Mater., 2008, 159, 483-491.

244 K. N. Handore, S. V. Bhavsar, N. Pande, P. K. Chhattise, S. B. Sharma, S. Dallavalle, V. Gaikwad, K. C. Mohite and V. V. Chabukswar, Polym.-Plast. Technol. Eng., 2014, 53, 734-741.

245 E. Fadavipoor, S. Nazari, A. Z. Ahmadi, M. Gorjizadeh, M. Afshari and M. Keshavarz, Orient. J. Chem., 2015, 31, 733.

246 K. B. Ghoreishi, M. A. Yarmo, N. M. Nordin and M. W. Samsudin, J. Chem., 2013, 2013, 1-10.

247 Y. Leng, S. Du, G. Feng, X. Sang, P. Jiang, H. Li and D. Wang, ACS Appl. Mater. Interfaces, 2019, 12, 474-483.

248 E. Esmaeilnezhad and H. J. Choi, J. Cleaner Prod., 2019, 231, 1218-1225.

249 J. Yu, Y. Lu, C. Yuan, J. Zhao, M. Wang and R. Liu, Electrochim. Acta, 2014, 143, 1-9.

250 M. Osial, M. Warczak, P. Kulesza, P. Krysiński and M. Gniadek, J. Electroanal. Chem., 2020, 877, 114664.

251 Y. I. Kurys, O. Ustavytska, D. Mazur, V. Koshechko and V. Pokhodenko, Theor. Exp. Chem., 2015, 50, 371-377.

252 R.-X. Wang, Y.-J. Fan, L. Wang, L.-N. Wu, S.-N. Sun and S.-G. Sun, J. Power Sources, 2015, 287, 341-348. 
253 N. Balis, V. Dracopoulos, M. Antoniadou and P. Lianos, Electrochim. Acta, 2012, 70, 338-343.

254 W. Zhou, Y. Du, F. Ren, C. Wang, J. Xu and P. Yang, Int. J. Hydrogen Energy, 2010, 35, 3270-3279.

255 Y. Yuan, S. Zhou and L. Zhuang, J. Power Sources, 2010, 195, 3490-3493.

256 H. T. Chung, G. Wu, Q. Li and P. Zelenay, Int. J. Hydrogen Energy, 2014, 39, 15887-15893.

257 K. Lee, L. Zhang, H. Lui, R. Hui, Z. Shi and J. Zhang, Electrochim. Acta, 2009, 54, 4704-4711.

258 M. Das and S. Roy, Mater. Sci. Semicond. Process., 2021, 121, 105332.

259 A. Walcarius, S. D. Minteer, J. Wang, Y. Lin and A. Merkoçi, J. Mater. Chem. B, 2013, 1, 4878-4908.

260 G. Inzelt, Conducting polymers: a new era in electrochemistry, Springer Science \& Business Media, 2012.

261 P.-G. Su, C.-T. Lee and C.-Y. Chou, Talanta, 2009, 80, 763-769.

262 L. Zhang, F. Meng, Y. Chen, J. Liu, Y. Sun, T. Luo, M. Li and J. Liu, Sens. Actuators, B, 2009, 142, 204-209.

263 N. Aydemir, J. Malmström and J. Travas-Sejdic, Phys. Chem. Chem. Phys., 2016, 18, 8264-8277.

264 A. Al-Ahmed, H. M. Bahaidarah and M. A. J. Mazumder, 2013.

265 M. Naseri, L. Fotouhi and A. Ehsani, Chem. Record, 2018, 18, 599-618.

266 M. Faraz, A. Abbasi, F. K. Naqvi, N. Khare, R. Prasad, I. Barman and R. Pandey, Sens. Actuators, B, 2018, 269, 195-202.

267 Z. Deng, R. Yu and B. Guo, Mater. Chem. Front., 2021, 5, 2092-2123.

268 Z. Deng, T. Hu, Q. Lei, J. He, P. X. Ma and B. Guo, ACS Appl. Mater. Interfaces, 2019, 11, 6796-6808.

269 Z. Deng, H. Wang, P. X. Ma and B. Guo, Nanoscale, 2020, 12, 1224-1246.

270 Z. Deng, Y. Guo, X. Zhao, P. X. Ma and B. Guo, Chem. Mater., 2018, 30, 1729-1742.

271 L. Kumar, R. Gupta, D. Thakar, V. Vibhu and S. Annapoorni, Plasmonics, 2013, 8, 487-494.

272 V. Gupta and L. Kumar, 2020.

273 P. C. Pandey, J. Chem. Soc., Faraday Trans. 1, 1988, 84, 2259-2265.

274 M. Ghita and D. W. Arrigan, Electrochim. Acta, 2004, 49, 4743-4751.

275 A. Kumar and R. Prakash, J. Nanosci. Nanotechnol., 2014, 14, 2501-2506.

276 X. Zhou, A. Wang, C. Yu, S. Wu and J. Shen, ACS Appl. Mater. Interfaces, 2015, 7, 11741-11747.

277 V. Divya, Y. Jeetika and M. Sangaranarayanan, Mater. Today: Proc., 2020, 26, 97-103.
278 P. C. Pandey, D. S. Chauhan and V. Singh, Electrochim. Acta, 2009, 54, 2266-2270.

279 V. Singh, D. S. Chauhan and P. C. Pandey, 2009.

280 P. Pandey, D. Chauhan and V. Singh, Mater. Sci. Eng., C, 2012, 32, 1-11.

281 A.-M. Yu, D.-M. Suna and H.-Y. Chen, Anal. Lett., 1997, 30, 1643-1652.

282 P. Singh, R. Prakash and K. Shah, Talanta, 2012, 97, 204-210.

283 J. Narang, N. Chauhan, P. Rani and C. Pundir, Bioprocess Biosyst. Eng., 2013, 36, 425-432.

284 S. Sharma, P. Joshi, S. Mehtab, M. G. H. Zaidi, K. Singhal and T. I. Siddiqi, J. Anal. Test., 2020, 4, 13-22.

285 U. Jain, S. Gupta and N. Chauhan, Int. J. Biol. Macromol., 2017, 105, 549-555.

286 S. Lata, B. Batra and C. Pundir, Process Biochem., 2012, 47, 2131-2138.

287 G. Nie, Z. Bai, J. Chen and W. Yu, ACS Macro Lett., 2012, 1, 1304-1307.

288 G. Nie, Y. Zhang, Q. Guo and S. Zhang, Sens. Actuators, B, 2009, 139, 592-597.

289 G. Nie, C. Li, L. Zhang and L. Wang, J. Mater. Chem. B, 2014, 2, 8321-8328.

290 T. Yang, X. Ren, M. Yang, X. Li, K. He, A. Rao, Y. Wan, H. Yang, S. Wang and Z. Luo, Biosens. Bioelectron., 2019, 141, 111406.

291 C. Yang, Q. Guo, Y. Lu, B. Zhang and G. Nie, Sens. Actuators, B, 2020, 303, 127246.

292 R. Li, L. Yao, Z. Wang, W. Lv, W. Wang, F. Kong and W. Wang, J. Electrochem. Soc., 2019, 166, B212.

293 Y. Lu, X. Zhao, Y. Tian, Q. Guo, C. Li and G. Nie, Microchem. J., 2020, 157, 104959.

294 N. Chauhan, J. Narang and C. Pundir, Biosens. Bioelectron., 2011, 29, 82-88.

295 P. C. Pandey, N. Katyal, G. Pandey and R. J. Narayan, MRS Commun., 2020, 10, 482-486.

296 P. Pandey, Sens. Actuators, B, 1999, 54, 210-214.

297 P. C. Pandey, D. S. Chauhan and R. Prakash, J. Appl. Polym. Sci., 2012, 125, 2993-2999.

298 M. Faraz, M. Shakir and N. Khare, New J. Chem., 2017, 41, 5784-5793.

299 M. Ramesan, K. Nushhat, K. Parvathi and T. Anilkumar, J. Mater. Sci.: Mater. Electron., 2019, 30, 13719-13728.

300 S. Sankar, A. A. Naik, T. Anilkumar and M. Ramesan, J. Appl. Polym. Sci., 2020, 137, 49145.

301 M. Baghayeri, M. Rouhi, M. M. Lakouraj and M. AmiriAref, J. Electroanal. Chem., 2017, 784, 69-76.

302 P. Mayuri, S.-T. Huang, V. Mani and A. S. Kumar, Electrochim. Acta, 2018, 268, 150-162.

303 M. Tebyetekerwa, X. Wang, I. Marriam, P. Dan, S. Yang and M. Zhu, Mater. Lett., 2017, 209, 400-403. 